UCRL-CR-128874

S/C-B333556

\title{
ACAB Software Upgrade
}

\section{J. Sanz}

J. M. Balmisa

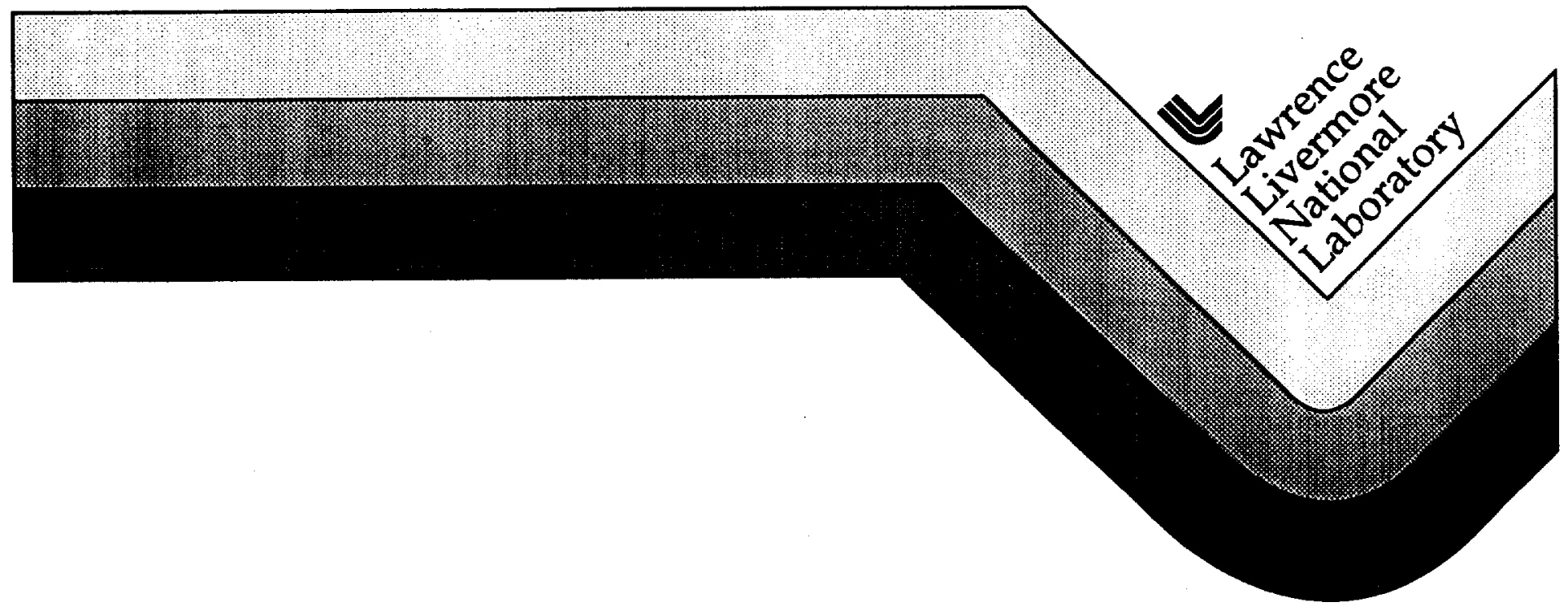




\section{Disclaimer}

This document was prepared as an account of work sponsored by an agency of the United States Government. Neither the United States Government nor the University of California nor any of their employees, makes any warranty, express or implied, or assumes any legal liability or responsibility for the accuracy, completeness, or usefulness of any information, apparatus, product, or process disclosed, or represents that its use would not infringe privately owned rights. Reference berein to any specific commercial product process, or service by trade name, trademark, manufacturer, or otherwise, does not necessarily constitute or imply its endorsement, recommendation, or favoring by the United States Government or the University of California. The views and opinions of authors expressed herein do not necessarily state or reflect those of the United States Government or the University of California, and shall not be used for advertising or product endorsement purposes.

This work was performed under the auspices of the U.S. Department of Energy by Lawrence Livermore National Laboratory under Contract W-7405-Eng-48. 
Report on:

\section{ACAB software upgrade}

(contract B333556)

J. Sanz ${ }^{(l)}$ and J.M. Balmisa ${ }^{(2)}$

October 1997

(1) Instituto de Fusión Nuclear (UPM)

*Permanent Address: ETS Ingenieros Industriales Universidad Nacional de Educación a Distancia (UNED)

${ }^{(2} \mathrm{PhD}$ at ETS Ingenieros Industriales (UNED) and Instituto de Fusión Nuclear (UPM)

*Permanent Address: Staff Consejo de Seguridad Nuclear (CSN) 



\title{
ACAB Software upgrade
}

\author{
J. Sanz and J.M. Balmisa
}

Summary of the contents

This report, according to the subcontract B333556 requirements, address two issues, stated as:

i) "Selection of the most current nuclear data libraries available".

ii) "User's manual of the updated ACAB code".

After a general summary of the major features of ACAB (Section D), highliting the new capabilities included in the present version of $A C A B$, the report is divided in sections structured as follows:

i) Firstly, we address the issue of the nuclear data libraries selected as starting point in preparing the libraries to be used directly by ACAB. Section II describes the main features of the selected libraries. In Section IV, the impact of using these libraries in Inertial Fusion Energy, IFE, applications is assessed by comparing activation results obtained using different activation cross-sections data libraries.

ii) Secondly, the points considered are the processing of libraries and libraries adapted to be directly read by ACAB. The "processing" efforts made whitin the frame of this project have been focussed on the COLLAPSE code. Important modifications have been made, and in Section IV we provide an overall description of the new version. The content of the data bases employed by the updated ACAB code are described in Section V.

iii) Thirdly, the input data file for running $A C A B$ is dealt with in Section VI, and some example problems are discussed in Section VII.

iv) Finally, regarding analysis of activation results, we described in Section VIII the updated version of the CHAINS code. 


\section{CONTENTS}

Page

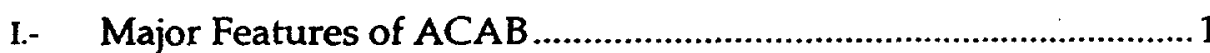

II.- Selection of Nuclear Data Libraries........................................... 6

A.- Activation Cross Section Data Library: FENDL/A-2.0 .....6

B.- Decay Data Library: FENDL/A-2.0............................... 11

C.- Fission Yield Data Library: JEF-2.2 .................................. 13

III.- Comparision Between Results Based on Different Cross Section Data Libraries: FENDL/A-2.0, EAF-4.1 and EAF-3.1 .20

IV.- COLLAPSE Processing Code ..................................................26

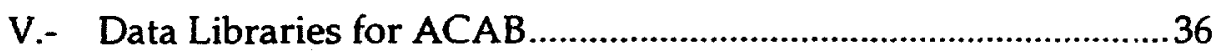

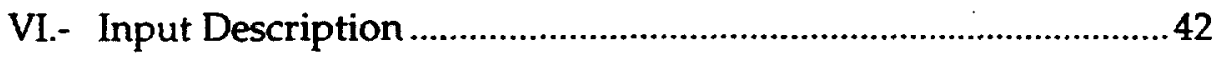

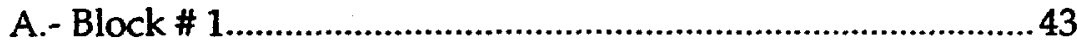

B.- Block \# 2 ...................................................................... 46

C. - Block \# 3..............................................................................49

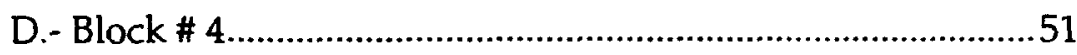

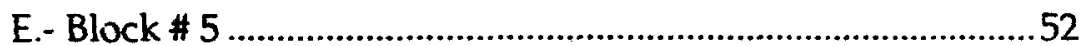

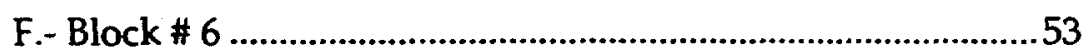

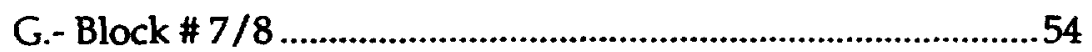

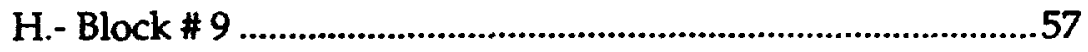

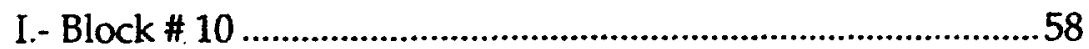

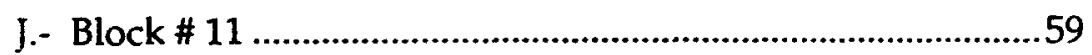

VII.- Example problems ......................................................................64

VIII.-Pathway analysis.CHAINS code ..........................................78

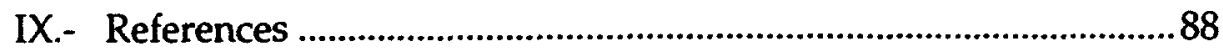




\section{LIST OF TABLES}

Table 1.New capabilities included in the updated ACAB code.

Table 2. Reaction types included in FENDL/A-2.

Table 3. Sources for the cross-section data of the inportnnt reaction sublibrary of FENDL/A-2.0

Tabla 4. Sources for the cross sections data of the inportant reaction sublibrary of FENDL/A-2.0.

Table5. Modes of decay and number of ground state and isomeric state daughters produced in each mode.

Table 6. Fissionable nuclides with fission products yields data in JEF-2.2.

Table 7. Sources for neutron-induced fission products yields.

Table 8. Comparison of SLB-concentration limits (in wt fraction) obtained from EAF-3.1,EAF-4.1 and FENDL/A-2.0.

Table 9. Comparison of remote recycling concentration limits (in wt fraction) obtained from EAF-3.1,EAF-4.1 and FENDL/A-2.0.

Table 10. Comparison of hands-on recycling concentration limits (in wt fraction) obtained from EAF-3.1,EAF-4.1 and FENDL/A-2.0.

Table 11. Limits on element concentrations (in wt fraction), and contribution of dominant radionuclides.

Table 12. Energy group boundaries for the Vitamin-J 175-group structure.

Table 13. Energy group boundaries for the GAM-II 100-group structure. 34

Table 14. Energy group boundaries for the 175-group energy structure. 35

Table15. Type of tables that are output by ACAB.

Table 16. Example ACAB output. Isotopic masses. 
Table 17. Example $A C A B$ output. Radionuclide activities.

Table 18. Example $A C A B$ output.Decay heat.

Table 19. Example ACAB output. Contact $\gamma$-ray.

Table 20. Example ACAB output.Contact Bremsstrahlung. 73

Table 21. Example ACAB output. Calculated $\gamma$-ray spectrum.

74

\section{LIST OF FIGURES}

Figure 1. Relative locations of the products from all the nuclear reactions, with exception of fission, that are considered by ACAB. 


\section{Major features of $\mathrm{ACAB}$}

The ACAB (ACtivation ABacus) code is a computer program designed to perform activation and transmutation calculations for fusion applications. The main computational algorithm is based on that of the ORIGEN ${ }^{2}$ code, and the program structure is based on that of the $\mathrm{ACFA}^{2}$ code.

$A C A B$ is able to perform space-dependent inventory calculations allowing for a very flexible geometry and neutron flux description. The code solves the general nuclear transmutation chains for multidimensional neutron flux distributions. One- and two-dimensional multigroup neutron fluxes generated by discrete ordinates transport codes can be used. In addition, ACAB can use three-dimensional neutron fluxes generated by Monte Carlo neutron transport codes allowing inventory calculations to be performed for complex geometries. The multigroup neutron fluxes may be given in an arbitrary group structure.

$A C A B$ considers decay transitions that proceed from the ground, first, and second isomeric states. All the neutron reactions that may occur in the different components of a fusion facility are treated in the code. Therefore, the reactions occuring at energies ranging from the thermal region to $20 \mathrm{MeV}$ are considered. Each of the neutron reactions may proceed from a target atom in the ground, first or second isomeric state and result in a product that is in the ground, first or second isomeric state. ACAB is also able to deal with sequential charged particle reactions as an additional mechanisms for the production of activity.

The code has been recently modify to fully treat actinides and fission products. In the inventory calculations you may consider up to 61 fissionable nuclides with the associated fission yields. Explicit information for independent yields coming from 19 fissionable nuclides is currently available. Fission yields for around 1450 nuclides can be managed. In figure 1 we show the relative locations of the products from all nuclear reactions, with exception of fission, that are considered by $\mathrm{ACAB}$.

$A C A B$ has the ability to simulate realistic operational scenarios of very different nuclear systems. In particular provide an accurate and efficient modeling of the pulsed schedule for inertial fusion experimental facilities, such as the National Ignition Facility, NIF. Any arbitrary irradiation/cooling history is represented by a series of irradiation/cooling periods, defined as a unit, which can be repeated a sepecified number of times and followed by distinct irradiation and cooling periods.

In addition, some modifications have been recently included allowing for "restart" options, which can be very useful to make easier activation modelling of hohlraum targets, and fusion reactor materials under the pulsed irradiation scenarios corresponding to Inertial Fusion Energy (IFE )power plants. 
ACAB's primary result is isotopic concentrations as a function of time for each spatial interval and/or zone defined in the system. From the isotopic concentrations, ACAB is able to generate radionuclide activities, afterheat, decay gamma spectra, contact dose rates, waste disposal ratings, and biological hazard potentials. Other quantities that depend upon isotopic concentrations and/or radionuclide activity can easily be added to $A C A B$.

In addition to the calculational facilities, $\mathrm{ACAB}$ also performs analysis of the activation results. Critical radionuclides are identified and pathways contributing to their production are evaluated.

Work in progress is mainly focussed on the following issues:

Computational procedure for activation analysis of targets in inertial experimental facilities similar to the National Ignition Facility (NIF). A computational procedure is being developed to compute the neutron-induced radioactivity associated to the targets used in the operational escenario of NIF. This enable ACAB to deal with the activation of the materials coming from D-T and non-tritium experiments, which are succesivelly deposited on the chamber wall and exposed to the neutrons of subsequent shots.

Computational methods for uncertainty analysis on activation calculations. A computational method is being implemented in ACAB to perform uncertainty analysis on activation calculations due to uncertainties in activation cross sections. This method is based on a first order Taylor series approach, and in the use of original algorithms to compute de derivative of the matrix exponential funcion. The method can be employed to compute the uncertainty in activation results coming from the uncertainty in each cross section, and to priorize the cross sections requiring more accuracy.

Some preliminary work has been also done to perform uncertainty analysis by the Monte Carlo method. This method will provide uncertainties in the activation results due to the uncertainties of the total set of cross sections.

Simplified methods for dealing with activation under pulsed irradiation regimes of IFE power reactors. When dealing with the problem, the methods currently implemented in $\mathrm{ACAB}$, although with high accuracy, may be questioned under the tradeoff between accuracy and time consuming. Therefore, some approximate methods will be implemented. The activation of several materials will be studied by the simplified methods and the realistic one, in order to determine which approximations, if any, could be acceptable to replace the current solution in modelling of pulsed irradiation under IFE power plant conditions.

Adjoint activation calculations. Work is currently underway to make ACAB able to performe adjoint calculations. This would provide straightforward which initial isotopes generate any radionuclide of interest and in what 
proportions they contribute to that production.

The performance capability of $A C A B$ has been tested in several benchmark exercises. It is worth mentioning the International Atomic Energy Agency (IAEA) Second International Activation Calculation Benchmark Comparition Study". The IAEA Benchmark was based on four criteria: (a) ability to read standard libraries (cross sections GAM-II or Vitamin-J group structures); (b) accurate (to within about 5\%) calculation of quantities of isotopes in multistep pathways; (c) ability to calculate light nuclide ( $\mathrm{H}$ and $\mathrm{He}$ isotopes) production; and (d) ability to treat isomeric states present in the libraries. Out of eleven worlwide codes participants of the study, $A C A B$ was one of the only two codes that was able to satisfy all four criteria, and was assessed as "suitable and satisfactory " for fusion applications.

The potential of ACAB for the IFE applications has been demostrated in a significant number of studies .It can mentioned ( in addition to the those directly related to members of the Instituto de Fusion Nuclear); the applications performed by the Department of Nuclear Enginnering at the University of California, Berkeley; the activation assessments of the conceptual reactor KOYO, proposed by the Institute of Laser Engineering (ILE) at the University of Osaka; and particularly, applications for IFE and NIF, and support for maintenance and the development of ACAB by Lawrence Livermore National Laboratory.

Table 1 gives a description of the major new capabilities included in the present version of $A C A B$, which enhance significantly the former version of $A C A B-2.0^{*}$. The code currently runs on Crays and on an HP/735 workstation. $A C A B$ is written in standard FORTRAN 77, so porting it onto other Unix-based work-stations should not be difficult. 
Table 1.- New capabilities included in the updated ACAB code.

\section{1.- Operational scenario (irradiation/cooling history).}

- A restart option is included to make easier deal with pulsed/intermittent irradiation.

- More options have been included to make easier modelling and input for arbitrary irradiation scenarios.

\section{2.- Nuclear processes.}

- Neutron reactions added: $(n, 4 n),(n, 4 n-m),(n, H n-s)$ and $(n, F)$.

- Generation of fission products.

- Modifications for dealing with $\beta^{+}$and electron capture transitions resulting in an excitated state product. Some trucation errors have been removed.

3.- Nuclear data libraries.

- Decay data library from FENDL/D-2.0.

- Photon yield library from FENDL/D-2.0.

- Activation cross section library from FENDL/A-2.0.

- Fission yield data from JEF-2.2.

- These libraries have allowed to increase significantly the number of nuclides treated by ACAB.

4.- Decay photons.

- Photons produced from second isomers have been added.

5.- Processing/collapsing of libraries.

- The COLLAPSE code can condese cross sections to a 175-group TART structure.

- COLLAPSE produce weithed fission yield cross section libraries.

6.- Pathway analysis.

- The CHAINS code has been modified to include all the nuclear processes implemented in the present version of $\mathrm{ACAB}$.

-Some inconsistences between identification numbers of neutron reactions and decay processes have been removed. 
Figure 1. Relative locations of products from all the nuclear reactions, with exception of fission,that are considered by ACAB.

\begin{tabular}{|c|c|c|c|c|c|}
\hline$Z+2$ & & & & $\left({ }^{3} \mathrm{He}, n\right)$ & $(\alpha \Omega)$ \\
\hline$Z+1$ & & & $\begin{array}{l}(p, n) \\
(d, 2 n)\end{array}$ & $\begin{array}{l}(d, n) \\
(t, 2 n)\end{array}$ & $(t, n)$ \\
\hline z & $(n, 4 n)$ & $(n, 3 n)$ & $(n, 2 n)$ & $\begin{array}{c}\text { Original } \\
\text { Nucleus } \\
\text { (nn) }\end{array}$ & $(n, \gamma)$ \\
\hline Z-1 & & $(n, n t)$ & $\begin{array}{c}(n, 2 n p) \\
(n, t) \\
(n, n d)\end{array}$ & $\begin{array}{l}(n, d) \\
(n, n p)\end{array}$ & $(n, p)$ \\
\hline$Z-2$ & $(n, 2 n \alpha)$ & $(n, n \alpha)$ & $\begin{array}{c}(n, \alpha) \\
\left(n, n^{3} \mathrm{He}\right)\end{array}$ & $\left(n_{0}^{3} \mathrm{He}\right)$ & $(n, 2 p)$ \\
\hline
\end{tabular}

Z-3 -

\begin{tabular}{|l|l|}
\hline$Z-4$ & $(n, 2 \alpha)$ \\
\hline
\end{tabular}

$\begin{array}{llllll}\mathrm{N}-4 & \mathrm{~N}-3 & \mathrm{~N}-2 & \mathrm{~N}-1 & \mathrm{~N} & \mathrm{~N}+1\end{array}$

Neutron Number

Note: ACAB considers twenty one netron reaction types (fission plus another 20 reaction types) and seven sequential charged particles reactions types. The target can be an atom in the ground,first or second isomeric state. Neutron reactions may result in a product that is in the ground, first or second isomeric state. 


\section{Selection of nuclear data libraries.}

The libraries selected as starting point to prepare those directly used by $\mathrm{ACAB}$ are the following:

- FENDL/A-2.05 is selected as the activation cross-section library.

- FENDL/D-2.06 is selected as the decay data library (it includes also the photon yield data ).

- JEF-2.27 is selected as the fission yield data libary.

In the rest of this section, the main characteristics of these libraries are described.

\section{A.- Activation cross section data library: FENDL/A-2.0.}

The FENDL/A-2.0 library is a neutron cross section data base produced within the IAEA FENDL project which has the goal of providing a comprehensive Fusion Evaluated Nuclear Data Library for predicting all nuclear processes in fusion devices.

The FENDL/A-2.0 file containts data for all stable and unstable target nuclides with half-lives longer than $1 / 2$ day. If a reaction produces isomers the cross section for the ground-and isomer- state are given separately. The FENDL/A-2.0 includes 739 target nuclides from $H(A=1, Z=1)$ to $\mathrm{Cm}(A=248$, $Z=96$ ) with 13,006 reactions, in the incident energy range up to $20 \mathrm{MeV}$. These reactions are significant in producing activation both at short and long cooling times. The reaction types and number of reactions for each type included in the library are given in Table 2 , and the sources for the cross section data of these reactions are listed in Table 3.

The FENDL/A-2.0 activation library can be considered as formed by two parts: i) a sublibrary of important reactions for fusion application, and ii) a basic library which complements the "important reaction sublibrary".

The FENDL/A-2.0 Sublibrary of Important Reactions contains 398 reactions important for fusion reactor technology in general, although it was at first particularly aimed for activation studies within the ITER design. The sources for the cross section data of these reactions are given in Table 4.

In the FENDL/A-2.0 Basic Library all the cross-section data important have been selected from the European Activation File version 4 (EAF-4.1) ${ }^{8}$.

Considering the two parts together, we have that in FENDL/A-2.0 the bulk of the data is EAF-4.1, with around 240 selections (see Table 4) from ADL3, JENDL/A-3.2, FENDL/A-1.1, ENDF/B-VI, IRDF-90.2, IRK and CRP. 
It has been emphasized5.9 that the basic library contains evaluated neutron activation cross sections selected from existing activation data files. In assembling this library, no additional evaluation work was performed in order to improve evaluations; only existing evaluations were considered for inclusion. Therefore, in many cases the data given are theoretical estimates without or with limited experimental verification so that the data uncertainty may be significantly higher than for those evolved from careful evaluation and validation (such as the important reactions). 
Tabla 2.- Reaction types included in FENDL/A-2.0. [Ref. 5]

\begin{tabular}{|c|c|}
\hline Reaction fNo & Number of Reactions \\
\hline N,2N & 971 \\
N,3N & 829 \\
N,4N & 21 \\
N,G & 972 \\
N,F & 61 \\
N,N & 252 \\
N,ND & 989 \\
N,NP & 986 \\
N,NA & 963 \\
N,NT & 906 \\
N,NH & 329 \\
N,2P & 872 \\
N,2 & 2 \\
N,P & 982 \\
N,D & 989 \\
N,A & 954 \\
N,T & 1010 \\
N,H & 914 \\
N,2NA & 2 \\
N,2NP & 1 \\
N,N2A & 1 \\
\hline Total & 13006 \\
\hline
\end{tabular}


Tabla 3.- Sources for the cross section data included in FENDL/A-2.0. [Ref. 5]

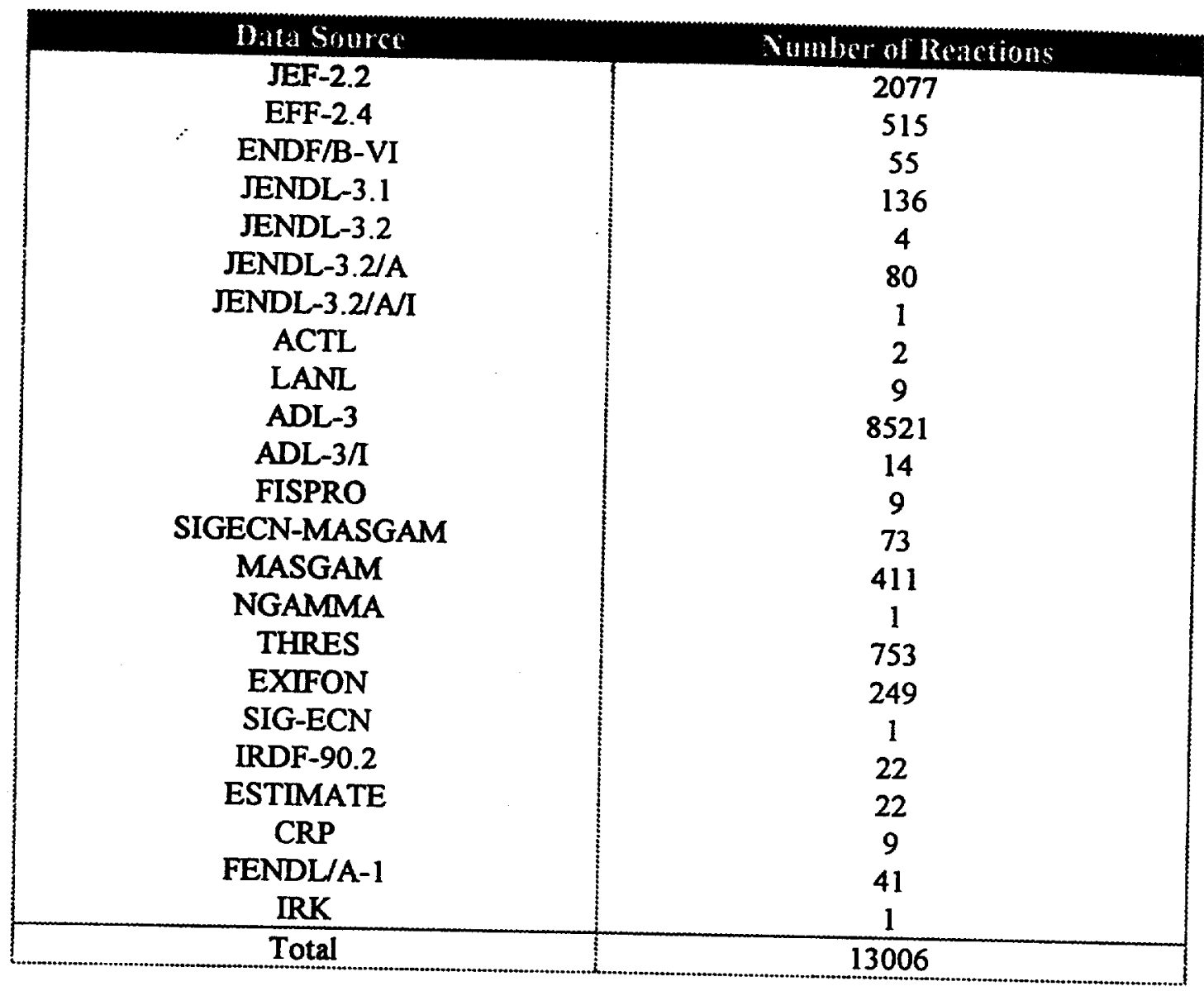


Table 4.- Sources for the cross section data of the important reaction sublibrary of FENDL/A-2.0. [Ref. 5]

\begin{tabular}{|c|c|}
\hline Bata Sourcc & Number or Targets \\
EAF-4.1 & 158 \\
ENDF/B-VI & 1 \\
JENDL/A-3.2 & 65 \\
ADL-3 & 135 \\
IRDF-90.2 & 1 \\
CRP(2) & 8 \\
FENDL/A-1.1 & 29 \\
IRK(1) & 1 \\
\hline Total & 398 \\
\hline
\end{tabular}

(1) IRK stands for evaluation originating from the Institute für Radiumforschung und Kernphysik Vienna.

(2) CRP is a product from Research Coordination Programme on the Activation Cross Sections for the Generation of Long-lived Radionuclides of IAEA [Ref. 10].

-The rest of selections come from well known and released libraries. 


\section{B.-Decay data library: FENDL/D-2.0}

The library selected is FENDL/D-2.0.

In the selection of the decay data library the criteria to follow is to take the one most compatible with the selected activation library (the FENDL/A-2.0 in our case). Consequently, the FENDL decay data library (FENDL/D-2.0) is the logical choice.

. The two main compatibility requirements between the activation and the decay library to take into account are: i) all nuclides referred to in the activation library must have data in the decay library., and ii) the identification of isomeric states used in both libraries should be identical.

In the selection of the decay data library for FENDL/D-2.0, the choice was to take directly the EAF-4.1 (EAF_DEC-4.1) decay library. With this choice, based on the fact that FENDL/A-2.0 is largely based on EAF-4.1, the two requirements above mentioned have been fulfilled. However, regarding the second requirement there are a few cases in which inconsistency of identification of isomeric states between the two libraries remain due to the inclusion of the important reactions subfile in FENDL/A-2.0

These inconsistencies, according to the FENDL/D-2.0 assessment6, to be on nuclides of very limited importance for fusion applications so was decided to let them remain. A new decay library version is expected to be released in a near future by the authors of FENDL removing these inconsistencies. Otherwise, corrections will be made by ourselves.

FENDL/D-2.0 contains decay properties (decay type, decay energy, halflife, photon yield) for 1875 nuclides and isomers, including ground, first and second isomeric states; and it is written in ENDF/B-VI format.

The library need to be processed before it can be used by ACAB. A program has been writen to read decay data libraries in ENDF/B-V.0 and VI format for producing two different files, one containig the photon yield information and the other the decay nuclear data, in the format required to be read by $A C A B$. 


\section{Table 5.-FENDL/D-2.0: Modes of decay and number of ground state and isomeric state daugthers produced in each mode}

\begin{tabular}{|c|c|c|c|}
\hline \multirow[b]{2}{*}{ Mode of decay } & \multicolumn{2}{|c|}{ Daughters } & \multirow[b]{2}{*}{$\begin{array}{l}2^{\text {nd }} \text { isomeric } \\
\text { state }\end{array}$} \\
\hline & Ground & $\begin{array}{l}1^{\text {st }} \text { isomeric } \\
\text { state }\end{array}$ & \\
\hline B decay & 719 & 64 & 2 \\
\hline 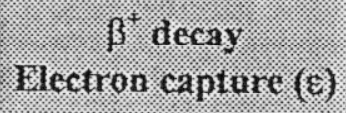 & 693 & 8 & - \\
\hline $\begin{array}{l}\text { Isomeric transition } \\
(\mathrm{IT})\end{array}$ & 268 & 6 & - \\
\hline alpha decay (a) & 1 & 1 & - \\
\hline Neatron decay $(\mathrm{n})$ & - & - & - \\
\hline Spontaneous fission & 22 & 一 & - \\
\hline proton decay $(p)$ & 3 & & - \\
\hline $\begin{array}{l}\beta \text { decay followed } \\
\text { by } \mathrm{n} \text { emission }(\beta, n)\end{array}$ & 6 & - & \\
\hline $\begin{array}{l}\beta \text { decay followed by } \\
\alpha \text { emission }(\beta, \alpha)\end{array}$ & 4 & - & \\
\hline
\end{tabular}




\section{C- Fission yield data library: JEF-2.2}

The JEF-2.2 fission yield library is selected.

This library contains the energy-dependent fission product yield data for three different incident neutron energies: $0.253 \mathrm{eV}, 0.4 \mathrm{MeV}$ and $14 \mathrm{MeV}$. Information is given for the independent and cumulative yield coming from 19 fissionable nuclides. The fission yield from each of the fissionable nuclides is given for around 1450 nuclides.

The fissionable nuclides with fission product yield data in JEF-2.2 are listed in Table 6. It can be seen that for some of these fissionable nuclides, yield data are not given for the three energy points, eventhough the fission cross section is not negligible in some cases for a neutron having the energy of a missing point. The sources for the fission yield data included in JEF-2.2 for the nuclides of Table 6, are provided in Table 7.

The format of the library is ENDF-6, and should be processed by the COLLAPS code (see Section IV) for producing the weighted fission yields libraries to be read directly by $A C A B$. 
Table 6.- Fissionable nuclides with fission product yield data in JEF-2.2.

\begin{tabular}{|c|c|c|c|}
\hline \multicolumn{4}{|c|}{ Incident neutron energies (en) } \\
\hline Fissionable & $2.53 \times 10^{2}$ & $4 \times 10^{5}$ & $14 \times 10^{6}$ \\
\hline Th-232 & ---1 & Y & Y \\
\hline U- 233 & Y & Y & Y \\
\hline U-234 & -- & $\mathrm{Y}$ & -- \\
\hline U-235 & Y & Y. & Y. \\
\hline U-236 & -- & $\mathrm{Y}$ & -- \\
\hline V.-238 & 2. & Y. & Y. \\
\hline Np-237 & Y & $\mathrm{Y}$ & -- \\
\hline$N_{p}-238$ & Y & $x$ & 2. \\
\hline Pu-238 & Y & Y & -- \\
\hline Pu-239 & Y & i. & 1. \\
\hline Pul-240 & -- & Y & -- \\
\hline $\mathrm{Pu}-241$ & i. & y. & 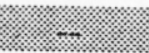 \\
\hline $\mathrm{Pu}-242$ & -- & $\mathrm{Y}$ & -- \\
\hline Arr-241 & Y & r. & 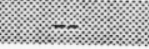 \\
\hline $\mathrm{Am}-242 \mathrm{~m}$ & Y & Y & -- \\
\hline An: 243 & Y. & i. & 2. \\
\hline $\mathrm{Cm}-243$ & $\mathrm{Y}$ & Y & -- \\
\hline $\mathrm{Cm}-244$ & Y. & Y. & - \\
\hline $\mathrm{Cm}-245$ & Y & Y & -- \\
\hline
\end{tabular}


TABLE 7. Sources for neutron-induced fission products yields.

JEF-2.2 TAPE 24 (FISSION YIELDS)

90-TH-232 WIN EVAL-JUN93 M.JAMES AND R.MILLS DIST-JUN93 930702

-JEF-2.2 MATERIAL 9061

- NEUTRON-INDUCED FISSION PRODUCT YIELDS

-ENDF-6 FORMAT

ADJUSTED INDEPENDENT AND CUMULATIVE YIELD LIBRARIES

TERNARY FISSION AND ISOMERIC SPLITTING INCLUDED

DESCRIBED WITHIN REPORTS AEA-TRS-1015, 1018 AND 1019.

THIS WORK WAS SPONSORED BY THE UKAEA, BNF PLC AND NUCIEAR

ELECTRIC THIS REMAINS THE JOINT PROPERTY OF THE SPONSORS

BUT CAN BE DISTRIBUTED FREELY. NO LUABILITY CAN BE ACCEPTED

BY THE SPONSORS FOR THE USE, OR MISUSE, OF THIS DATA.

92-U-233 WIN EVAL-IUN93 M.JAMES AND R.MILLS

DIST-JUN93 930702

-JEF-2.2 MATERIAL 9234

-NEUTRON-INDUCED FLSION PRODUCT YIELDS

- ENDF-6 FORMAT

ADIUSTED INDEPENDENT AND CUMULATIVE YIELD LIBRARIES TERNARY FLSSION AND ISOMERIC SPLITTING INCLUDED DESCRIBED WITHIN REPORTS AEA-TRS-1015, 1018 AND 1019.

THIS WORK WAS SPONSORED BY THE UKAEA, BNF PLC AND NUCLEAR ELECTRIC. THIS REMAINS THE JOINT PROPERTY OF THE SPONSORS BUT CAN BE DISTRIBUTED FREELY. NO LIABILITY CAN BE ACCEPTED BY THE SPONSORS FOR THE USE, OR MLSUSE, OF THIS DATA.

92-U-234 WIN EVAL-JUN93 M.JAMES AND R.MILLS DIST-JUN93 930702

-JEF-2.2 MATERIAL 9237

-NEUTRON-INDUCED FBSSION PRODUCT YIELOS

-ENDF-6 FORMAT

ADUSTED INDEPENDENT AND CUMULATIVE YIELD UIBRARIES TERNARY FLSION AND ISOMERIC SPLITTING INCLUDED DESCRIBED WITHIN REPORTS AEA-TRS-1015, 1018 AND 1019. THIS WORK WASSPONSORED BY THE UKAEA, BNF PLC AND NUCLEAR ELECTRIC THIS REMAINS THE JOINT PROPERTY OF THE SPONSORS BUT CAN BE DISTRIBUTED FREELY. NO LABIUTY CAN BE ACCEPTED BY THE SPONSORS FOR THE USE, OR MISUSE, OF THIS DATA.

92-U-235 WIN EVAL-JUN93 M.JAMES AND R.MILLS

-JEF-22 MATERIAL 9240

-NEUTRON-INDUCED FISSION PRODUCT YIELDS

ENDF-6 FORMAT

ADIUSTED INDEPENDENT AND CUMULATIVE YIELD LIBRARIES TERNARY FISSION AND ISOMERIC SPLTTING INCLUDED DESCRIBED WITHIN REPORTS AEA-TRS-1015, 1018 AND 1019.

THIS WORK WASSPONSORED BY THE UKAEA, BNF PLC AND NUCLEAR ELECTRIC THIS REMAINS THE JONNT PROPERTY OF THE SPONSORS BUT CAN BE DISTRIBUTED FREELY. NO LIABILITY CAN BE ACCEPTED BY THESPONSORS FOR THE USE, OR MLSUSE, OF THLS DATA. 
Table 7 continued

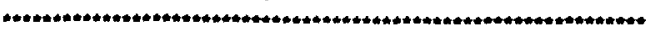

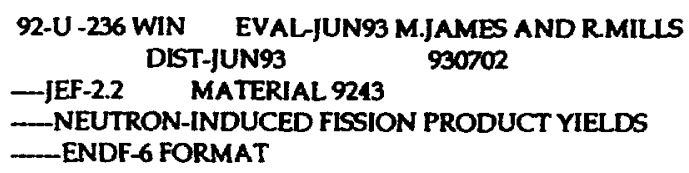

ADJUSTED INDEPENDENT AND CUMULATIVE YIELD LIBRARIES TERNARY FISSION AND ISOMERIC SPLITTING INCLUDED DESCRIBED WITHIN REPORTS AEA-TRS-1015, 1018 AND 1019. THIS WORK WAS SPONSORED BY THE UKAEA, BNF PLC AND NUCLEAR ELECTRIC. THIS REMAINS THE JOINT PROPERTY OF THESPONSORS BUT CAN BE DISTRIBUTED FREELY. NO LIABILITY CAN BE ACCEPTED BY THE SPONSORS FOR THE USE, OR MISUSE, OF THIS DATA.

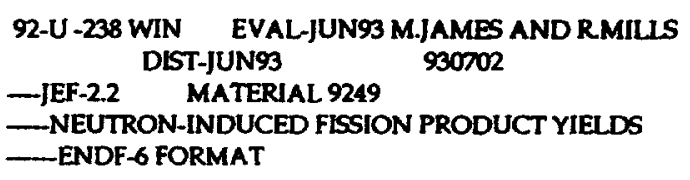

ADJUSTED INDEPENDENT AND CUMULATIVE YIELD LIBRARIES TERNARY FISSION AND ISOMERIC SPLTTING INCLUDED DESCRIBED WITHIN REPORTS AEA-TRS-1015, 1018 AND 1019.

THIS WORK WAS SPONSORED BY THE UKAEA, BNF PLC AND NUCLEAR ELECTRIC. THIS REMAINS THE JOINT PROPERTY OF THE SPONSORS BUT CAN BE DISTRIBUTED FREELY. NO LIABILITY CAN BE ACCEPTED BY THE SPONSORS FOR THE USE, OR MISUSE, OF THIS DATA.

93-NP-237 WIN EVAL-JUN93 M.JAMES AND R.MILLS DIST-JUN93 930702

-JEF-2.2 MATERIAL 9346

- NEUTRON-INDUCED FISSION PRODUCT YIELDS

-ENDF-6 FORMAT

ADJUSTED INDEPENDENT AND CUMULATIVE YIELD LIBRARIES TERNARY FISSION AND ISOMERIC SPLITTING INCLUDED DESCRIBED WITHIN REPORTS AEA-TRS-1015, 1018 AND 1019. THIS WORK WAS SPONSORED BY THE UKAEA, BNF PLC AND NUCLEAR ELECTRIC. THIS REMAINS THE JOINT PROPERTY OF THE SPONSORS BUT CAN BE DISTRIBUTED FREELY. NO UABIUTY CAN BE ACCEPTED BY THE SPONSORS FOR THE USE, OR MISUSE, OF THIS DATA.

\section{3-NP-238 WIN EVAL-JUN93 M.JAMES AND R.MILIS

$$
\text { DIST-JUN93 } 930702
$$ \\ -JEF-22 MATERIAL 9349 \\ -NEUTRON-INDUCED FISSION PRODUCT YIELDS \\ -ENDF-6 FORMAT}

ADJUSTED INDEPENDENT AND CUMULATIVE YIELD LIBRARIES TERNARY FISSION AND ISOMERIC SPLTTING INCLUDED DESCRIBED WITHIN REPORTS AEA-TRS-1015, 1018 AND 1019. THIS WORK WAS SPONSORED BY THE UKAEA, BNF PLC AND NUCLEAR ELECTRIC. THIS REMAINS THE JOINT PROPERTY OF THE SPONSORS BUT CAN BE DISTRIBUTED FRFELY. NO LIABILTYY CAN BE ACCEPTED BY THE SPONSORS FOR THE USE, OR MISUSE, OF THIS DATA. 
Table 7 continued

$94-P U-238$ WIN EVAL-JUN93 M.JAMES AND R.MILLS
DIST-JUN93 930702
MEF-2.2 $\quad$ MATERIAL 9437
-NEUTRON-INDUCED FISSION PRODUCT YIELDS
ENDF-6 FORMAT

ADJUSTED INDEPENDENT AND CUMULATIVE YIELD LIBRARIES TERNARY FISSION AND ISOMERIC SPLITTING INCLUDED DESCRIBED WITHIN REPORTS AEA-TRS-1015, 1018 AND 1019.

THIS WORK WAS SPONSORED BY THE UKAEA, BNF PLC AND NUCLEAR ELECTRIC. THIS REMAINS THE JOINT PROPERTY OF THE SPONSORS BUT CAN BE DISTRIBUTED FREELY. NO LABILITY CAN BE ACCEPTED BY THE SPONSORS FOR THE USE, OR MISUSE, OF THIS DATA.

94-PU-239 WIN EVAL-JUN93 M.JAMES AND R.MILLS

-JEF-22 MATERIAL 9440

-NEUTRON-INDUCED FISSION PRODUCT YIELDS

-ENDF-6 FORMAT

ADJUSTED INDEPENDENT AND CUMULATIVE YIELD LIBRARIES TERNARY FLSSION AND ISOMERIC SPLITTING INCLUDED DESCRIBED WITHIN REPORTS AEA-TRS-1015, 1018 AND 1019. THIS WORK WAS SPONSORED BY THE UKAEA, BNF PLC AND NUCLEAR ELECTRIC. THLS REMAINS THE JOINT PROPERTY OF THE SPONSORS BUT CAN BE DISTRIBUTED FREELY. NO LIABILITY CAN BE ACCEPTED BY THE SPONSORS FOR THE USE, OR MISUSE, OF THIS DATA.

\footnotetext{
94-PU-240 WIN EVAL-JUN93 M.JAMES AND R.MILLS DIST-JUN93 930702

-JEF-2.2 MATERIAL 9443

-NEUTRON-INDUCED FISSION PRODUCT YIELDS

-ENDF-6 FORMAT
}

ADJUSTED INDEPENDENT AND CUMULATIVE YIELD LIBRARIES TERNARY FISSION AND ISOMERIC SPLITTING INCLUDED DESCRIBED WITHIN REPORTS AEA-TRS-1015, 1018 AND 1019. THIS WORK WAS SPONSORED BY THE UKAEA, BNF PLC AND NUCLEAR ELECTRIC THIS REMAINS THE JOINT PROPERTY OF THE SPONSORS BUT CAN BE DISTRIBUTED FREELY. NO UAABILTTY CAN BE ACCEPTED BY THE SPONSORS FOR THE USE, OR MISUSE, OF THIS DATA.

94-PU-241 WIN EVAL-JUN93 M.JAMES AND R.MILIS DIST-JUN93 930702

-JEF-22 MATERIAL 946

- NEUTRON-INDUCED FISSION PRODUCT YIELDS

-ENDF-6 FORMAT

ADJUSTED INDEPENDENT AND CUMULATIVE YIELD LIBRARIES TERNARY FISSION AND LSOMERIC SPLITTING INCLUDED DESCRIBED WITHIN REPORTS AEA-TRS-1015, 1018 AND 1019. THIS WORK WAS SPONSORED BY THE UKAEA, BNF PLC AND NUCLEAR ELECTRIC THIS REMAINS THE JOINT PROPERTY OF THE SPONSORS BUT CAN BE DISTRIBUTED FREELY. NOLIABILTYY CAN BE ACCEPTED BY THE SPONSORS FOR THE USE, OR MISUSE, OF THIS DATA. 
Table 7 continued

\author{
94-PU-242 WIN EVAL-JUN93 M.JAMES AND R.MILLS \\ DIST-JUN93 930702 \\ - JEF-2.2 MATERIAL 9449 \\ -NEUTRON-INDUCED FISSION PRODUCT YIELDS \\ - ENDF-6 FORMAT
}

ADIUSTED INDEPENDENT AND CUMULATIVE YIELD LIBRARIES TERNARY FISSION AND ISOMERIC SPLITTING INCLUDED DESCRIBED WITHIN REPORTS AEA-TRS-1015, 1018 AND 1019. THIS WORK WAS SPONSORED BY THE UKAEA, BNF PLC AND NUCLEAR ELECTRIC THIS REMAINS THE JOINT PROPERTY OF THE SPONSORS BUT CAN BE DISTRIBUTED FREELY. NO LIABILITY CAN BE ACCEPTED BY THE SPONSORS FOR THE USE, OR MISUSE, OF THIS DATA.

95-AM-241 WIN EVAL-JUN93 M.JAMES AND R.MILLS
DIST-JUN93 930702

-JEF-2.2 MATERIAL 9543

- NEUTRON-INDUCED FISSION PRODUCT YIELDS

-ENDF-6 FORMAT

ADJUSTED INDEPENDENT AND CUMULATIVE YIELD LIBRARIES

TERNARY FISSION AND ISOMERIC SPLITTING INCLUDED

DESCRIBED WITHIN REPORTS AEA-TRS-1015, 1018 AND 1019.

THIS WORK WAS SPONSORED BY THE UKAEA, BNF PLC AND NUCLEAR

ELECTRIC THIS REMAINS THE JOINT PROPERTY OF THE SPONSORS

BUT CAN BE DISTRIBUTED FREELY. NO LIABILITY CAN BE ACCEPTED

BY THE SPONSORS FOR THE USE, OR MISUSE, OF THIS DATA.

95-AM-242MWIN EVAL-JUN93 M.JAMES AND R.MILLS
DIST-JUN93 930702

-JEF-2.2 MATERIAL 9547

- NEUTRON-INDUCED FISSION PRODUCT YIELDS

-ENDF-6 FORMAT

LISO SET TO 1 RAF CULHAM 4/11/94

ADJUSTED INDEPENDENT AND CUMULATIVE YIELD LIBRARIES

TERNARY FISSION AND ISOMERIC SPLITTING INCLUDED

DESCRIBED WITHIN REPORTS AEA-TRS-1015, 1018 AND 1019.

THIS WORK WAS SPONSORED BY THE UKAEA. BNF PLC AND NUCLEAR

ELECTRIC. THIS REMAINS THE JOINT PROPERTY OF THE SPONSORS

BUT CAN BE DISTRIBUTED FREELY. NO LIABILITY CAN BE ACCEPTED BY THE SPONSORS FOR THE USE, OR MISUSE, OF THIS DATA.

95-AM-243 WIN EVAL-JUN93 M.JAMES AND RMILLS

DIST-JUN93 930702

-JEF-22 MATERIAL 9549

- NEUTRON-INDUCED FISSION PRODUCT YIELDS

- ENDF-6 FORMAT

ADJUSTED INDEPENDENT AND CUMULATIVE YIELD LIBRARIES

TERNARY FISSION AND ISOMERIC SPLITTING INCLUDED

DESCRIBED WITHIN REPORTS AEA-TRS-1015, 1018 AND 1019.

THIS WORK WAS SPONSORED BY THE UKAEA, BNF PLC AND NUCLEAR

ELECTRIC. THIS REMAINS THE JOINT PROPERTY OF THE SPONSORS

BUT CAN BE DISTRIBUTED FREELY. NO LIABILTTY CAN BE ACCEPTED

BY THESPONSORS FOR THE USE, OR MISUSE, OF THIS DATA. 
Table 7 continued

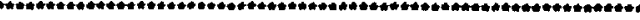

96-CM-243 WIN EVALJUN93 M.JAMES AND RMILIS DIST-JUN93 930702

-JEF-2.2 MATERIAL 9640

- NEUTRON-INDUCED FISSION PRODUCT YIELDS

-ENDF-6 FORMAT

ADJUSTED INDEPENDENT AND CUMULATIVE YIELD LJBRARIES TERNARY FISSION AND ISOMERIC SPLITINIG INCLUDED DESCRIBED WITHIN REPORTS AEA-TRS-1015, 1018 AND 1019. THIS WORK WASSPONSORED BY THE UKAEA, BNF PLC AND NUCLEAR ELECTRKC THIS REMAINS THE JOINT PROPERTY OF THE SPONSORS BUT CAN BE DISTRIBUTED FREELY. NO LIABILITY CAN BE ACCEPTED BY THE SPONSORS FOR THE USE, OR MISUSE, OF THIS DATA.

96-CM-244 WIN EVAL-JUN93 M.JAMES AND R.MILLS DIST-JUN93 930702

-JEF-2.2 MATERIAL 9643

-NEUTRON-INDUCED FISSION PRODUCT YIELDS

-ENDF-6 FORMAT

ADJUSTED INDEPENDENT AND CUMULATIVE YIELD LIBRARIES TERNARY FISSION AND ISOMERIC SPLITTING INCLUDED DESCRIBED WITHIN REPORTS AEA-TRS-1015, 1018 AND 1019. THIS WORK WAS SPONSORED BY THE UKAEA, BNF PLC AND NUCLEAR ELECTRIC THIS REMAINS THE JOINT PROPERTY OF THE SPONSORS BUT CAN BE DISTRIBUTED FREELY. NO LIABILITY CAN BE ACCEPTED BY THE SPONSORS FOR THE USE, OR MLSUSE, OF THIS DATA.

96-CM-245 WIN EVAL-JUN93 M.JAMES AND R.MILLS DIST-JUN93 930702

-JEF-2.2 MATERIAL 9646

- NEUTRON-INDUCED FISSION PRODUCT YIELDS

-ENDF-6 FORMAT

ADJUSTED INDEPENDENT AND CUMULATIVE YIELD LBRARIES TERNARY FLSTION AND ISOMERIC SPLITTING INCLUDED DESCRIBED WITHIN REPORTS AEA-TRS-1015, 1018 AND 1019. THIS WORK WAS SPONSORED EY THE UKAEA, BNF PLC AND NUCLEAR ELECTRIC THIS REMANS THE JOINT PROPERTY OF THE SPONSORS BUT CAN EE DETTRBUTED FREEY Y. NO UABIUTY CAN BEACCEPTED BY THE SPONSORS FOR THE USE, OR MESUSE, OF THIS DATA. 


\section{Comparison between results based on different cross-section data libraries: FENDL/A-2.0, EAF-4.1, and EAF-3.1.}

This section is primarily intended to show how results based on FENDL/A-2.0, the newest activation library, compare with those based on some other earlier important libraries such as EAF-3.111 and EAF-4.1. We have selected the EAF-4.1 for comparison purposes because this library is the basic one for FENDL/A-2.0, and in fact, there are differences between both for cross sections of only $\approx 235$ reactions out of 13006 . As far as EAF-3.1, we show results based on this library, although it is the former version of EAF-4.1, for two reasons: i) EAF-3.1 can be considered as one of the most complete activation libraries up to 1996, just when the EAF-4.1 started to be used, and then results based on EAF-3.1 are a good indication of the state-of-art on activation studies before that year, and ii) EAF-3.1 is the library used in the former version of $A C A B$ (ACAB- 2.0).

In the exercice performed here we compute the concentration limits (CL's) corresponding to hands-on recycling, remote recycling and shallow land burial (SLB) for each of the natural elements from $\mathrm{H}$ to $\mathrm{Bi}$, using FENDL/ $\mathrm{A}$ 2.0, EAF-4.1 and EAF-3.1.

The neutron environment for this exercice is taken ${ }^{12}$ from the midplane region of the first structural wall (FSW) of the HYLIFE-II'3 reactor vessel. In this zone, the most-neutron exposed portion of the vessel structure, the flux intensity is $1.29 \times 10^{15} \mathrm{~cm}^{-2} \mathrm{~s}^{-1}$, assuming a continuous irradiation of $30 \mathrm{yr}$ (corresponding to the desirable FSW life time) and a $75 \%$ capacity factor. The average neutron energy is $0.38 \mathrm{MeV}$.

In defining CL's for recycling, two criteria are considered: hands-on recycling will be acceptable when the contact dose rate does not exceed 25 $\mu \mathrm{Sv} / \mathrm{h}$ at $100 \mathrm{yr}$ cooling, and remote recycling when the dose rate is kept below $10 \mathrm{mSv} / \mathrm{h}$ within $50 \mathrm{yr}$ cooling. The CL's on each of the elements are calculated by assuming the element to be placed in a non-active matrix of iron. In ranking the acceptability of elements for SLB we have adopted the U.S. class C waste criteria (regulatory guide 10CFR61) using as specific activity limits (SAL's in $\mathrm{Ci} / \mathrm{m}^{3}$ ) those calculated by Fetter et al ${ }^{14}$. The concentration limit for SLB, i.e., that for which WDR=1, is computed assuming the element to be present in a non active matrix of a material with density that of iron $\left(7.87 \mathrm{~g} \mathrm{~cm}^{-3}\right)$. Limits on elements placed in a matrix of different density, $D_{\operatorname{man}}$ can be obtained by multiplying the limits computed in this Section by the factor $D_{m a} / 7.87$. The SLB-concentration limits are calculated for shutdown after 30 yr operation.

The concentrations limits of those elements restricted for the considered waste management criteria have been compared in Table 8 (for SLBconcentration limits), Table 9 (for remote recycling CL's), and Table 10 (for hand-on recycling CL's). In this Tables, elements are listed in decreasing order of absolute Relative Differences (the definition of the RD index is given at the bottom of the Tables) between EAF-3.1 and FENDL/A-2.0. 
When comparing EAF-3.1 versus FENDL/A-2.0 we find that most of the elements present negative RD. These differences are very significant for a great number of elements, and so their radiological impact is very conservatively assessed if EAF-3.1 is used. This explains that in earlier works, proposed low activation (LA) elements such as $\mathrm{Ta}$, or $\mathrm{W}$, were assessed as undesirable even as minor constituent elements in IFE environments; and impurities such as $\mathrm{Ag}$ were considered very critical.

Only a few elements present positive relative differences. These differences for SLB concentration limits, except for $C_{0}(R D=0.65)$, are never higher than 0.3. For recycling, the highest $\mathrm{RD}$ is around 0.9 for $\mathrm{Rh}, \mathrm{Se}, \mathrm{Ni}$ and Zn.

When comparing EAF-4.1 with FENDL/A-2.0, we find that for most of the elements the differences are negligible. When existing, the relative differences are in most cases negative. The most important occur for $\mathrm{O}$ and $\mathrm{N}$ (not limited with FENDL). These elements, when comparing SLB concentration limits, exhibit an $\mathrm{RD}=-0.9$. For Ir the difference is also significant $(\mathrm{RD}=-0.6)$. For recycling the highest difference appears for $I r$, with an $R D$ around -0.6 . For positive RD, and SLB-CL's, the highest differences are for $\mathrm{Al}(\mathrm{RD}=0.65)$ and $\mathrm{Co}$ $(\mathrm{RD}=0.38)$, for remote recycling there is only one significant difference, $\mathrm{Zn}$ $(\mathrm{RD}=1.3)$, and for hands-on recycling there are two, $\mathrm{Tl}(\mathrm{RD}=0.95)$ and $\mathrm{Al}$ $(\mathrm{RD}=0.65)$.

It can be concluded that i) large differences are observed between some results obtained using the new data libraries, EAF-4.1, FENDL/A-2.0, and a former one, EAF-3.1, and ii) EAF-4.1 and FENDL/A-2.0 provide in general similar results, but for a few elements, significant differences are found.

Finally, we show in Table 11 concentrations limits for recycling and SLB computed with FENDL/A-2.0, as well as the dominant radionuclides with a contribution (given in brackets in the Table) higher than $5 \%$ to the radiological quantity setting the concentration limit for each waste management criteria.

The implications of these results in ranking and selecting elements for LA material compositions attractive for waste management have been discussed elsewhere ${ }^{15}$. Here, the results are presented so that they can be used to assess how conclusions of earlier works dealing with the activation of the liquid protected FSW of IFE reactors (in which LLNL has a lot of experience, such as the case of HYLIFE-II reactor) are changed when using FENDL/ A-2.0. 
Table 8. Comparison of SLB-concentration limits ( in wtfraction) obtained from EAF-3.1, EAF-4.1, and FENDL/A-2.0.

\begin{tabular}{|c|c|c|c|c|c|}
\hline \multirow[t]{2}{*}{ ELEMENT } & \multicolumn{2}{|c|}{ EAF-3.1 } & \multicolumn{2}{|c|}{ EAF-4.1 } & FENDUA-2.0 \\
\hline & $\mathrm{CL}$ & $\mathbf{A D}^{*}$ & $\mathrm{CL}$ & RD & $\mathrm{CL}$ \\
\hline TA & 5.55E-05 & -0.991 & 5.16E-03 & -0.148 & $6.06 \mathrm{E}-03$ \\
\hline$w$ & 3.02E-05 & -0.990 & $2.58 \mathrm{E}-03$ & -0.187 & $3.18 E-03$ \\
\hline RE & 2.33E-05 & -0.990 & 1.87E-03 & -0.218 & 2.39E-03 \\
\hline os & 5.70E-05 & -0.988 & 3.14E-03 & -0.358 & 4.90E-03 \\
\hline $\mathbf{R H}$ & $1.44 E-02$ & 0.971 & $5.14 E-03$ & -0.296 & $7.30 E-03$ \\
\hline HF & 2.65E-04 & -0.970 & $8.66 E-03$ & -0.022 & 8.86E-03 \\
\hline PT & 6.00E-01 & -0.957 & $7.61 E+00$ & -0.450 & $1.38 \mathrm{E}+01$ \\
\hline IR & $3.14 E-02$ & -0.940 & 2.00E-01 & -0.619 & 5.24E-01 \\
\hline $\mathrm{CD}$ & $8.04 E-04$ & -0.933 & 1.15E-02 & -0.041 & $1.20 E-02$ \\
\hline LU & 1.13E-03 & -0.908 & $1.24 E-02$ & 0.006 & $1.23 E-02$ \\
\hline$A G$ & 8.58E-05 & -0.885 & 6.65E-04 & -0.107 & $7.44 E-04$ \\
\hline YB & $1.96 E-02$ & -0.774 & 8.75E-02 & 0.008 & $8.68 E-02$ \\
\hline Co & $1.61 E-01$ & 0.649 & $1.35 E-01$ & 0.379 & 9.78E-02 \\
\hline TB & $1.84 E-06$ & -0.619 & 4.82E-06 & 0.000 & 4.82E-06 \\
\hline DY & 2.95E-06 & -0.619 & 7.73E-06 & 0.000 & 7.73E-06 \\
\hline EU & 2.73E-06 & -0.618 & 7.11E-06 & -0.004 & $7.14 E-06$ \\
\hline GD & 2.08E-06 & -0.617 & 5.42E-06 & -0.002 & 5.42E-06 \\
\hline ER & $1.03 E-03$ & -0.615 & 2.68E-03 & 0.001 & $2.68 E-03$ \\
\hline SM & 5.53E-06 & -0.614 & 1.42E-05 & -0.007 & $1.43 E-05$ \\
\hline No & $1.80 \mathrm{E}-04$ & -0.605 & 4.47E-04 & -0.019 & 4.56E-04 \\
\hline HO & 1.37E-03 & -0.601 & 3.31E-03 & .0 .037 & $3.44 E-03$ \\
\hline$N$ & 7.15E-04 & -0.472 & 7.53E-04 & -0.444 & $1.35 E-03$ \\
\hline PD & 4.31E-03 & 0.471 & 2.04E-03 & -0.303 & 2.93E-03 \\
\hline SN & $1.96 \mathrm{E}-01$ & -0.441 & 3.51E-01 & 0.000 & 3.51E-01 \\
\hline$K$ & 5.14E-03 & -0.423 & $3.73 E-03$ & -0.582 & B.91E-03 \\
\hline TM & 4.47E-01 & -0.334 & $6.75 E-01$ & 0.006 & $6.71 E-01$ \\
\hline 0 & $2.22 E+\infty 0$ & -0.319 & 4.37E-01 & -0.866 & $3.26 E+\infty 0$ \\
\hline NE & $1.32 E+\infty$ & 0.280 & $1.05 E-01$ & -0.898 & $1.03 E+00$ \\
\hline$Z R$ & 1.02E-03 & 0.191 & $8.56 \mathrm{E}-04$ & 0.000 & 8.56E-04 \\
\hline CA & 4.23E-01 & -0.158 & $3.49 E-01$ & -0.305 & $5.02 E-01$ \\
\hline MO & 1.30E-05 & 0.138 & $1.14 E-05$ & -0.001 & $1.14 E-05$ \\
\hline $\mathrm{CU}$ & $6.60 \mathrm{E}-01$ & -0.134 & 9.04E-01 & 0.186 & 7.62E-01 \\
\hline$A L$ & 2.10E-02 & 0.114 & 3.11E-02 & 0.648 & $1.89 E-02$ \\
\hline$A \cap$ & 3.32E-02 & -0.102 & $3.69 E-02$ & 0.000 & 3.69E-02 \\
\hline BI & 9.83E-05 & -0.101 & 9.82E-05 & -0.102 & $1.09 E-04$ \\
\hline CS & 1.08E-01 & -0.064 & 1.15E-01 & -0.001 & $1.15 E-01$ \\
\hline$X E$ & 1.55E-01 & 0.050 & $1.48 E-01$ & 0.000 & $1.48 E-01$ \\
\hline GE & $1.26 E-01$ & 0.048 & $120 E-01$ & 0.000 & $1.20 E-01$ \\
\hline RU & 4.99E-05 & 0.038 & 4.80E-05 & 0.000 & 4.81E-05 \\
\hline KR & $5.86 E-02$ & 0.018 & 5.76E-02 & 0.000 & 5.76E-02 \\
\hline AS & 3.39E-03 & -0.017 & 3.45E-03 & 0.000 & 3.45E-03 \\
\hline$C L$ & 3.58E-04 & 0.011 & 3.53E-04 & -0.001 & 3.54E-04 \\
\hline NB & 6.99E-07 & 0.010 & 6.93E-07 & 0.001 & $6.93 E-07$ \\
\hline $\mathbf{N I}$ & 3.37E-01 & -0.009 & 3.42E-01 & 0.006 & 3.40E-01 \\
\hline TE & 5.51E-02 & -0.008 & $5.55 E-02$ & 0.000 & 5.55E-02 \\
\hline SE & $1.56 \mathrm{E}-03$ & -0.008 & 1.57E-03 & 0.000 & $1.57 E-03$ \\
\hline 1 & 3.47E-01 & -0.003 & 3.48E-01 & 0.000 & 3.48E-01 \\
\hline BR & 2.23E-03 & 0.000 & 2.23E-03 & 0.000 & 2.23E-03 \\
\hline
\end{tabular}

- RD: (Results for a paticular activation library-Results for a reference library)/(Reference library results).

- Reference library: FENDL/A-2.0 
Table 9. Comparison of remote recycling concentration limits (in wt fraction) obtained from EAF-3.1, EAF-4.1, and FENDL/A-2.0.

\begin{tabular}{|c|c|c|c|c|c|}
\hline ELEMENT & \multicolumn{2}{|c|}{ EAF-3.1 } & \multicolumn{2}{|c|}{ EAF-4.1 } & FENDL/A-2.0 \\
\hline & $\mathrm{CL}$ & $\mathrm{RD}^{*}$ & $\mathrm{CL}$ & AD & $\mathrm{CL}$ \\
\hline TA & $9.39 E-04$ & -0.991 & $8.73 E-02$ & -0.148 & $1.03 E-01$ \\
\hline$w$ & $5.12 E-04$ & -0.990 & 4.37E-02 & -0.187 & $5.38 E-02$ \\
\hline RE & 3.95E-04 & -0.990 & $3.16 \mathrm{E}-02$ & -0.218 & 4.04E-02 \\
\hline os & $9.63 E-04$ & -0.988 & 5.23E-02 & -0.352 & $8.06 E-02$ \\
\hline HF & $4.52 E-03$ & -0.979 & 2.09E-01 & -0.042 & 2.18E-01 \\
\hline LU & 1.99E-02 & -0.942 & $3.45 E-01$ & 0.000 & $3.45 E-01$ \\
\hline$Z N$ & $1.47 E+00$ & 0.937 & $1.76 E+00$ & 1.317 & $7.59 E-01$ \\
\hline IR & $5.28 E-01$ & -0.935 & $3.27 E+00$ & -0.599 & 8.17E+00 \\
\hline$C D$ & $1.66 E-03$ & -0.928 & 2.22E-02 & -0.037 & 2.31E-02 \\
\hline RH & $3.04 E-02$ & 0.920 & 1.11E-02 & -0.302 & 1.58E-02 \\
\hline SE & 8.58E-02 & 0.907 & $4.50 E-02$ & 0.000 & $4.50 E-02$ \\
\hline$A G$ & 1.81E-04 & -0.884 & $1.40 E-03$ & -0.106 & $1.56 E-03$ \\
\hline $\mathbf{N I}$ & 5.19E-04 & 0.880 & 3.07E-04 & 0.112 & 2.76E-04 \\
\hline BR & $1.99 E-03$ & 0.876 & $1.06 E-03$ & 0.000 & $1.06 E-03$ \\
\hline YB & $3.69 E-01$ & -0.837 & $2.28 E+00$ & 0.005 & 2.27E+00 \\
\hline KR & $1.06 E-03$ & 0.739 & 6.07E-04 & 0.000 & 6.07E-04 \\
\hline TB & 5.44E-05 & -0.619 & $1.43 E-04$ & 0.000 & $1.43 E-04$ \\
\hline DY & 8.73E-05 & -0.619 & $2.29 E-04$ & 0.000 & 2.29E-04 \\
\hline ER & $3.06 E-02$ & -0.614 & $7.94 E-02$ & 0.001 & $7.93 E-02$ \\
\hline GD & $6.05 E-05$ & -0.609 & 1.53E-04 & -0.013 & $1.55 E-04$ \\
\hline$R B$ & 1.65E-01 & 0.608 & $1.02 E-01$ & 0.000 & $1.02 E-01$ \\
\hline HO & 4.07E-02 & -0.600 & $9.80 E-02$ & -0.037 & $1.02 E-01$ \\
\hline EU & 7.71E-05 & -0.593 & 1.83E-04 & -0.034 & $1.90 E-04$ \\
\hline PD & $8.70 E-03$ & 0.417 & 4.29E-03 & -0.301 & $6.14 E-03$ \\
\hline 1 & 2.14E-01 & -0.387 & $3.50 E-01$ & 0.000 & $3.50 E-01$ \\
\hline$R U$ & 8.91E-02 & 0.234 & 5.46E-02 & -0.244 & 7.22E-02 \\
\hline TE & 3.19E-01 & -0.201 & 3.99E-01 & -0.001 & $3.99 E-01$ \\
\hline SN & 3.65E-01 & -0.153 & 4.30E-01 & 0.000 & 4.31E-01 \\
\hline $\mathrm{CU}$ & 2.72E-03 & -0.147 & 3.10E-03 & -0.030 & 3.19E-03 \\
\hline 81 & $1.56 E-04$ & -0.134 & $1.87 E-04$ & 0.039 & 1.80E-04 \\
\hline MO & 5.09E-02 & -0.116 & $6.09 E-02$ & 0.059 & 5.75E-02 \\
\hline$S M$ & 2.25E-05 & -0.098 & $2.48 E-05$ & -0.004 & 2.50E-05 \\
\hline $\mathrm{CS}$ & 9.08E-05 & -0.082 & 9.88E-05 & 0.000 & 9.89E-05 \\
\hline BA & 4.30E-03 & -0.073 & $3.72 E-03$ & -0.199 & 4.64E-03 \\
\hline$X E$ & 1.55E-04 & 0.044 & $1.49 E-04$ & 0.000 & 1.49E-04 \\
\hline $\mathrm{CO}$ & 3.23E-06 & -0.016 & $3.29 E-06$ & 0.001 & $3.28 E-06$ \\
\hline CE & 6.18E-01 & 0.010 & $6.10 \mathrm{E}-01$ & -0.003 & 6.12E-01 \\
\hline ND & 4.74E-05 & -0.010 & 4.79E-05 & -0.001 & 4.79E-05 \\
\hline NB & $1.93 E-05$ & 0.009 & 1.91E-05 & 0.001 & 1.91E-05 \\
\hline MN & 1.85E-01 & 0.007 & $1.83 E-01$ & -0.001 & 1.83E-01 \\
\hline FE & 2.86E-03 & 0.002 & 2.85E-03 & 0.000 & 2.85E-03 \\
\hline PR & 4.67E-01 & 0.000 & 4.66E-01 & 0.000 & 4.66E-01 \\
\hline
\end{tabular}

- RD: (Results for a paticular activation library-Results for a reference library)/(Reference library results).

- Reference library: FENDUA-2.0 
Table 10. Comparison of hands-on recycling concentration limits (in wt fraction) obtained from EAF-3.1, EAF-4.1, and FENDL/A-2.0.

\begin{tabular}{|c|c|c|c|c|c|}
\hline \multirow[t]{2}{*}{ ELEMENT } & \multicolumn{2}{|c|}{ EAF-3.1 } & \multicolumn{2}{|c|}{ EAF-4.1 } & \multirow{2}{*}{$\frac{\text { FENDUA-2.0 }}{\mathrm{CL}}$} \\
\hline & $\mathrm{CL}$ & $\mathrm{RO}^{*}$ & $\mathrm{CL}$ & RD & \\
\hline$T A$ & $2.71 E-06$ & -0.991 & $2.52 E-04$ & -0.148 & $2.96 E-04$ \\
\hline$w$ & $1.48 E-06$ & -0.990 & $1.26 E-04$ & -0.187 & $1.55 \mathrm{E}-04$ \\
\hline RE & $1.14 E-06$ & -0.990 & $9.12 E-05$ & -0.218 & 1.17E-04 \\
\hline os & $2.78 E-06$ & -0.988 & $1.54 E-04$ & -0.358 & $2.39 E-04$ \\
\hline HF & 1.30E-05 & -0.977 & 5.54E-O4 & -0.037 & $5.75 E-04$ \\
\hline PT & 2.93E-02 & -0.957 & $3.73 E-01$ & -0.453 & $6.81 E-01$ \\
\hline IR & $1.53 E-03$ & -0.940 & $9.76 E-03$ & -0.619 & $2.56 E-02$ \\
\hline $\mathbf{L U}$ & $5.71 E-05$ & -0.935 & B.79E-04 & 0.002 & B.77E-04 \\
\hline $\mathrm{CD}$ & $4.61 E-06$ & -0.932 & 6.54E.05 & -0.040 & $6.82 E-05$ \\
\hline $\mathrm{CA}$ & 1.04E-02 & -0.924 & $1.51 E-01$ & 0.110 & $1.36 E-01$ \\
\hline RH & 8.33E-05 & 0.922 & $3.02 E-05$ & -0.303 & 4.33E-05 \\
\hline SE & $5.40 E-03$ & 0.903 & $2.84 E-03$ & 0.000 & $2.84 E-03$ \\
\hline$A G$ & 4.93E-07 & -0.885 & 3.81E-06 & -0.107 & $4.27 E-06$ \\
\hline $\mathrm{NI}$ & 9.23E-0. & 0.879 & 5.46E-04 & 0.112 & 4.91E-04 \\
\hline YB & 1.05E-03 & -0.835 & 6.41E-03 & 0.006 & 6.37E-03 \\
\hline KR & 6.65E-05 & 0.737 & 3.83E-05 & 0.000 & $3.83 E-05$ \\
\hline BR & $1.04 E-04$ & 0.725 & 6.05E-05 & 0.000 & $6.05 E-05$ \\
\hline or & 2.25E-07 & -0.619 & 5.89E-07 & 0.000 & 5.89E-07 \\
\hline TB & $1.40 E-07$ & -0.619 & 3.67E-07 & 0.000 & $3.67 E-07$ \\
\hline ER & $7.88 E-05$ & -0.614 & 2.05E-04 & 0.001 & $2.04 E-04$ \\
\hline GD & $1.56 \mathrm{E}-07$ & -0.610 & $3.96 E-07$ & -0.011 & $4.00 E-07$ \\
\hline RB & $1.04 E-02$ & 0.610 & $6.47 \mathrm{E}-03$ & 0.000 & $6.47 E-03$ \\
\hline HO & $1.05 E-04$ & -0.601 & 2.53E-04 & -0.037 & 2.62E-04 \\
\hline SN & $6.24 E-03$ & -0.598 & $1.55 E-02$ & -0.001 & $1.55 E-02$ \\
\hline EU & $2.00 E-07$ & -0.597 & $4.83 E-07$ & -0.028 & 4.97E-07 \\
\hline $\mathrm{TI}$ & $3.26 \mathrm{E}-01$ & -0.586 & $1.54 E+\infty 0$ & 0.953 & 7.87E-01 \\
\hline SM & 3.56E-07 & -0.523 & $7.18 \mathrm{E}-\mathrm{C} 7$ & -0.038 & $7.46 E-07$ \\
\hline PD & 2.47E-05 & 0.467 & 1.17E-05 & -0.303 & $1.68 E-05$ \\
\hline SC & $8.29 E-02$ & 0.376 & $6.03 \mathrm{E}-\mathrm{C2}$ & 0.000 & 6.02E-02 \\
\hline 1 & $2.23 E-03$ & -0.374 & $3.55 E-03$ & 0.000 & $3.55 E-03$ \\
\hline$T M$ & 3.38E-02 & -0.322 & 5.01E-02 & 0.006 & $4.98 \mathrm{E}-02$ \\
\hline PB & 2.22E-02 & -0.274 & $3.18 E-8 \mathrm{C}$ & 0.040 & $3.06 E-02$ \\
\hline RU & $2.39 E-04$ & 0.222 & $1.48 E-0=$ & -0.243 & $1.96 E-04$ \\
\hline ZR & $3.26 E-02$ & -0.219 & $4.29 E-0 z$ & 0.028 & 4.17E-02 \\
\hline SB & $1.22 E-01$ & -0.207 & $1.54 E-C ?$ & -0.001 & $1.54 \mathrm{E}-01$ \\
\hline LA & $1.95 E-02$ & 0.199 & $1.63 \mathrm{E}-\mathrm{z}$ & -0.002 & 1.63E-02 \\
\hline ND & $4.19 E-06$ & -0.192 & 5.07E-C5 & -0.022 & $5.18 E-06$ \\
\hline TE & $3.21 E-03$ & -0.188 & 3.95E-C3 & 0.000 & 3.95E-03 \\
\hline SA & 2.31E-01 & 0.158 & $1.86 E-C 1$ & -0.065 & $1.99 \mathrm{E}-01$ \\
\hline CU & $4.84 E-03$ & -0.147 & $5.51 E-C 3$ & -0.030 & $5.68 E-03$ \\
\hline $\mathbf{K}$ & 7.50E-02 & -0.141 & 8.86E-02 & 0.014 & 8.73E-02 \\
\hline 81 & $1.16 E-06$ & -0.134 & $1.39 E-06$ & 0.040 & $1.34 E-06$ \\
\hline MO & $1.28 E-04$ & -0.120 & $1.54 \mathrm{E}-04$ & 0.053 & $1.46 E-04$ \\
\hline BA & 1.01E-04 & -0.119 & $6.43 E-05$ & -0.437 & $1.14 E-04$ \\
\hline $\overrightarrow{A L}$ & 2.18E-03 & 0.114 & $3.23 E+03$ & 0.648 & $1.96 E-03$ \\
\hline CS & 8.44E-07 & -0.067 & $9.04 E-07$ & 0.000 & 9.05E-07 \\
\hline$X E$ & 1.25E-06 & 0.049 & $1.19 E-06$ & 0.000 & $1.19 E-06$ \\
\hline $\mathrm{CE}$ & 7.56E-02 & 0.027 & 7.08E-02 & -0.039 & $7.36 \mathrm{E}-02$ \\
\hline $\mathrm{CO}$ & 5.75E-06 & -0.016 & 5.85E-06 & 0.001 & $5.84 E-06$ \\
\hline NB & 4.83E-08 & 0.009 & $4.78 E-08$ & 0.000 & $4.78 E-08$ \\
\hline MN & $3.28 E-01$ & 0.007 & $3.26 \mathrm{E}-01$ & 0.000 & 3.26E-01 \\
\hline PR & 6.21E-02 & -0.005 & $6.23 E-02$ & -0.002 & $6.24 E-02$ \\
\hline FE & $5.09 E-03$ & 0.003 & $5.08 E-03$ & 0.000 & 5.07E-03 \\
\hline
\end{tabular}

- RD: (Results for a paticular activation library-Results for a reference library)/(Reference library results).

- Reference library: FENDL/A-2.0 


\section{Table 11. Limits on element concentrations (in wt fraction), and contribution of dominant radionuclides.}

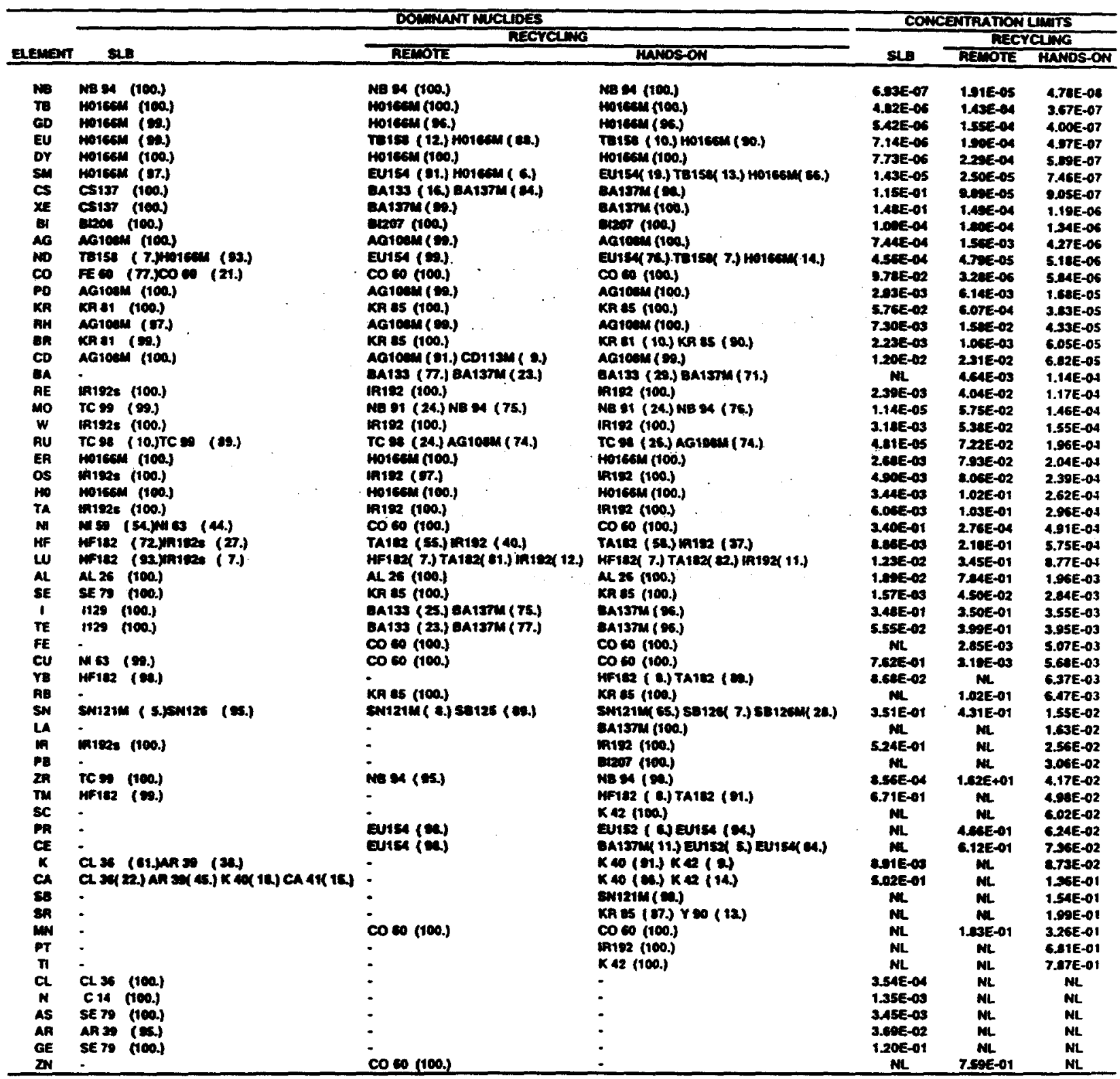

Elements not restricted for $\mathrm{SLB}$ and Recycling eriteria: $\mathrm{H}, \mathrm{He} \mathrm{L,} \mathrm{Be,} \mathrm{B,} \mathrm{C,} \mathrm{O,} \mathrm{F,} \mathrm{Ne,} \mathrm{Na,} \mathrm{Mg,} \mathrm{Si,} \mathrm{P,} \mathrm{S,} \mathrm{TI,} \mathrm{V,} \mathrm{Cr,} \mathrm{Ga,} \mathrm{Y,} \mathrm{Yb,} \mathrm{Au,} \mathrm{Hg}$ 


\section{Collapse processing code.}

COLLAPSE is a utility program that has two major facilities. Firstly it is used to condense multigroup cross section libraries down to a single group. When running COLLAPSE in this mode (ISFIS=0), that we call hereafter "standard mode", the neutron flux is used as a weighting function to produce the 1-group energy-averaged ("effective") cross sections. The neutron spectrum may be input in an arbitrary group structure. Secondly, COLLAPS can use fission yield data in conjunction with fission cross sections and neutron spectrum to compute effective fission yield cross sections, <yos. When running COLLAPSE in this mode (ISFIS=1), that it will be referred to as "fission mode" hereafter, it is produced a library containing 1-group effective cross sections, and other containing 1-group effective fission yield cross sections.

When $A C A B$ is going to be run for inventory calculations considering fission products, previously to run it, the user must run COLLAPS with the option ISFIS=1, since $A C A B$ need as input the effective fission yield cross section library, such as it is output by COLLAPS. When the inventory of fission product is not going to be computed by $A C A B$, the user is recommended to use COLLAPS (with the option ISFIS=0), but it is not mandatory, since $A C A B$ can read a library in any group structure, provided it is in EAF format.

Regarding the operation of COLLAPS in the standard mode, the cross section libraries to be "collapsed" must be in the format used by the European Activation File (EAF). COLLAPSE currently is able to handle cross section libraries in the standard Vitamin-J (175 groups), GAM-II (100 groups), and TART (175 groups) group structures. These group structures are given in Tables 12-14. The ability to deal with libraries in other group structures can be easily implemented in COLLAPS. The neutron spectrum employed to condense the cross section library, if possible, is advised to be in one of those structures. When the neutron spectrum is given in a group structure different from those listed above, COLLAPSE begins by converting the spectrum into one of the standard structures (as specified by the user). After conversion is completed, the code condenses the cross section library.

When COLLAPS operates in the fission mode, the quantity to be computed is the effective fission yield cross section $\langle\gamma \sigma\rangle$. This is defined as the spectrum-averaged neutron cross section for formation of nuclei of type $i$ by fission in the nuclei of type $j$, and may be expressed as

$$
\left\langle\gamma_{j, i} \sigma_{f, j}\right\rangle=\frac{\int_{0}^{\infty} \gamma_{j, i}(E) \sigma_{f . j}(E) \phi(E)}{\phi_{T}}
$$

where, 
$\gamma_{j, i}$ is the probability that a a type-i nuclide will be formed as a fission product by absortion of a neutron of energy $E$ by a nuclide of type $j$.

$\sigma_{f j}$ is the microscopic fission cross section of type $\mathrm{j}$ nuclei for neutrons of energy $\mathrm{E}$.

$\phi_{T}$ is the total energy integrated neutron flux.

In computing this quantity some assumptions are made to deal with the information from JEF-2.2:

i) Three energy regions are defined, assuming that independent yield data are constant in the energy range of each region. The energy ranges for these regions are: $\mathrm{E}<200 \mathrm{keV}$ (low energy region), $5 \mathrm{MeV}>\mathrm{E}>200 \mathrm{keV}$ (medium energy region), and $\mathrm{E}>5$ $\mathrm{MeV}$ (high energy region). These regions have been selected taking into account the three energy incident energy points for yield data considered in JEF-2.2, that is: $\gamma$ at $0.0253 \mathrm{eV}, \gamma$ at $0.4 \mathrm{MeV}$ and $\gamma$ at $14 \mathrm{MeV}$. So, these points are assigned to the low,medium and high energy regions, respectively.

ii) For some of the fissionable nuclides considered in JEF-2.2, yield data are not given for all of the three energy points, even though the fission cross section is not negligible for the neutron having the energy of a missing point. To work out this situation we have assigned to an energy point lacking yield data, the yield data of the closer one.

iii) In JEF-2.2 there are 19 fissionable nuclides, while in the activation library FENDL/A-2.0 there are 61 nuclides having fission cross sections. COLLAPS allows to obtain $\langle y\rangle\rangle$ files for both 19 and 61 nuclides. In obtaining the library of the effective fission yield cross sections for the 61 nuclides, the nuclides with no fission yield data in JEF-2.2, are assumed to have those of the neighbouring nuclide with fission yields available.

COLLAPSE is controlled via the standard input unit (file 5). Unit 2 must contain the cross section library to be condensed. COLLAPS write on UNIT 18 the independent fission yields for the three energy points, this file is referred to as the extended fission yield library. This library is not dependent on the weighting neutron spectrum and therefore, it can be used once generated in a previous run, as an input file containig the fission yield information, instead of using the basic fission yield library,JEF-2.2 (UNIT 17).

Output is automatically written to two files: unit 9 contains the 1-group cross section library in the EAF format, and unit 8 gives the 1-group neutron flux and average neutron energy. When runnig COLLAPS in the fission mode, UNIT 96 is 
generated containing the one-group fission yield cross sections. Also UNIT 18 is generated containig the extended library of independent fission yields. This library can contain the information for all fissionables nuclides included in JEF-2.2 and/or in the reaction cross section data library.

The input file is formatted and must contain the following information:

\section{Card \#1: (format is 214)}

The first card is used to specify the group structure that is used in the cross section library and for the neutron flux.

\# Parameter Description

$1 \quad$ ILIB

Group structure used in the cross section library:

1 GAM-II (100 groups)

2 Vitamin-J (175 groups)

3 TART (175 groups)

$\begin{array}{ll}1 & \text { GAM-II } \\ 2 & \text { Vitamin-J } \\ 3 & \text { TART } \\ 4 & \text { Other (arbitrary) }\end{array}$

Card \#2: $\quad$ (FORTRAN free format)

This card is used for reading the information heading the activation crosssection library.

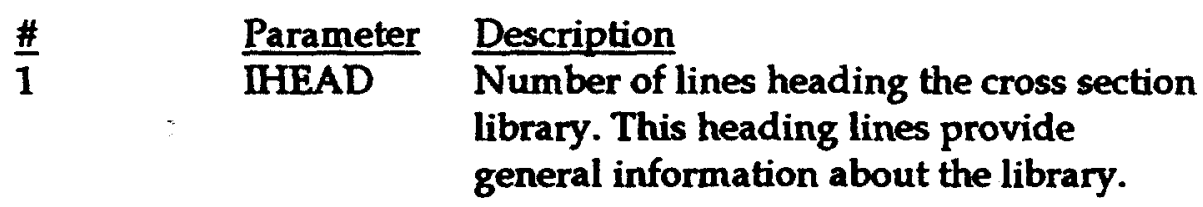


Card \#3: (FORTRAN free format)

This card controls the generation of the effective fission yield cross section library. If the first parameter of this card is 0 , the rest will not have any effect and can take any value.

\section{$\frac{\#}{1}$}

Parameter

ISFIS

2

IGEN
Description

Indicator for the fission mode operation.

0 No effect. The other parameters of this card don't have any effect if ISFIS $=0$.

1 Fission information is processed.

Indicator for controlling the generation of the "extended" fission yield data library.

0 No effect. Standard fission mode of operation for the generation of the effective fission yield cross section library.

1 -Generation of the "extended" fission yield data library (UNIT 18) for all fissionable nuclides included in the basic (UNIT 17) fission yield data library.

-Generation of UNIT 28, this one contains the extended fission yield data library for all fissionable nuclides included in the reaction cross section data library. After the generation of UNIT 18 and UNIT 28 the code STOP. No effective fission yield cross section library is generated.

$0 \quad$ No effect. The code reads UNIT18 (extended fission yield data).

1 Reading and processing of the basic fission yield data library JEF-2.2. 

(UNIT 96).

0 Effective fission yield data library is generated for the fissionable nuclides included in the original fission yield data library (UNIT 17).

1 Effective yield data library is generated for all fissionable nuclides included in the reaction cross section library (UNIT 2).

Card \#4: $\quad$ (FORTRAN free format)

This Card gives the fission yield energy group structure for processing of JEF2.2. Independent yield data are assumed to be constant in each energy group.

$\begin{array}{ll}\# \quad \text { Parameter } & \text { Description } \\ \text { Energy boundaries }(\mathrm{eV}) \text { of the energy regions where } \\ \text { independent yield data are assumed to be constant. } \\ \text { The energy boundaries are given in order of decreasing } \\ \text { energy [2]. } \\ \text { The group boundaries corresponding to each energy } \\ \text { group are: } 14 \mathrm{Mev}-\mathrm{EB}(1), \mathrm{EB}(1)-\mathrm{EB}(2) \text { y } \mathrm{EB}(2)-0.0253 \mathrm{Mev} \\ \text { The values suggested are } 5 \mathrm{Mev} \text { for } \mathrm{EB}(1) \text { and } 200 \mathrm{Kev} \\ \text { for } \mathrm{EB}(2) .\end{array}$

Card *5: (format is 2I4)

This card gives the number of groups used in the neutron spectrum and the units of the neutron flux.

\begin{tabular}{|c|c|c|}
\hline & $\frac{\text { Parameter }}{\text { NGROUP }}$ & $\begin{array}{l}\text { Description } \\
\text { The absolute value of NGROUP is the num } \\
\text { groups of the neutron spectrum: } \\
\text { If NGROUP < } 0 \text {, the neutron flux group stru } \\
\text { in order of decreasing energy. } \\
\text { If NGROUP }>0 \text {, the neutron flux group str } \\
\text { in order of increasing energy. }\end{array}$ \\
\hline 2 & $\mathrm{FF}$ & $\begin{array}{l}\text { Units used for the neutron flux description: } \\
\begin{array}{cl}0 & \text { Total scalar flux }\left[\mathrm{n} / \mathrm{cm}^{2}-\mathrm{s}\right] \\
1 & \text { Flux density }\left[\mathrm{n} / \mathrm{cm}^{2}-\mathrm{s}-\mathrm{MeV}\right]\end{array}\end{array}$ \\
\hline
\end{tabular}


Card \#6: (format is 6E12.5)

Card \#6 will only appear if IESF = 4 indicating that a group structure other than GAM-II, Vitamin-J, or TART will be used to specify the neutron flux.

$\begin{array}{ll}\# \text { Parameter } & \begin{array}{l}\text { Description } \\ \text { Energy boundaries of the group structure used for the } \\ \text { neutron flux. The order of the energy boundaries is given } \\ \text { by the sign of NGROUP.[NGROUP+1]. }\end{array}\end{array}$

Card \#7: (format is 6E12.5)

When IESF $\neq 4$, card \#6 will not appear, and thus, card \#7 will immediately follow card \#5.

$\begin{array}{ll}\# \quad \frac{\text { Parameter }}{1} & \begin{array}{l}\text { Description } \\ \text { Flux levels within each energy group. Units of the flux } \\ \text { are given by FF and order (ascending or descending } \\ \text { energy) is given by the sign of NGROUP. [ABS(NGROUP)]. }\end{array}\end{array}$

Example input file:

23

16

1011

5.E+06 2.E+05

$-1750$

$1.00000 \mathrm{E}+001.00000 \mathrm{E}+001.00000 \mathrm{E}+001.00000 \mathrm{E}+001.00000 \mathrm{E}+001.00000 \mathrm{E}+00$

$1.00000 \mathrm{E}+001.00000 \mathrm{E}+001.00000 \mathrm{E}+001.00000 \mathrm{E}+001.00000 \mathrm{E}+001.00000 \mathrm{E}+00$

$1.00000 \mathrm{E}+001.00000 \mathrm{E}+001.00000 \mathrm{E}+001.00000 \mathrm{E}+001.00000 \mathrm{E}+001.00000 \mathrm{E}+00$

$1.00000 \mathrm{E}+001.00000 \mathrm{E}+001.00000 \mathrm{E}+001.00000 \mathrm{E}+001.00000 \mathrm{E}+001.00000 \mathrm{E}+00$

$1.00000 \mathrm{E}+001.00000 \mathrm{E}+001.00000 \mathrm{E}+001.00000 \mathrm{E}+001.00000 \mathrm{E}+001.00000 \mathrm{E}+00$

1.00000E+00 1.00000E+00 1.00000E+00 1.00000E+00 1.00000E+00 1.00000E+00

$1.00000 \mathrm{E}+001.00000 \mathrm{E}+001.00000 \mathrm{E}+001.00000 \mathrm{E}+001.00000 \mathrm{E}+001.00000 \mathrm{E}+00$

$1.00000 \mathrm{E}+001.00000 \mathrm{E}+001.00000 \mathrm{E}+001.00000 \mathrm{E}+001.00000 \mathrm{E}+001.00000 \mathrm{E}+00$

$1.00000 \mathrm{E}+001.00000 \mathrm{E}+001.00000 \mathrm{E}+001.00000 \mathrm{E}+001.00000 \mathrm{E}+001.00000 \mathrm{E}+00$

$1.00000 \mathrm{E}+001.00000 \mathrm{E}+001.00000 \mathrm{E}+001.00000 \mathrm{E}+001.00000 \mathrm{E}+001.00000 \mathrm{E}+00$

$1.00000 \mathrm{E}+001.00000 \mathrm{E}+001.00000 \mathrm{E}+001.00000 \mathrm{E}+001.00000 \mathrm{E}+001.00000 \mathrm{E}+00$

$1.00000 \mathrm{E}+001.00000 \mathrm{E}+001.00000 \mathrm{E}+001.00000 \mathrm{E}+001.00000 \mathrm{E}+001.00000 \mathrm{E}+00$

$1.00000 \mathrm{E}+001.00000 \mathrm{E}+001.00000 \mathrm{E}+001.00000 \mathrm{E}+001.00000 \mathrm{E}+001.00000 \mathrm{E}+00$

$1.00000 \mathrm{E}+001.00000 \mathrm{E}+001.00000 \mathrm{E}+001.00000 \mathrm{E}+001.00000 \mathrm{E}+001.00000 \mathrm{E}+00$ 
$1.00000 \mathrm{E}+001.00000 \mathrm{E}+001.00000 \mathrm{E}+001.00000 \mathrm{E}+001.00000 \mathrm{E}+001.00000 \mathrm{E}+00$ $1.00000 \mathrm{E}+001.00000 \mathrm{E}+001.00000 \mathrm{E}+001.00000 \mathrm{E}+001.00000 \mathrm{E}+001.00000 \mathrm{E}+00$ $1.00000 \mathrm{E}+001.00000 \mathrm{E}+001.00000 \mathrm{E}+001.00000 \mathrm{E}+001.00000 \mathrm{E}+001.00000 \mathrm{E}+00$ $1.00000 \mathrm{E}+001.00000 \mathrm{E}+001.00000 \mathrm{E}+001.00000 \mathrm{E}+001.00000 \mathrm{E}+001.00000 \mathrm{E}+00$ $1.00000 \mathrm{E}+001.00000 \mathrm{E}+001.00000 \mathrm{E}+001.00000 \mathrm{E}+001.00000 \mathrm{E}+001.00000 \mathrm{E}+00$ $1.00000 \mathrm{E}+001.00000 \mathrm{E}+001.00000 \mathrm{E}+001.00000 \mathrm{E}+001.00000 \mathrm{E}+001.00000 \mathrm{E}+00$ $1.00000 \mathrm{E}+001.00000 \mathrm{E}+001.00000 \mathrm{E}+001.00000 \mathrm{E}+001.00000 \mathrm{E}+001.00000 \mathrm{E}+00$ $1.00000 \mathrm{E}+001.00000 \mathrm{E}+001.00000 \mathrm{E}+001.00000 \mathrm{E}+001.00000 \mathrm{E}+001.00000 \mathrm{E}+00$ $1.00000 \mathrm{E}+001.00000 \mathrm{E}+001.00000 \mathrm{E}+001.00000 \mathrm{E}+001.00000 \mathrm{E}+001.00000 \mathrm{E}+00$ $1.00000 \mathrm{E}+001.00000 \mathrm{E}+001.00000 \mathrm{E}+001.00000 \mathrm{E}+001.00000 \mathrm{E}+001.00000 \mathrm{E}+00$ $1.00000 \mathrm{E}+001.00000 \mathrm{E}+001.00000 \mathrm{E}+001.00000 \mathrm{E}+001.00000 \mathrm{E}+001.00000 \mathrm{E}+00$ $1.00000 \mathrm{E}+001.00000 \mathrm{E}+001.00000 \mathrm{E}+001.00000 \mathrm{E}+001.00000 \mathrm{E}+001.00000 \mathrm{E}+00$ $1.00000 \mathrm{E}+001.00000 \mathrm{E}+001.00000 \mathrm{E}+001.00000 \mathrm{E}+001.00000 \mathrm{E}+001.00000 \mathrm{E}+00$ $1.00000 \mathrm{E}+001.00000 \mathrm{E}+001.00000 \mathrm{E}+001.00000 \mathrm{E}+001.00000 \mathrm{E}+001.00000 \mathrm{E}+00$ $1.00000 \mathrm{E}+001.00000 \mathrm{E}+001.00000 \mathrm{E}+001.00000 \mathrm{E}+001.00000 \mathrm{E}+001.00000 \mathrm{E}+00$ $1.00000 \mathrm{E}+00$

In the above example, the neutron flux is given in TART 175-group format while the activation cross section are given in VITAMIN 175-group format. The number 16 means that there are 16 heading lines in FENDL-A/2.0. The parameters of the next card are: ISFIS=1 (meaning that $A C A B$ is going to run in "fission mode"),IGEN=0 ( so this is a "standard fission mode of operation", and the effective fission yields cross section library is generated), $I S O C A=1$ ( in this case the the basic fission yields data library JEF- 2.2 is processed) and IBEST $=1$ ( the effective fission yield data library is generated for all fissionables nuclides contained in the activation library). The next card shows the two values suggested in card \#4 for the energies limiting the three regions are considered in fission yield processing.The negative sign in front of the $\mathbf{1 7 5}$ in the following card, indicates that the fluxes will follow in order of descending energy. The fluxes are given in units of $n / \mathrm{cm}^{2}-\mathrm{s}$ as indicated by $F F=0$. Because IESF $\neq 4$, card \#6 is omitted, and the 175 fluxes immediately follow card \#5. 
Table 12. Energy group boundaries for the Vitamin-J 175-group structure. The upper energy for group \#1 is $19.6 \mathrm{MeV}$.

\begin{tabular}{|c|c|c|c|c|c|c|c|}
\hline Group " & $E$ - (MeV) & Group * & $E_{-}$(MeV) & Group \# & $E(\mathrm{MeV})$ & Group 1 & $E_{\text {in }}(\mathrm{MeV})$ \\
\hline 1 & $1.73 \mathrm{E}+01$ & 46 & $231 E+00$ & 91 & 213E-01 & 136 & 2.61E-03 \\
\hline 2 & $1.69 E+01$ & 47 & $2.23 E+00$ & 92 & 202E-01 & 13. & $2.49 \mathrm{E}-03$ \\
\hline 3 & $1.65 E+01$ & 48 & $212 E+00$ & 93 & $1.93 E-01$ & 138 & $225 E-03$ \\
\hline 4 & 1STE+01 & 49 & $202 E+00$ & 94 & $1.83 E-01$ & 139 & 2.03E-03 \\
\hline 5 & $1.49 E+01$ & 50 & $1.92 E+00$ & 95 & $1.74 \mathrm{E}-01$ & 140 & $1.58 \mathrm{E}-03$ \\
\hline 6 & $1.45 E+01$ & 51 & $183 \mathrm{E}+00$ & 96 & $1.66 \mathrm{E}-0 \mathrm{I}$ & 141 & $123 E-03$ \\
\hline 7 & $1.42 E+01$ & 52 & $174 E+00$ & 97 & $158 \mathrm{E}-01$ & 142 & 9.61E-04 \\
\hline 8 & $138 \mathrm{E}+01$ & 53 & $1.65 \mathrm{E}+00$ & 98 & 1SOE-01 & 143 & 7.49E-04 \\
\hline 9 & $135 E+01$ & 54 & $157 E+00$ & 99 & $1.43 E-01$ & 144 & $5.83 E-04$ \\
\hline 10 & $1.28 \mathrm{E}+01$ & 55 & $150 E+00$ & 100 & 1.36E-01 & 145 & 454E-04 \\
\hline 11 & $1.25 E+01$ & 56 & $1.42 E+00$ & 101 & $129 \mathrm{E}-01$ & 146 & 354E-04 \\
\hline 12 & $1.22 \mathrm{E}+01$ & 57 & $135 E+00$ & 102 & $123 E-01$ & 147 & 275E-04 \\
\hline 13 & $1.16 E+01$ & 58 & $1.29 E+\infty 0$ & 103 & 1.17E-0I & 148 & 214E-04 \\
\hline 14 & $1.11 E+01$ & 59 & $1.22 E+00$ & 104 & 1.11E-01 & 149 & 1.67E-04 \\
\hline 15 & 1.05E+01 & 60 & $116 E+00$ & 105 & 980E-02 & 150 & $130 \mathrm{E}-04$ \\
\hline 16 & $1.00 \mathrm{E}+01$ & 61 & L.11E+00 & 106 & 8.65E:02 & 151 & $1.01 E-04$ \\
\hline 17 & $951 E+00$ & 62 & $1.00 \mathrm{E}+00$ & 107 & $825 \mathrm{E}-02$ & 152 & 7.89E-05 \\
\hline 18 & $9.05 E+00$ & 63 & 9.62E-01 & 108 & 7.95E-02 & 153 & 6.14E-05 \\
\hline 19 & $8.61 E+00$ & 64 & 9.07E-01 & 109 & $7.20 \mathrm{E}-02$ & 154 & 4.79E-05 \\
\hline 20 & $8.19 E+00$ & 65 & $8.63 E-01$ & 110 & $674 E-02$ & 155 & $3.73 E-05$ \\
\hline 21 & $7.79 E+00$ & 66 & 8.21E-01 & 111 & $5.66 \mathrm{E}-02$ & 156 & 290E-05 \\
\hline 22 & $7.41 E+00$ & 67 & $781 E-01$ & 112 & $5.25 E-02$ & 157 & $226 \mathrm{E}-05$ \\
\hline 23 & $7.05 E+00$ & 68 & $7.43 E-01$ & 113 & $4.63 E-02$ & 158 & $1.76 E-05$ \\
\hline 24 & $6.70 E+00$ & 69 & 7.07E-01 & 114 & $4.09 E-02$ & 159 & 1.37E-05 \\
\hline 25 & $6.59 E+00$ & 70 & $6.72 \mathrm{E}-01$ & 115 & $3.43 E-02$ & 160 & 1.07E-05 \\
\hline 26 & $6.38 E+00$ & 71 & $6.39 \mathrm{E}-01$ & 116 & $3.18 E-02$ & 161 & 8.32E-06 \\
\hline 27 & $603 \mathrm{E}+00$ & 72 & 6.08E-01 & 117 & 285E-02 & 162 & $6.48 \mathrm{E}-06$ \\
\hline 28 & $5.77 \mathrm{E}+00$ & 73 & $5.78 \mathrm{E}-01$ & 118 & 270E-02 & 163 & 5.04E-06 \\
\hline 29 & $5.49 \mathrm{E}+00$ & 74 & $5.50 E-01$ & 119 & 261E-02 & 164 & 3.93E-06 \\
\hline 30 & $522 E+\infty$ & 75 & $5.23 \mathrm{E}-01$ & 120 & 248E-02 & 165 & $3.06 E-06$ \\
\hline 31 & $4.97 \mathrm{E}+00$ & 76 & $4.98 \mathrm{E}-01$ & 121 & $242 E-02$ & 166 & $238 E-06$ \\
\hline 32 & $4.72 E+00$ & $\pi$ & $+50 E-01$ & 122 & $236 E-02$ & 167 & $1.86 \mathrm{E}-06$ \\
\hline 33 & $4.49 \mathrm{E}+00$ & 78 & $408 E-01$ & 123 & 219E-02 & 166 & $1.44 \mathrm{E}-06$ \\
\hline 34 & $4.07 \mathrm{E}+00$ & 79 & $388 E-01$ & 124 & $1.93 E-02$ & 169 & $1.13 E-06$ \\
\hline 35 & $3.68 \mathrm{E}+00$ & 80 & $3.69 \mathrm{E}-01$ & 125 & $150 E-02$ & 170 & $8.76 E-07$ \\
\hline 36 & $3.33 \mathrm{E}+\infty 0$ & 81 & $3.34 E-01$ & 126 & 1.17E-02 & 171 & $6.83 E-07$ \\
\hline 37 & $3.17 E+00$ & 82 & $3.02 \mathrm{E}-01$ & 127 & $1.06 \mathrm{E}-02$ & 172 & 5.32E-07 \\
\hline 38 & $3.01 \bar{E}+00$ & 83 & $2.98 E-01$ & 128 & $9.12 \mathrm{E}-03$ & 173 & 4.14E-07 \\
\hline 39 & $2.87 E+00$ & 84 & 2.97E-01 & 129 & 7.10E-03 & 174 & $1.00 \mathrm{E}-07$ \\
\hline 40 & $273 E+00$ & 85 & $295 \mathrm{E}-01$ & 130 & $5.53 \mathrm{E}-03$ & 175 & $1.00 \mathrm{E}-11$ \\
\hline 41 & $259 \mathrm{E}+00$ & 86 & 2.S7E-01 & 131 & $4.31 E-03$ & & \\
\hline 42 & $247 \mathrm{E}+00$ & 87 & $2.73 \mathrm{E}-01$ & 132 & $3.71 E-03$ & & \\
\hline 43 & $239 E+00$ & 88 & 2.47E-01 & 133 & $3.35 \mathrm{E}-03$ & & \\
\hline 44 & $2.37 E+00$ & 89 & 2.35E-01 & 134 & $3.04 \mathrm{E}-03$ & & \\
\hline 45 & $235 E+00$ & 90 & $2.24 E-01$ & 135 & $275 \mathrm{E}-03$ & & \\
\hline
\end{tabular}


Tabla13. Energy group boundaries for the GAM-II 100-group structure. The upper energy of group \#1 is $14.9 \mathrm{MeV}$.

\begin{tabular}{|c|c|c|c|c|c|}
\hline Group & $\mathrm{E}_{\min }(\mathrm{MeV})$ & Group * & $E_{\min }(\mathrm{MeV})$ & Group \$ & $\mathrm{E}_{\min }(\mathrm{MeV})$ \\
\hline 1 & $1.35 \mathrm{E}+01$ & 36 & $4.08 \mathrm{E}-01$ & 71 & 454E-04 \\
\hline 2 & $1.22 E+01$ & 37 & 3. $=E-01$ & 72 & $354 E-04$ \\
\hline 3 & $1.11 E+01$ & 38 & $3.34 E-01$ & 73 & 2.75E-04 \\
\hline 4 & $1.00 \mathrm{E}+01$ & 39 & $3.02 \mathrm{E}-01$ & 74 & 2.14E-04 \\
\hline 5 & $9.05 E+00$ & 40 & 2.73E-01 & 75 & $1.67 \mathrm{E}-04$ \\
\hline 6 & $8.19 E+\infty 0$ & 41 & 247E-01 & 76 & 1.30E-04 \\
\hline 7 & $7.41 E+00$ & 42 & $224 E-01$ & 77 & 1.01E-04 \\
\hline 8 & $6.70 \mathrm{E}+00$ & 43 & $2.02 E-01$ & 78 & 7.89E-05 \\
\hline 9 & $6.07 \mathrm{E}+\infty 00$ & 44 & 1.83E-0I & 79 & 6.14E-05 \\
\hline 10 & $5.49 E+00$ & 45 & $1.66 \mathrm{E}-01$ & 80 & 4.79E-05 \\
\hline 11 & 4.97E +00 & 46 & $150 \mathrm{E}-01$ & 81 & 3.73E-05 \\
\hline 12 & $4.49 E+00$ & 47 & $136 \mathrm{E}-01$ & 82 & 290E-05 \\
\hline 13 & $1.07 E+00$ & 48 & $1.23 \mathrm{E}-01$ & 83 & 226E-05 \\
\hline 14 & $3.68 \mathrm{E}+00$ & 49 & 1.11E-01 & 84 & $1.76 \mathrm{E}-05$ \\
\hline 15 & $333 E+00$ & 50 & 8.65E-02 & 85 & $137 \mathrm{E}-05$ \\
\hline 16 & $3.01 E+00$ & 51 & 6.74E-02 & 86 & 1.07E-05 \\
\hline 17 & $273 E+00$ & 52 & $5.25 E-02$ & 87 & $832 E-06$ \\
\hline 18 & $247 \mathrm{E}+00$ & 53 & $4.09 \mathrm{E}-02$ & 88 & $6.48 \mathrm{E}-06$ \\
\hline 19 & $223 E+00$ & 54 & $3.18 E-02$ & 89 & $5.04 \mathrm{E}-06$ \\
\hline 20 & $202 E+00$ & 55 & 2.48E-02 & 90 & $3.93 E-06$ \\
\hline 21 & $183 E+00$ & 56 & $1.93 E-02$ & 91 & $3.06 \mathrm{E}-06$ \\
\hline 22 & $1.65 E+\infty 0$ & 57 & $150 E-02$ & 92 & $238 E-06$ \\
\hline 23 & $150 \mathrm{E}+00$ & 58 & 1.17E-02 & 93 & $1.86 \mathrm{E}-06$ \\
\hline 24 & $135 \mathrm{E}+00$ & 59 & $9.12 E-03$ & 94 & $1.45 \mathrm{E}-06$ \\
\hline 25 & $1.22 \mathrm{E}+\infty 0$ & 60 & $7.10 \mathrm{E}-03$ & 95 & $1.13 E-06$ \\
\hline 26 & $1.11 E+\infty$ & 61 & $5.53 E-03$ & 96 & $8.76 \mathrm{E}-07$ \\
\hline 27 & $1.00 E+\infty 00$ & 62 & 4.31E-03 & 97 & $6.83 \mathrm{E}-07$ \\
\hline 28 & 9.0TE-01 & 63 & $3.35 E-03$ & 98 & 5.32E-07 \\
\hline 29 & S.21E-01 & 64 & $2.61 E-03$ & 99. & $4.14 E-07$ \\
\hline 30 & $7.43 \mathrm{E}-01$ & 65 & $203 E-03$ & 100 & $5.10 E-09$ \\
\hline 31 & $6.72 \mathrm{E}-01$ & 66 & $1.58 E-03$ & & \\
\hline 32 & $6.08 \mathrm{E}-01$ & 67 & $123 E-03$ & & \\
\hline 33 & $5.50 E-01$ & 68 & 9.61E-04 & & \\
\hline 34 & $4.98 E-01$ & 69 & $7.49 \mathrm{E}-04$ & & \\
\hline 35 & $+50 E-01$ & 70 & 5.83E-04 & & \\
\hline
\end{tabular}


Table 14. Energy group boundaries for the TART 175-group structure. The upper energy for group \#175 is $20.0 \mathrm{MeV}$.

\begin{tabular}{|c|c|c|c|c|c|c|c|}
\hline Group : & $\mathrm{E}_{\mathrm{m}}(\mathrm{MeV})$ & Group * & $E_{-}(\mathrm{MeV})$ & Group: & $\mathrm{E}_{\min }(\mathrm{MeV})$ & Group $\$$ & $\mathrm{E}_{\min }(\mathrm{MeV})$ \\
\hline 1 & $131 \mathrm{E}-09$ & 46 & $4.92 \mathrm{E}-05$ & 91 & $1.06 \mathrm{E}-03$ & 136 & $274 E+\infty 0$ \\
\hline 2 & $5.23 E-09$ & 47 & $5.12 E-05$ & 92 & $1.31 \mathrm{E}-03$ & 137 & $3.01 E+\infty$ \\
\hline 3 & $2.09 E-08$ & 48 & 5.33E-05 & 93 & $158 \mathrm{E}-03$ & 138 & $322 \pi E+\infty$ \\
\hline 4 & $3.27 \mathrm{E}-08$ & 49 & $5.65 \mathrm{E}-05$ & 94 & $188 \mathrm{E}-03$ & 139 & $3.53 E+00$ \\
\hline 5 & $4.70 \mathrm{E}-08$ & 50 & 5.76E-05 & 95 & $2.21 \mathrm{E}-03$ & 140 & $381 \mathrm{E}+00$ \\
\hline 6 & $832 E-08$ & 51 & 6.10E-05 & 96 & $256 E-03$ & 141 & $4.07 E+00$ \\
\hline 7 & 1.31E-07 & .52 & $6.33 \mathrm{E}-05$ & 97 & 294E-03 & 142 & $4.40 E+\infty 0$ \\
\hline 8 & $1.88 \mathrm{E}-07$ & 53 & 656E-05 & 98 & 3.35E-03 & 143 & $4.70 E+00$ \\
\hline 9 & $256 E-07$ & 54 & 6.67E-05 & 99 & $3.78 \mathrm{E}-03$ & 144 & $4.99 E+00$ \\
\hline 10 & $3,35 E-07$ & 55 & 7.03E-05 & 100 & $4.23 E-03$ & 145 & $5.35 E+00$ \\
\hline 11 & $4.23 \mathrm{E}-08$ & 56 & 7.16E-05 & 101 & $5.76 E-03$ & 146 & $5.66 \mathrm{E}+00$ \\
\hline 12 & $5.12 E-07$ & 57 & $7.53 \mathrm{E}-05$ & 102 & $7.53 \mathrm{E}=03$ & 147 & $6.04 E+00$ \\
\hline 13 & $753 E-07$ & 58 & 7.78E-OS & 103 & $1.03 E-02$ & 148 & $6.37 E+\infty 0$ \\
\hline 14 & $1.18 E-06$ & 59 & 7.91E-05 & 104 & $1.51 E-02$ & 149 & $6.74 E+00$ \\
\hline 15 & 1.51E-06 & 60 & 8.17E-05 & 105 & $209 E-02$ & 150 & $7.16 \mathrm{E}+00$ \\
\hline 16 & 2.09E-06 & 61 & $8.43 E-05$ & 106 & $2.65 E-02$ & 151 & $7.55 E+00$ \\
\hline 17 & 274E-06 & 62 & $8.83 \mathrm{E}-05$ & 107 & $327 \mathrm{E}-02$ & 152 & $7.91 \mathrm{E}+00$ \\
\hline 18 & $3.53 \mathrm{E}-06$ & 63 & 9.11E-05 & 108 & 3.95E-02 & 153 & $832 \mathrm{E}+00$ \\
\hline 19 & 4.70E-06 & 64 & 9.39E-05 & 109 & 4.70E-02 & 154 & $8.79 E+00$ \\
\hline 20 & $5.66 \mathrm{E}-06$ & 65 & 9.67E-05 & 110 & $5.76 \mathrm{E}-02$ & 155 & $9.18 E+00$ \\
\hline 21 & 6.74E-06 & 66 & 9.81E-05 & 111 & $7.00 \mathrm{E}-02$ & 156 & $9.67 \mathrm{E}+00$ \\
\hline 22 & $8.32 E-06$ & 67 & 1.03E-04 & 112 & $8.32 E-02$ & 157 & $1.01 E+01$ \\
\hline 23 & $9.62 E-06$ & 68 & $1.10 E-04$ & 113 & $9.89 \mathrm{E}-02$ & 158 & $1.06 \mathrm{E}+01$ \\
\hline 24 & $1.10 E-05$ & 69 & 1.18E-04 & 114 & $1.31 E-01$ & 159 & $1.10 \mathrm{E}+01$ \\
\hline 25 & $1.31 E-05$ & 70 & $1.26 \mathrm{E}-04$ & 115 & $1.82 E-01$ & 160 & $1.16 \mathrm{E}+01$ \\
\hline 26 & 1.47E-05 & 71 & $134 \mathrm{E}-04$ & 116 & 2.08E-01 & 161 & $1.20 \mathrm{E}+01$ \\
\hline 27 & $1.58 \mathrm{E}-05$ & 72 & 1.41E-04 & 117 & $2.42 \mathrm{E}-01$ & 162 & $1.25 E+01$ \\
\hline 28 & $-1.76 \mathrm{E}-05$ & 73 & 1.51E-04 & 118 & $271 \mathrm{E}-01$ & 163 & $1.31 E+01$ \\
\hline 29 & i.88E-05 & 74 & $1.60 \mathrm{E}-04$ & 119 & 294E-01 & 164 & $1.35 E+01$ \\
\hline 30 & $208 E-05$ & 75 & 1.69E-04 & 120 & 3.35E-01 & 165 & $1.39 E+01$ \\
\hline 31 & $2.28 E-05$ & 76 & $1.79 E-04$ & 121 & $3.78 \mathrm{E}-01$ & 166 & $1.41 E+01$ \\
\hline 32 & $242 E-05$ & 77 & $1.89 \mathrm{E}-04$ & 122 & $4.23 \mathrm{E}-01$ & 167 & $1.44 E+01$ \\
\hline 33 & 256E-05 & 78 & $1.99 E-04$ & 123 & 5.12E-01 & 168 & $1.47 \mathrm{E}+01$ \\
\hline 34 & 271E-05 & 79 & 209E-04 & 124. & 6.33E-01 & 169 & $1.52 E+01$ \\
\hline 35 & 286E-05 & 80 & 274E-04 & 125 & $7.53 \mathrm{E}-01$ & 170 & $1.58 E+01$ \\
\hline 36 & 294E-05 & 81 & 3.27E-04 & 126 & $8.83 E-01$ & 171 & $1.63 E+01$ \\
\hline 37 & $3.10 \mathrm{E}-05$ & 82 & 3.81E-04 & 127 & $1.03 E+00$ & 172 & $1.69 E+01$ \\
\hline 36 & 3.35E-05 & 83 & $4.70 \mathrm{E}-04$ & 228 & $1.18 E+\infty 0$ & 173 & $1.75 \mathrm{E}+01$ \\
\hline 39 & $3.60 \mathrm{E}-05$ & 84 & $4.99 E-04$ & 129 & $1.34 E+00$ & 174 & $1.81 \mathrm{E}+01$ \\
\hline 40 & 3.87E-05 & 85 & $5.66 \mathrm{E}-04$ & 130 & $1.51 E+100$ & 175 & $1.88 \mathrm{E}+01$ \\
\hline 41 & 4.05E-05 & 86 & $6.04 \mathrm{E}-04$ & 131 & $1.69 E+\infty$ & & \\
\hline 42 & $4.23 E-05$ & 87 & $6.37 \mathrm{E}-04$ & 132 & $1.89 E+00$ & & \\
\hline+3 & $4.33 E-05$ & 88 & $7.16 \mathrm{E}-04$ & 133 & $2.09 E+00$ & & \\
\hline 44 & 4.62E-05 & 89 & $8.32 \mathrm{E}-04$ & 134 & $231 E+00$ & & \\
\hline 45 & 4.72E-05 & 90 & $9.18 \mathrm{E}-04$ & 135 & $253 E+00$ & & \\
\hline
\end{tabular}




\section{Data libraries for ACAB.}

ACAB makes use of six different data libraries. These libraries provide data corresponding to:

1) decay data (UNIT 3);

2) photon production (UNIT 33);

3) neutron reaction cross sections (UNIT4);

4) mass attenuation coefficients (UNIT 68);

5) $\quad \beta$ decay data (UNIT 27); and

6) specific activity limits for Waste Disposal Ratings (UNIT55).

\section{Decay library}

Only isotopes that are included in the decay library may be generated in $A C A B$ calculations. The current decay data library is based on the FENDL/D2.0 library, taken from the International Atomic Energy Agency, IAEA. Modes of decay considered in the library are listed in table 5 . The decay library has data for $2^{\text {nd }}$ isomeric states, including transitions from the $2^{\text {nd }}$ to $1^{\text {ta }}$ isomeric states. Also possible are $\beta^{+}$and $\beta$-transitions to excited states. A utility program is used to read the decay library, and a file with information for natural isotopic abundances taken (Nuclear Wallet Cards, July 1995) ${ }^{16}$ in order to create the library for use with $A C A B$, Unit 3 . This library has a title card which is followed by two lines of data for each isotope. These lines are formatted and contain the following information:

Line \#1: (format is I4, 18, 13, 4X, 6E10.3)

$\begin{array}{ll}\# & \frac{\text { Parameter }}{1} \\ 2 & \text { NLB } \\ & \text { NUCL }\end{array}$

\section{Description}

Library identifier.

Isotope identifier. $\left(=Z \times 10^{4}+A \times 10+M\right)$.

$Z=$ atomic number; $A=$ mass number; $M=$ isomeric state ( 0 for ground state, 1 for $1^{\text {st }}$ isomer, 2 for $2^{\text {nd }}$ isomer).

3

IU

Units of the half-life:

$\begin{array}{ll}1 & \text { Seconds } \\ 2 & \text { Minutes } \\ 3 & \text { Hours } \\ 4 & \text { Days } \\ 5 & \text { Years } \\ 6 & \text { Stable } \\ 7 & 10^{3} \text { years } \\ 8 & 10^{6} \text { years } \\ 9 & 10^{9} \text { years }\end{array}$


electron capture. result in a product in an excited state.

8 FA Fraction of $\alpha$ transitions.

9 FIT Fraction of isomeric transitions to the ground state.

Line \#2: (format is $14,5 X, 4 \mathrm{E} 10.3,1 \mathrm{E} 11.4,2 \mathrm{E} 10.3$ )

\begin{tabular}{|c|c|c|}
\hline \# & Parameter & Description \\
\hline$\overline{1}$ & $\overline{\text { NLB }}$ & Library identifier. \\
\hline 2 & FB & Fraction of $\beta$-transitions. \\
\hline 3 & FSF & $\begin{array}{l}\text { Fraction of transitions from the } 2^{\text {nd }} \text { to } 1^{\text {st }} \text { isomeric } \\
\text { state. }\end{array}$ \\
\hline 4 & FN & Fraction of $(\beta+n)$ transitions. \\
\hline 5 & QREC & Average energy of the emitted $\alpha+\beta+\gamma$. \\
\hline 6 & ABUN & Natural isotopic abundance. \\
\hline 7 & ARCG & Maximum permissible concentration in $\operatorname{air}\left(\mathrm{Ci} / \mathrm{m}^{3}\right)$. \\
\hline 8 & WRCG & $\begin{array}{l}\text { Maximum permissible concentration in water } \\
\left(\mathrm{Ci} / \mathrm{m}^{3}\right) \text {. }\end{array}$ \\
\hline
\end{tabular}

Example:

$\begin{array}{llllllllllll}1771922 & 17.600 E+09 & 0.000 E+00 & 0.000 E+00 & 0.000 E+00 & 0.000 E+00 & 1.000 E+00\end{array}$

$10.000 \mathrm{E}+00 \quad 0.000 \mathrm{E}+00 \quad 0.000 \mathrm{E}+00 \quad 1.610 \mathrm{E}-01 \quad 0.000 \mathrm{E}+00 \quad 0.000 \mathrm{E}+00 \quad 0.000 \mathrm{E}+00$

This example gives decay information for ${ }^{192 n I r . ~ I t ~ s h o w s ~ t h a t ~ t h e ~ h a l f-l i f e ~}$ is $7.6 \times 10^{9}$ seconds $=241$ years, that $100 \%$ of the isomeric transitions go to the ground state, and that the average energy of $\alpha+\beta+\gamma$ is $0.161 \mathrm{MeV}$ per disintegration. When maximum permissible concentrations for a given radionuclide are not available, as they are not for ${ }^{192 n} \mathrm{Ir}$, a value of $0.0 \mathrm{Ci} / \mathrm{m}^{3}$ is specified and not used for the BHP computation.

\section{Photon library}

The photon library consists of data from FENDL/D-2.0. A utility program is used to extract the photon information from this library for use with $A C A B$, Unit 33 . The photon library also contains two lines per isotope and contains the following information:

\section{Line \#1: (format is I3, A4, I3, A1, 4X, I5)}

\begin{tabular}{|c|c|c|}
\hline \# & Parameter & Description \\
\hline$\overline{1}$ & $\overline{\mathrm{Z}}$ & Atomic number. \\
\hline 2 & SYMBOL & Chemical symbol of the nuclide. \\
\hline 3 & A & Mass number. \\
\hline 4 & STATE & 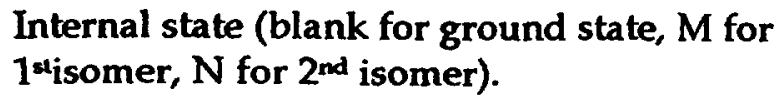 \\
\hline
\end{tabular}



follow.

Line \#2: (format is (ENER(N), INTS(N), N=1,NR) 6E11.4)

\begin{tabular}{|c|c|c|}
\hline \# & Parameter & Description \\
\hline$\overline{1}$ & $\overline{\text { ENER }}$ & Photon energy (MeV). \\
\hline 2 & INTS & $\begin{array}{l}\text { Number of photons of that energy emitted per } \\
100 \text { disintegrations. }\end{array}$ \\
\hline
\end{tabular}

Example:

11 NA 24

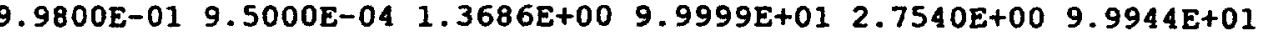

$2.8700 \mathrm{E}+00 \quad 2.0000 \mathrm{E}-04 \quad 3.8672 \mathrm{E}+00 \quad 5.2000 \mathrm{E}-02 \quad 4.2380 \mathrm{E}+00 \quad 7.5000 \mathrm{E}-04$

This example gives 6 photon yields for ${ }^{24} \mathrm{Na}$. The data shows that nearly 100 photons at $1.37 \mathrm{MeV}, 100$ photons at $2.75 \mathrm{MeV}$ and 0.05 photons at 3.87 $\mathrm{MeV}$ are emitted per $10024 \mathrm{Na}$ disintegrations. Photons are produced at other energies but at rates of less than 1 per $10^{5}$ disintegrations.

\section{Cross section library}

$A C A B$ currently uses the FENDL/A-2.0. This library follows the ENDF/ $B$ format. Other libraries currently adapted for use in ACAB are the EAF-4.1 and the EAF_3.1. These libraries are in the 175-group Vitamin-J group structure, the 100-group GAM-II group structure, and the 175-group TART group structure. (See tables 12,13,14).

$A C A B$ can be used with any group structure as long as the cross sections and fluxes use the same structure. When this is not possible, one can use the COLLAPSE (see section IV) code to generate 1-group cross sections and a 1group flux from an arbitrary group structure and one of the existing versions of the cross section library.

$A C A B$ reads the cross section library from unit 4. For each reaction, there are four lines of formatted data that contain the following information:

Line \#1: (format is $316,3 X, 13 A 4)$

$\begin{array}{lll}\frac{\#}{1} & \begin{array}{l}\text { Parameter } \\ \text { MAT }\end{array} & \begin{array}{l}\text { Description } \\ \text { Nuclide identifier that is composed in the same } \\ \text { manner as NUCLID (see block\#4) }\end{array} \\ 3 & \text { MT } & \begin{array}{l}\text { Reaction identification number } \\ \text { Mumber of group cross sections } \\ \text { that follow for the MTreaction on the MAT target }\end{array}\end{array}$


Lines \#2 and \#3 contain alphanumeric text that provides information about the source of the cross section data. The format for these lines is A80.

Line \#4: (format is 6E11.4)

$\begin{array}{lll}\# & \frac{\text { Parameter }}{\text { XSEC }} & \begin{array}{l}\text { Description } \\ \text { Group cross section values in order of decreasing } \\ \text { energy. [MAXG]. }\end{array}\end{array}$

Example:

260540103064 FE 54 (N,P )MN $54 \quad 1.0000+00^{*}$

JENDL-3.2/A

1.44243E-01 1.78388E-01 1.93273E-01 2.17498E-01 2.77143E-01 3.05415E-01

3.32740E-01 3.59740E-01 3.88597E-01 4.20519E-01 4.67806E-01 4.90825E-01

5.17509E-01 5.33006E-01 5.38475E-01 5.32787E-01 5.29980E-01 5.29970E-01

5.29970E-01 5.29969E-01 5.29247E-01 5.25649E-01 5.21871E-01 5.14627E-01

5.05856E-01 5.00722E-01 4.99981E-01 4.94351E-01 4.77434E-01 4.51470E-01

4.20320E-01 3.85977E-01 3.53527E-01 3.01523E-01 2.50248E-01 2.20914E-01

1.80842E-01 1.50903E-01 1.24257E-01 1.01958E-01 8.28641E-02 6.59863E-02

5.57254E-02 5.15133E-02 4.98545E-02 4.74010E-02 4.25914E-02 3.51130E-02

2.66249E-02 1.93511E-02 1.40036E-02 8.98573E-03 5.83579E-03 3.78654E-03

1.83925E-03 9.17771E-04 7.75506E-04 6.40134E-04 5.11356E-04 3.88892E-04

2.72320E-04 1.08842E-04 1.61658E-07 0.00000E+00

This example contains the cross section data for the ${ }^{54} \mathrm{Fe}(n, p){ }^{54} \mathrm{Mn}$ reaction. The first line provides header information that gives the target atom, the reaction number, the number of cross sections that follow, and the reaction name. The second and third lines are used for general/comment information. Beginning with the fourth line, the reaction cross sections are given in order of decreasing neutron energy. This reaction is a threshold reaction, cross sections are given in 64 groups.

Fission yield cross-section library.

The one-group fission yields cross-sections are read from Unit 96. For each fission product, the effective fission yield cross sections coming from every fissionable nuclide are given. The information is provided in increasing order of the Nuclide Identifier ( that is $10000^{*} \mathrm{Z}+10^{\star} \mathrm{A}+\mathrm{IS}$ ) of the fission product.

$\begin{array}{ll}\text { Line \#1: } & \text { (format is E11.6) } \\ \frac{\text { Parameter }}{\text { \# }} & \frac{\text { Description }}{\text { Nuclide identifier }}\end{array}$




$\begin{array}{ll}\text { Line \#2: } & \begin{array}{l}\text { (format is 6E11.6) } \\ \text { Parameter }\end{array} \\ \frac{\text { FISYI }}{1} & \begin{array}{l}\text { Description } \\ \text { One-group fission yield cross section from every } \\ \text { fissionable nuclide. [19] or [61]. }\end{array}\end{array}$

Example:

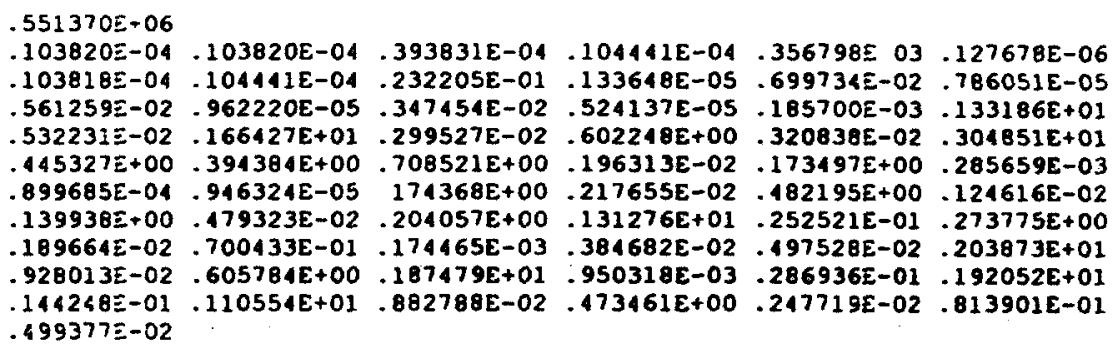

This example containes the one-group fission yield cross sections for Cs-137 coming from all the fissionable nuclides (61) included in FENDL/A-2.0.

\section{Mass attenuation coefficient library}

Mass attenuation coefficients are read from Unit 68. These have been recompiled and calculated by $\mathrm{Hubble}^{17}$. These are given in 35 energy groups that range from $1.0-1.5 \mathrm{keV}$ to $15-20 \mathrm{MeV}$. The mass attenuation file contains data for 40 elements with atomic numbers as low as hydrogen (1) and as high as uranium (92). The mass attenuation coefficients are given in units of $\mathrm{m}^{2} / \mathrm{kg}$.

Example:

PB 82

$6.205 E-3 \quad 5.658 E-3 \quad 4.972 E-3 \quad 4.675 E-3 \quad 4.391 E-3 \quad 4.272 E-3$

$4.197 E-3 \quad 4.234 E-3 \quad 4.607 E-3 \quad 5.222 E-3 \quad 7.103 E-3 \quad 8.869 E-3$

$\begin{array}{llllll}1.248 \mathrm{E}-2 & 1.613 \mathrm{E}-2 & 2.323 \mathrm{E}-2 & 4.026 \mathrm{E}-2 & 9.985 \mathrm{E}-2 & 2.014 \mathrm{E}-1\end{array}$

$5.550 \mathrm{E}-1 \quad 2.419 \mathrm{E}-1 \quad 5.020 \mathrm{E}-1 \quad 8.041 \mathrm{E}-1 \quad 1.436 \mathrm{E}+0 \quad 3.032 \mathrm{E}+0$

$\begin{array}{lllllll}8.636 \mathrm{E}+0 & 1.116 \mathrm{E}+1 & 1.306 \mathrm{E}+1 & 2.287 \mathrm{E}+1 & 4.672 \mathrm{E}+1 & 7.304 \mathrm{E}+1\end{array}$

$1.251 E+2 \quad 1.965 E+2 \quad 1.285 E+2 \quad 2.356 E+2 \quad 5.210 E+2$

\section{B decay library}

Unit 27 gives the average energy per $\beta$-decay and the fraction of disintegrations that occur via $\beta$-decay for each isotope. This information is derived from UKDECAY3 and is used to calculate the Bremsstrahlung dose rates. 
Example:

60140

$4.94750 E+04 \quad 1.00000 E+00$

This example gives the $\beta$-decay information for ${ }^{14} \mathrm{C}$. The average energy of $\beta$ particles is approximately $49.5 \mathrm{keV}$ and $\beta$-decay occurs for $100 \%$ of the disintegrations.

\section{WDR library}

Specific activity limits are read from Unit 55. These limits are maximum concentrations allowed in $\mathrm{Ci} / \mathrm{m}^{3}$ for the waste to be eligible for shallow land burial. The limits used by $A C A B$ are those calculated by Fetter, Cheng, and Mann'14.

Example:

$1302609.0000 \mathrm{E}-2$

This example give the specific activity limit for ${ }^{26} \mathrm{Al}$ as $0.09 \mathrm{Ci} / \mathrm{m}^{3}$. That is, radioactive waste that contains only ${ }^{26} \mathrm{Al}$ at a concentration of less than 0.09 $\mathrm{Ci} / \mathrm{m}^{3}$ would be eligible for near-surface land disposal as Class $\mathrm{C}$ waste. 


\section{Input Description}

$A C A B$ input data is structured in data blocks.Blocks $\# 1, \# 2, \# 3, \# 5, \# 6, \# 7, \# 8$ and \#9 are read in FIDO free format, and the rest (blocks \#4, \#10 and \#11 are read in FORTRAN free format. In the FIDO format blocks, all cards starting with a number $\$$ accept integer values, and those starting with numbert require floating point values must end with a " $T$ ".

Comments may be interspersed throughout an ACAB input file. Comments are denoted by a single quote (') in the first column of any line.

Numbers in [ ] are dimensions of the vector or matrix being described. Expressions in \{ \} represent conditions that must be fulfilled in order to correctly enter input. Recommended values for input are specified in ().

We will now go through the $A C A B$ input one block at a time. For each card, an example will be given. 


\section{Block \#1:}

The $A C A B$ input file begins with a title card that gives a general description of the calculation being performed. This card may contain character information and be up to 80 characters in length ( 20 A4 format).

Example:

Activation of alumina first wall coating on NIF - single, $20 \mathrm{MJ}$ yield

The $17 \$ \$$ card is a "catch-all" that gives much of the general information about what type of calculation is being performed.

17\$\$ All integer parameters [21]

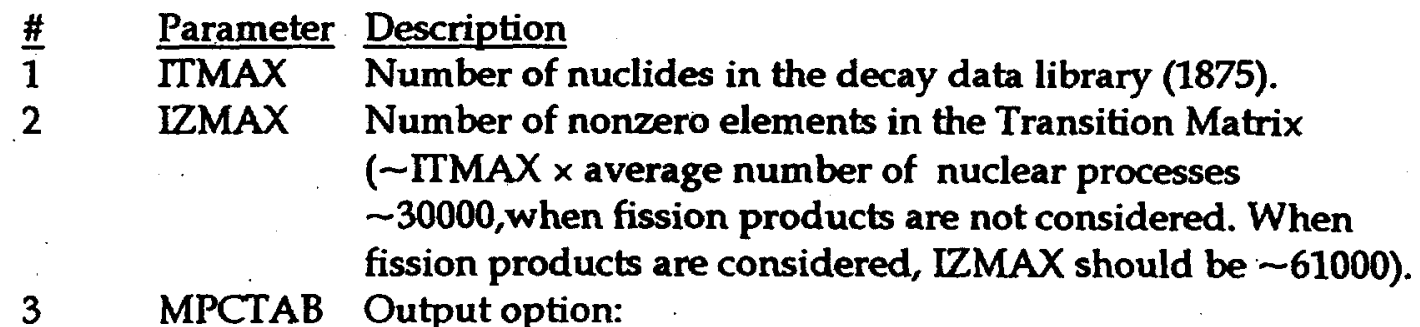

0 No effect.

1 Print radioactive concentration guides and must be specified to perform calculation of biological hazard potentials (see JTO).

$4 \quad \mathrm{IR}$

Output option:

0 . No effect.

1 Print all elements of the Transition Matrix.

$5 \quad$ JTO Output option (see Table IV):

0 Print all available tables for all isotopes, elements, and most important isotopes for post-irradiation periods. BHPs are provided only if $\mathrm{MPCTAB}=1$. If NTABLE $=1$, only tables for the most important isotopes are printed.

1 Only selected output tables are printed. Tables are selected using the $8 \$$ card.

6 NTABLE Output option:

0 No effect.

1 Only tables for most important isotopes. Cutoff points are selected using MSTAR and CUTOFF ( $7^{\text {t* }}$ card).

\section{MSTAR} Timestep used to select the most important isotopes. This timestep is chosen from the post-irradiation periods. Only isotopes with values greater than the thresholds given in CUTOFF are printed.

Note: If NTABLE $=0$, MSTAR has no effect. 
1 Read initial concentrations as elements.

2 Read initial concentrations as isotopes.

$9 \quad$ NFD Input option (see ISOZO on 5\$\$ card in block 5):

0 No effect.

1 Read continuous feed data for elements.

2 Read continuous feed data for isotopes.

$10 \quad$ NOGG

Number of energy groups for gammas emitted by decay.

11 NGRP

12 IGRP

13 IGE Number of energy groups for neutrons.

Number of energy groups for gammas used in previous transport calculations. IGRP will be nonzero only when flux files obtained from coupled neutron-gamma transport calculations are provided.

Type of geometry:

One-dimensional:

1 planar

2 cylindrical

3. spherical

Two-dimensional:
$1 \quad x-y$
$2 r-z$
$3 \mathrm{r}-\theta$

Three dimensional:

4 It is recommended for flux spatial distributions from Monte Carlo neutron transport codes

$14 \quad$ IZM

Number of material zones.

$15 \quad \mathrm{IM}$

$16 \quad \mathrm{JM}$

17. IFLU

$18 \quad$ IPRT

Number of spatial intervals in $1-D$, in $3-D$, or number of $1^{\text {st }}$ dimension spatial intervals in 2-D calculations.

Number of $2^{\text {nd }}$ dimension spatial intervals in 2-D calculations. Not used for 1-D or Monte Carlo calculations.

Input option:

0 No effect.

1 Flux in BCD structure with FIDO free format.

2 Flux in binary tape.

Output option:

0 No effect.

1 Print scalar neutron flux.

19 ILIB

Output option:

0 No effect.

1 Print a mean energy photon production data per disintegration for all isotopes in NOGG-group structure.

20 IRAD Output option:

0 No effect.

1 Print concentrations (number of atoms) during 
21 IPUN

$\mathbf{T}$

irradiation times for all isotopes.

Option for generation of unit 9:

0 No effect.

1 Print photon release rates (photons $/ \mathrm{cm}^{3}-\mathrm{s}$ ) in a NOGG-group structure. Spatial dependece is included. This option is useful as a source term for subsequent photon photon transport calculations.

End of block \#1.

Example:

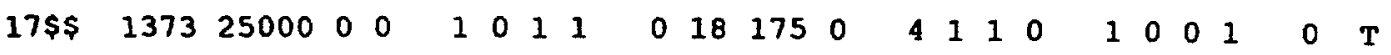

This card indicates that there are up to 1373 isotopes in the decay library and up to 25000 nonzero elements in the Transition Matrix. The first timestep is used to determine the list of most important isotopes. Initial concentrations are read as elements. The neutron flux is in 175 groups and gammas produced by activation are to be divided into 18 groups. The geometry is 3-D from a Monte Carlo transport problem. There is one material zone that has only a single interval. The flux is given in the FIDO free format, and concentrations are requested for all isotopes during the irradiation period. The " $\mathrm{T}$ " can be placed at the end of the line as in the example or may be on a separate line. The additional spacing between groups of inputs is not required but helps in reading of input files. 


\section{Block \#2:}

The second input block contains detailed information about the current calculation. The user can elect to receive zonal results by solving the transmutation equations by interval or by using a spatially-averaged flux for the entire zone. The spatially-averaged flux, $\phi_{z}$ for a zone $k$ is defined by the following equation:

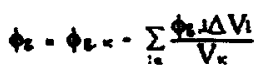

where:

$\phi_{g l}$ is the scalar neutron flux in energy group $g$ and interval $l$ in zone $k$,

$\Delta V_{1}$ is the volume of interval $l$ in zone $k$, and

$V_{x}$ is the volume of zone $x$.

$1^{\text {t* }} \quad$ XRR . Boundaries for $1^{\text {st }}$ dimension intervals in $\mathrm{cm}$. For 3-D (IGE =4) configurations, this card gives the volume of each zone in $\mathrm{cm}^{3}$ and must end with an additional nonzero value. [ $\mathrm{IM}+1]$.

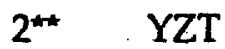
Boundaries for $2^{\text {nd }}$ dimension intervals in $\mathrm{cm}$. This card is omitted when 1-D or 3-D geometry is chosen by the IGE parameter. [JM + 1] $0 \mathrm{JM}>0\}$.

3\$\$ MA Zone number identification of each spatial interval, going from left to right and bottom to top. [IM] or [IM $\times$ JM].

Number of initial elements or isotopes per zone. Negative values are used when zone averaged fluxes are used. A zero (0) must be included to omit a zone. [IZM].

5\$\$ ISOZO Number of elements or isotopes per zone for continuous feed. [IZM] $\{$ INDF $>0$ 0 .

6* EGRP Energy boundaries for gammas produced by activation. These boundaries are given in order of decreasing energy in $\mathrm{MeV}$. [NOGG + 1] \{NOGG > 0\}.

7 CUTOFF Threshold values for different output tables. Any isotopes whose value in the timestep MSTAR falls below CUTOFF will be omitted from the corresponding output table. One threshold value must be given for each of the six types. The six types of output tables are described in Table 15. [6].

Allows selection of desired output tables. The 18 values correspond to the 18 tables (three of each type) described in Table 2. [18] JTO $=1$ ].

0 No effect.

1 Print output table.

$\mathrm{T} \quad$ End of block \#2. 
Example \#1:

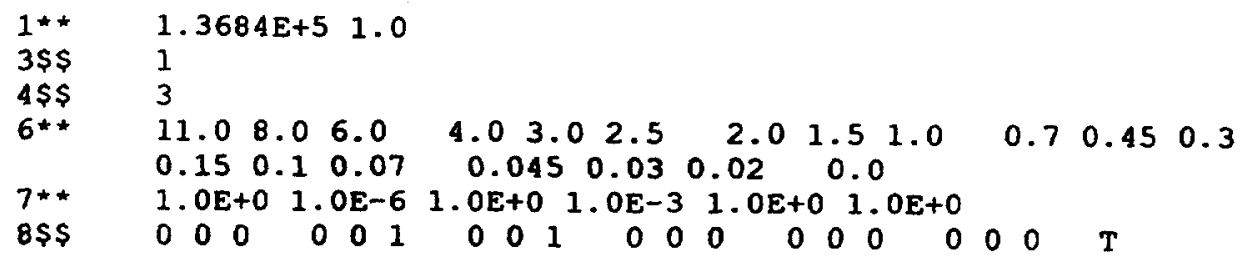

This example is for a 3-D geometry description. Only a single zone is included with a volume of $1.3684 \mathrm{E}+5 \mathrm{cc}$ (a nonzero value ends the $1^{\text {* }}$ card). The zone is numbered as zone \#1 and three initial elements will be given. A total of 19 energies are given creating an 18-group structure for gamma-rays produced by activation. Only 2 of the 18 tables have been requested (table \#4 is grams of the most important isotopes and table \#7 is activity in $\mathrm{Bq}$ of the most important isotopes). Cutoff values have been specified for each of the table types. Again, the " $\mathrm{T}$ " signifying the end of this block has been included at the end of the $8 \$ \$$ card, but could be placed on a separate line.

Example \#2:

$\begin{array}{llccc}3 \$ \$ & 111 & 2222 & 33 & \\ 4 \$ \$ & 3 & 3 & & 6\end{array}$

This example is for a case with three zones. There are three intervals in the first zone, four intervals in the second zone, and two intervals in the third zone. The transmutation equations will be solved by intervals for all three zones, because all values of NUCZO are positive. The number of nuclides or elements in each zone are 3,3 , and 6 , respectively.

Example \#3:

$\begin{array}{lcccc}3 \$ \$ & 111 & 2222 & 33 & \\ 4 \$ \$ & 3 & 0 & -6\end{array}$

Again, three zones are included in this example. This time, the transmutation equations are solved by interval in the first zone, the second zone is ignored, and results for the third zone are calculated using a zone-averaged flux. The first zone contains three nuclides or elements and the third zone contains six. 
TABLA15. Type of tables that are output by ACAB.

\begin{tabular}{|c|c|c|c|}
\hline $\begin{array}{l}\text { Output } \\
\text { Table \# }\end{array}$ & $\begin{array}{l}\text { Table } \\
\text { Type }\end{array}$ & Output Quantity & Output Scope \\
\hline 1 & \multirow{3}{*}{1} & \multirow{3}{*}{ gram-atoms (moles) } & all isotopes \\
\hline 2 & & & all elements \\
\hline 3 & & & most important isotopes \\
\hline 4 & \multirow{3}{*}{2} & \multirow{3}{*}{ mass (grams) } & all isotopes \\
\hline 5 & & & all elements \\
\hline 6 & & & most important isotopes \\
\hline 7 & \multirow{3}{*}{3} & \multirow{3}{*}{ activity $(\mathrm{Bq})$} & all isotopes \\
\hline 8 & & & all elements \\
\hline 9 & & & most important isotopes \\
\hline 10 & \multirow{3}{*}{4} & \multirow{3}{*}{ afterheat (W) } & all isotopes \\
\hline 11 & & & all elements \\
\hline 12 & & & most important isotopes \\
\hline 13 & \multirow{3}{*}{5} & \multirow{3}{*}{ BHP in air $\left(\mathrm{m}^{3}\right)$} & all isotopes \\
\hline 14 & & & - all elements \\
\hline 15 & & & most important isotopes \\
\hline 16 & \multirow{3}{*}{6} & \multirow{3}{*}{$\mathrm{BHP}$ in water $\left(\mathrm{m}^{3}\right)$} & all isotopes \\
\hline 17 & & & all elements \\
\hline 18 & & & most important isotopes \\
\hline
\end{tabular}

Note: The $18 \mathrm{ACAB}$ output tables can be categorized into six types according to the quantity that is indicated ( grams-atoms,mass,activity, afterheat,BHP in air,and BHP in water). Each of the six types may be generated for all isotopes,all elements, and most important isotopes. Tables to be generated are specified on the $8 \$ \$$ card. If most important isotopes are to be outputted, cutoffs must be specified on the $7^{* *}$ card. 
Block \#3:

Block \#3 consists only of the $9^{\text {tt }}$ card which inputs the energy- and spatiallydependent fluxes. Block $\# 3$ is needed only if IFLU $=1$.

9* FLUX Multigroup scalar fluxes of neutrons and gammas (n/ $\left.\mathrm{cm}^{2}-\mathrm{s}\right)$. $[(\mathrm{NGRP}+\mathrm{IGRP}) \times \mathrm{IM}]$ for $\mathrm{JM}=0$, or [(NGRP + IGRP) $\times \mathrm{IM} \times$ $\mathrm{JM}]$ for $\mathrm{JM}>0$.

i.e. $\mathrm{JM}=0$,

** neutrons **

1st group - spatial intervals from 1 to $\mathrm{IM}$.

2nd group - spatial intervals from 1 to $\mathrm{IM}$.

$\cdots$

$\cdots$

$\ldots$

NGRP group - spatial intervals from 1 to IM.

*. gammas **

NGRP + 1 group - spatial intervals from 1 to $\mathrm{MM}$.

...

$\cdots$

$\ldots$

NGRP + IGRP - spatial intervals from 1 to IM.

T End of block \#3.

Example:

9*+

$\begin{array}{llllll}0.00000 E+00 & 0.00000 E+00 & 0.00000 E+00 & 0.00000 E+00 & 0.00000 E+00 & 0.00000 E+00\end{array}$ $\begin{array}{lllllll}0.00000 E+00 & 0.00000 E+00 & 0.00000 E+00 & 0.00000 E+00 & 2.24560 E+12 & 1.28748 E+09\end{array}$

$9.36590 E+C 9 \quad 1.09117 E+11 \quad 5.71239 E+10 \quad 2.29345 E+10 \quad 2.24553 E+10 \quad 2.21273 E+10$

$2.07259 \mathrm{E}+10 \quad 2.42329 \mathrm{E}+10 \quad 1.93205 \mathrm{E}+10 \quad 2.33644 \mathrm{E}+10 \quad 3.29684 \mathrm{E}+10 \quad 3.10372 \mathrm{E}+10$

$2.67600 E+10 \quad 2.73849 E+10 \quad 2.78341 E+10 \quad 3.11134 E+10 \quad 2.99179 E+10 \quad 4.24145 E+10$ $4.27637 \mathrm{E}+10 \quad 5.38507 \mathrm{E}+10 \quad 4.97128 \mathrm{E}+10 \quad 5.60370 \mathrm{E}+10 \quad 6.80981 \mathrm{E}+10 \quad 5.99109 \mathrm{E}+10$ $7.02953 \mathrm{E}+10 \quad 8.36346 \mathrm{E}+10 \quad 9.05295 \mathrm{E}+10 \quad 1.14939 \mathrm{E}+11 \quad 1.06675 \mathrm{E}+11 \quad 1.57469 \mathrm{E}+11$ $1.41095 \mathrm{E}+11 \quad 1.46795 \mathrm{E}+11 \quad 1.70587 \mathrm{E}+11 \quad 1.77039 \mathrm{E}+11 \quad 1.96036 \mathrm{E}+11 \quad 2.06424 \mathrm{E}+11$ $2.20851 E+112.64793 E+112.26939 E+11 \quad 3.27008 E+11 \quad 3.53680 E+112.67274 E+11$ $\begin{array}{llllllll}1.86971 E+11 & 1.85623 E+11 & 1.61273 E+11 & 1.04622 E+11 & 2.06572 E+11 & 1.62587 E+11\end{array}$ $\begin{array}{llllll}1.40515 E+11 & 2.66758 E+11 & 3.28667 E+11 & 5.34534 E+10 & 1.36869 E+11 & 2.55764 E+11\end{array}$ $\begin{array}{llllll}1.80476 E+11 & 8.37936 \mathrm{E}+10 & 2.71935 \mathrm{E}+10 & 1.90595 \mathrm{E}+11 & 2.07160 \mathrm{E}+11 & 1.67033 \mathrm{E}+11\end{array}$ $1.51164 \mathrm{E}+11 \quad 1.10752 \mathrm{E}+11 \quad 8.90825 \mathrm{E}+10 \quad 1.05012 \mathrm{E}+11 \quad 3.98039 \mathrm{E}+10 \quad 3.85728 \mathrm{E}+10$ $3.90367 E+10 \quad 3.37028 \mathrm{E}+10 \quad 3.35326 \mathrm{E}+10 \quad 5.06135 \mathrm{E}+10 \quad 6.28872 \mathrm{E}+10 \quad 6.67807 \mathrm{E}+10$ $6.35506 \mathrm{E}+10 \quad 4.52059 \mathrm{E}+10 \quad 3.19280 \mathrm{E}+10 \quad 4.79158 \mathrm{E}+10 \quad 3.39836 \mathrm{E}+10 \quad 1.50696 \mathrm{E}+10$ $\begin{array}{llllll}1.88315 E+10 & 3.65922 \mathrm{E}+10 & 1.72076 \mathrm{E}+10 & 5.67439 \mathrm{E}+10 & 2.29198 \mathrm{E}+10 & 4.53192 \mathrm{E}+10\end{array}$ $8.10556 \mathrm{E}+10 \quad 1.58072 \mathrm{E}+10 \quad 1.52956 \mathrm{E}+10 \quad 1.53275 \mathrm{E}+10 \quad 1.60421 \mathrm{E}+10 \quad 1.56105 \mathrm{E}+10$ $1.49453 \mathrm{E}+10 \quad 1.95372 \mathrm{E}+10 \quad 1.23915 \mathrm{E}+10 \quad 1.68609 \mathrm{E}+10 \quad 1.69424 \mathrm{E}+10 \quad 1.87165 \mathrm{E}+10$ $1.77789 \mathrm{E}+10 \quad 1.13412 \mathrm{E}+10 \quad 3.76854 \mathrm{E}+09 \quad 8.06483 \mathrm{E}+09 \quad 7.66558 \mathrm{E}+097.87956 \mathrm{E}+09$ $1.42777 \mathrm{E}+10 \quad 9.44282 \mathrm{E}+098.04090 \mathrm{E}+09 \quad 4.57391 \mathrm{E}+098.45258 \mathrm{E}+09 \quad 1.32726 \mathrm{E}+10$ $4.45566 \mathrm{E}+09 \quad 1.27853 \mathrm{E}+10 \quad 4.53097 \mathrm{E}+09 \quad 8.68020 \mathrm{E}+09 \quad 9.08462 \mathrm{E}+09 \quad 1.53207 \mathrm{E}+10$ 
$5.39231 \mathrm{E}+09 \quad 1.53635 \mathrm{E}+10 \quad 1.13034 \mathrm{E}+10 \quad 9.46579 \mathrm{E}+09 \quad 1.11856 \mathrm{E}+10 \quad 5.90132 \mathrm{E}+09$

$1.59676 \mathrm{E}+10 \quad 5.75868 \mathrm{E}+09 \quad 1.03850 \mathrm{E}+10 \quad 1.12432 \mathrm{E}+10 \quad 1.70752 \mathrm{E}+10 \quad 1.86777 \mathrm{E}+10$

$1.80729 \mathrm{E}+10 \quad 1.41357 \mathrm{E}+10 \quad 6.93439 \mathrm{E}+09 \quad 1.64552 \mathrm{E}+10 \quad 1.38189 \mathrm{E}+10 \quad 1.68749 \mathrm{E}+10$

$1.51662 E+102.35880 E+102.36985 E+10 \quad 1.64662 E+10 \quad 2.58199 E+10 \quad 1.63296 E+10$

$2.85504 E+10 \quad 4.01943 E+10 \quad 3.27129 E+10 \quad 3.57419 E+10 \quad 4.94656 E+10 \quad 3.82529 E+10$

$4.33785 E+10 \quad 6.86971 E+10 \quad 5.28651 E+10 \quad 5.69083 E+10 \quad 6.72074 E+10 \quad 5.57159 E+10$

$\begin{array}{lllllll}8.78042 E+10 & 7.18004 E+10 & 3.50706 E+10 & 4.01719 E+10 & 4.58855 E+10 & 4.78985 E+10\end{array}$

$5.17701 E+10 \quad 5.87309 E+10 \quad 6.69443 E+10 \quad 3.50314 E+10 \quad 9.78391 E+110.00000 E+00$

$0.00000 \mathrm{E}+00 \mathrm{~T}$

This example gives the 175-group energy-dependent neutron fluxes for a single zone as calculated from a $14.1 \mathrm{MeV}$ point source without inclusion of gammas. Note that $14.1 \mathrm{MeV}$ lies within group \#11, and thus, the first 10 energy groups have fluxes of zero. Special attention must be paid to the fact that the fluxes for the highest energy group must be given for each zone or interval before the $2^{\text {nd }}$ group begins.

It is worth noting that in a general case, the energy dependent fluxes should be given consistently with the cross sections activation library. If cross sections are given as a function of decreasing/increasing energy, the neutron spectrum must be given following the same structure, that is, as a function of decreasing/increasing energy. 
Block \#4:

Block \#4 allows for a RESTART OPTION, and is currently implemented for one material zone and one interval. It contains one card that is read in FORTRAN free format. The restart option can be very useful for calcullations under pulsed irradiation regimes characteristc of conceptual IFE reactors., and it works as follows.

$A C A B$ produces in all inventory calculation runs the UNIT37, which contains the composition in g-atom for all isotopes in the last time step of the problem. This UNIT can be used as input of new initial material composition if you want to continue the calculation in a new run.

\section{Card \#1:}
\# Parameter Description
1 IREST Indicator for restart option.
0 No effect.
1 The initial material composition is read from UNIT 37, instead of using BLOCK \#5 (this is used as explained next, for a non-restart case).

Example:

0

A non-restart case is considered, and UNIT 37 is not read. Initial composition must be given in Block \#5. 


\section{Block \#5.}

Block \#5 is used to specify the initial material composition in a non-restart run. This Block must be omitted for a non-restart run. The nuclide identifier is defined as:

$$
\text { NUCLID }=10000 \times Z+10 \times A+I S
$$

where:

$\mathrm{Z}=$ atomic number,

$A=$ atomic mass of nuclide, and

IS = state indicator $(0=$ ground state, $1=$ first isomeric state, and 2 = second isomeric state)

The identifier for an element follows the pattern set by the nuclide identifier:

$$
\text { ELEMID }=10000 \times Z
$$

This block must be repeated if more than one material zone is to be considered (including the " $\mathrm{T}$ " that denotes the end of the block).

$10 \$ \$$ INUCL Identifiers of the initial elements or isotopes. [NUCZO].

$11^{\star \star}$ XCOMP Concentrations of the initial elements or isotopes given in units of atoms/barn-cm. [NUCZO].

T End of block \#5.

Example \#1:

$10 \$ \$ 80000120000130000$

$11 * * 6.09 \mathrm{E}-02 \quad 1.52 \mathrm{E}-02 \quad 3.05 \mathrm{E}-02 \mathrm{~T}$

This example specifies that the elements oxygen, magnesium, and aluminum are the initial constituents of the material being irradiated. They are present in 6.09 $\times 10^{22}, 1.52 \times 10^{22}$, and $3.05 \times 10^{22}$ atoms/cc, respectively $\left(10^{24}\right.$ atoms/cc $=1$ atom $\times$ barn $\left.^{-1} \times \mathrm{cm}^{-1}\right)$.

Example \#2:

$10 \$ \$ 741860$

$11 * \star \quad 6.00 \mathrm{E}-02 \mathrm{~T}$

The second example is for the irradiation of ${ }^{187} \mathrm{~W}$. It is present at an atomic density of $6.00 \times 10^{22}$ atoms/cc. 
Block \#6:

Block \#6 is used to specify materials that are subject to continuous feed. This block must be repeated if more than one zone undergoes continuous feed. This block is only required if INFD $>0$.

12\$\$ IDNUM Identification of the element or isotope with continuous feed. [ISOZO].

13** XFEED Feed rates in g-atoms (moles) per second. [ISOZO] \{INDFD $>0$ \}.

T End of block \#6.

\section{Example:}

$12 \$ \$ 260000$

13** 1.00E+00 T

This example indicates that natural iron is continuously fed at a rate of $\mathbf{1}$ gatoms/s. 


\section{Block \#7 and \#8:}

Blocks \#7 and \#8 are used to specify the irradiation and post-irradiation temporal history. Here, the user selects the timesteps that will be used to reach the desired irradiation time and the specific post-irradiation (cooling) times at which the full output is generated. ACAB starts its internal clock at zero when the calculation begins. Whenever an irradiation period ends, the clock is reset to zero. Whenever an irradiation period begins, however, the clock is not reset. It continues from the previous cooling period (or zero if the calculation has just begun).

Due to the nature of the computational solution (the matrix exponential method), it is recommended that the irradiation times ramp up by factors of two and the cooling times ramp up by factors of three (see example).

$A$ "set" is defined as a grouping of a $14 \$ \$$ card and a $15^{\star \star}$ card. The $14 \$ \$$ card gives. ACAB information about the number of irradiation and/or cooling timesteps, and the $15^{\text {t* }}$ card provides the actual timesteps. Up to 10 timesteps may be specified within a set. For more than 10 timesteps, multiple sets are required. Each set may consist entirely of irradiation, entirely of cooling, or of irradiation followed by cooling. Since the clock is initially set to zero, only the ending times of the timesteps must be provided.

Sets may be grouped into a "unit" that gets repeated a specified number of times and may be followed by additional sets. The use of units makes the definition of complex irradiation/cooling histories easier. A complete explanation of the use of units is given in Block \#11, Card \#3.

14\$\$ All integer parameters [8]

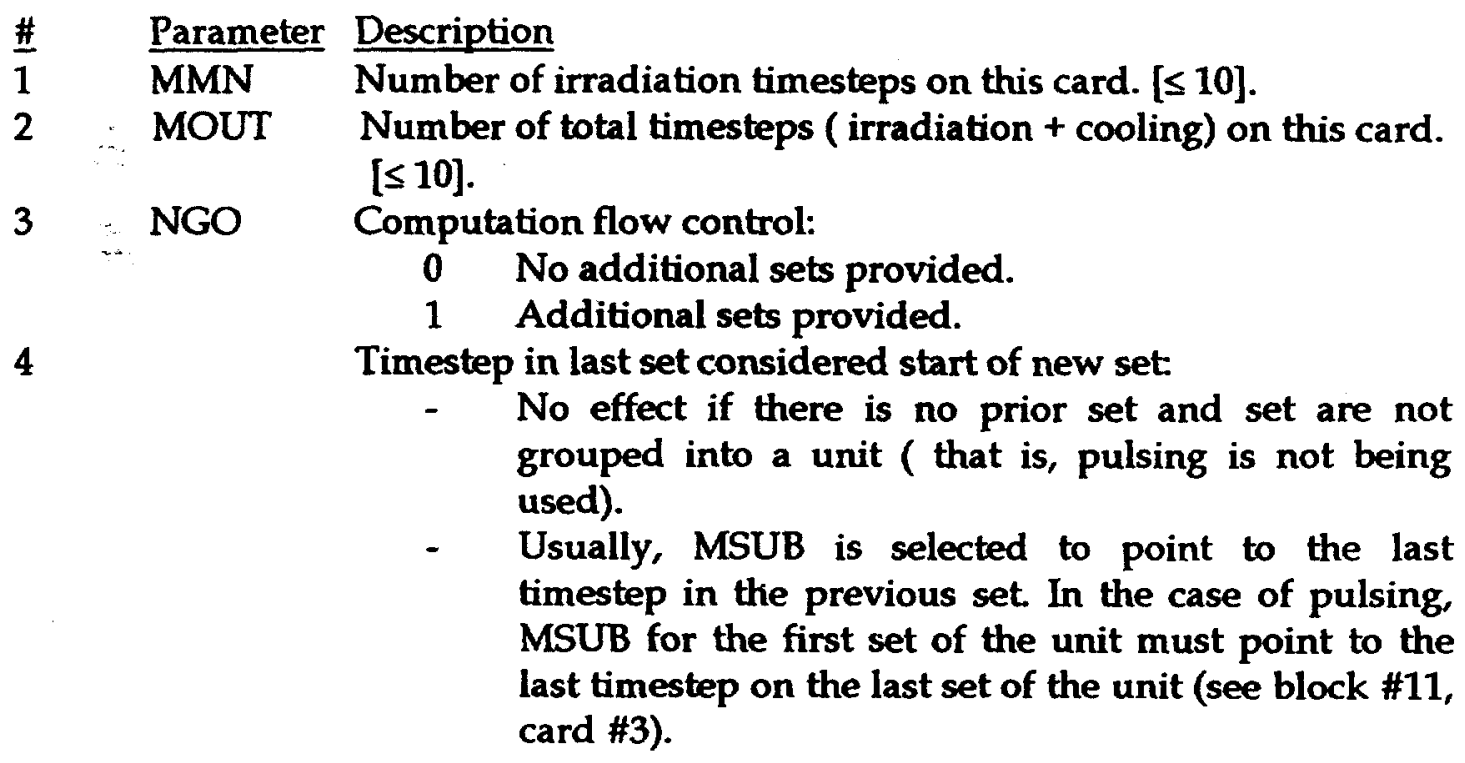


5 IUNIT Physical unit of the timesteps:

1 Seconds

2 Minutes

3 Hours

4 Days

5 Years

$610^{3}$ years

$710^{6}$ years

$810^{9}$ years

6 MFEED Continuous feed option:

0 No effect.

1 Continuous feed used in current set.

7 IOUT Output option:

0 No effect.

1 Print output tables by spatial interval.

8 IPLOT Preparation of data for plotting (generation of unit 11):

0 No effect - unit 11 is not generated.

1 Output tables by interval.

2 Output tables by zone.

T End of block \#7.

15* TIMES Ending times of each timestep. Note that the clock is set to zero when the calculation begins and is reset to zero whenever an irradiation period ends (shutdown). [MOUT].

T End of block \#8.

Blocks \#7 and \#8 must be repeated for all time sets of interes.

Example:

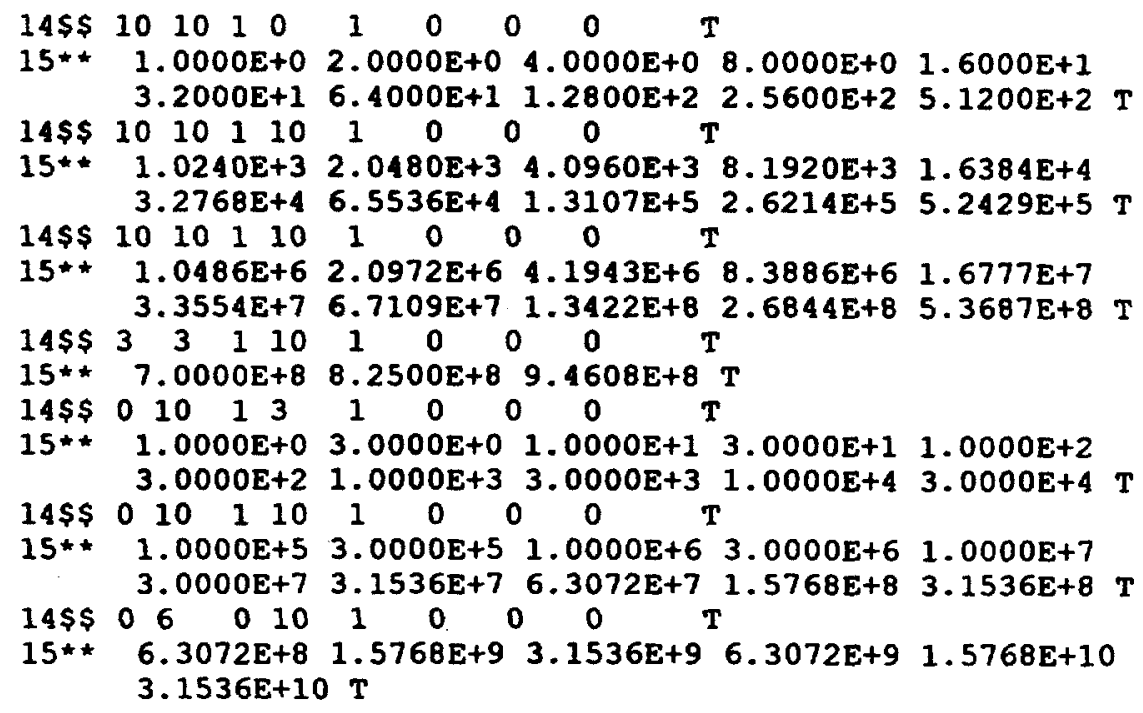


In this example, the irradiation lasts for a total of $9.4608 \times 10^{8}$ seconds years). The irradiation timesteps ramp up by factors of 2 from 1 second to 30 years. The last irradiation time occurs on the $4^{\text {th }}$ set. The cooling times begin on the $5^{\text {th }}$ set and increase in most cases by factors of 3 . Occasionally, the ratio between two cooling times is less than 3 , because a specific cooling time is desired. For example, the $6^{\text {th }}$ set has successive cooling times of $3.0 \times 10^{7}$ seconds and $3.1536 \times 10^{7}$ seconds. The latter time was selected as it corresponds to 1 year of cooling.

In this example, the irradiation and cooling times were kept on separate cards in order to make them easier to understand. This is not required. The first 7 cooling times from the $5^{\text {th }}$ set could have been placed on the end of the $4^{\text {th }}$ set. This results in the $4^{\text {th }}$ set looking like this:

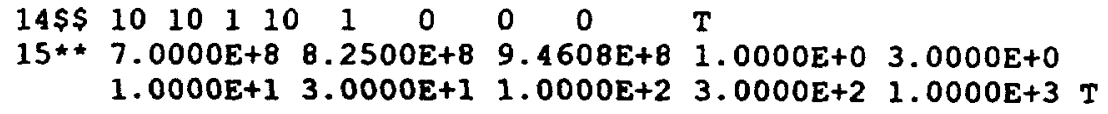

Note that the cooling times are still given relative to the end of the irradia-tion period, because the clock is reset to zero when the irradiation period ends. Also, attention must be paid to the fact that each $14 \$ \$$ card and each $15^{* 4}$ card must end with a "T" as they constitute individual blocks of input data. 


\section{Block \#9:}

Block \#9 tells $\mathrm{ACAB}$ what truncation error is allowable and allows the user to scale the total flux (so that all of the fluxes don't have to be multiplied by $75 \%$, for example).

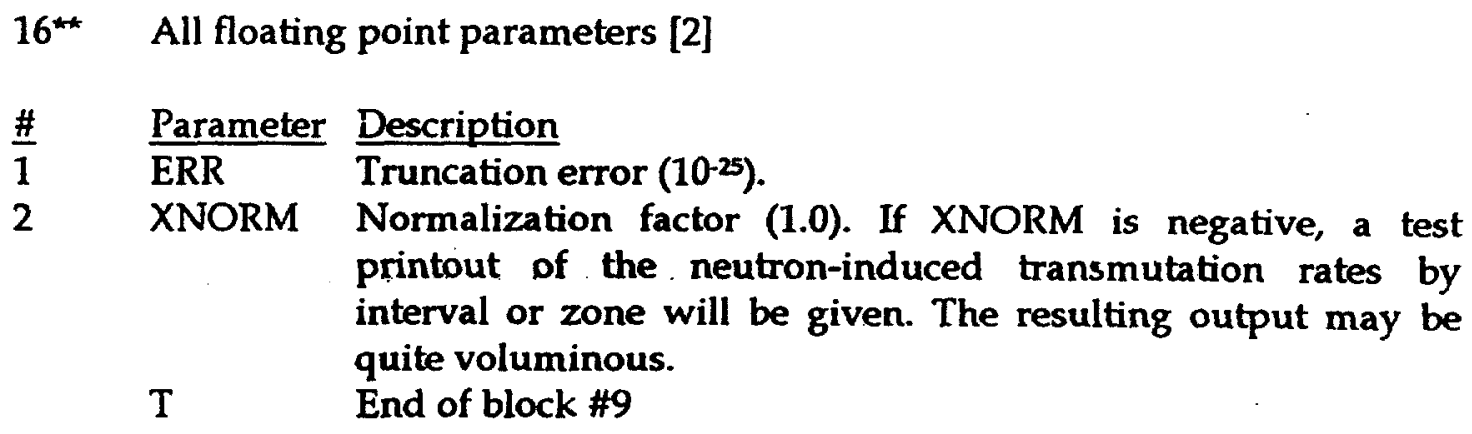
printout of the neutron-induced transmutation rates by interval or zone will be given. The resulting output may be $\mathrm{T}$ quite voluminous.

T End of block \#9

Example:

$16 * 1.0 \mathrm{E}-25 \quad 7.50 \mathrm{E}-01 \mathrm{~T}$

This example uses the standard truncation error, but tells ACAB to scale all of the fluxes by a factor of 0.75 . This might be done if the user desired to simulate $\mathbf{4 0}$ years of operation at $75 \%$ of capacity, for example. 


\section{Block \#10:}

The FORTRAN free format is used to read block \#10. This block is used to control the computing of fission product inventory.

\section{Card \#1:}

\# Parameter Description

1 IGFP Option to calculate the inventory of fission products if actinides were initially present.

0 No effect. All nuclear reactions, including fission, are considered in the calculation. But fission yield data are assumed to be zero (UNIT 96 is not read).

1 Fission products are included in inventory calculations. (UNIT 96 must be given).

2 IWFYD Type of effective fission yield cross section library (UNIT 96). No effect if IGFP is equal to zero.

0 Weighted fission yield cross sections for all fissionables nuclides included in the basic fission yield data library (JEF-2.2) are read.

1 Effective fission yield cross sections for all fissionable nuclides included in the activation library (UNIT 4) are read.

Example \#1:

11

This card tells ACAB to read UNIT 96 that includes fission yield cross sections from all the fissionable nuclides in the activation library.

Example \#2:

$0 \quad 1$

The UNIT 96 is not read, so ACAB does not deal with fission products. It doesn «t matter the value of the second parameter. 


\section{Block \#11:}

The four cards are read by ACAB as FORTRAN free format. These cards tell $A C A B$ about the type of run (for pathway analysis or inventory calculations) and type of output desired and allow the user to define the operational scenario (irradiation/cooling history) in terms of a "unit".

\section{Card \#1:}

$\frac{\text { \# }}{1} \quad \frac{\text { Parameter }}{\text { IWP }} \frac{\text { Description }}{\text { Type of ACA }}$

1 Reading and processing of the decay and cross section libraries. Transition matrix information and some contents from the decay library ( such as decay heat, natural isotopic abundances, etc) are written in UNIT 31. This unit can be read from inputs files with IWP=3. $A C A B$ can make a run for inventory calculation if the second parameter of this card IMTX, is not equal to 1 .

2 Reading UNIT 31, previously generated in runs with IWP $=1$. Decay and cross sections libraries are not required as inputs. $\mathrm{ACAB}$ can proceed for inventory calculations if IMTX is not equal to 1.

3 Run for pathway analysis. Generates unit 22 which gives the number of nuclides on the decay library, the number of non-zero terms on the transition matrix, parents and processes by which the different isotopes are produced. $A C A B$ execution stops after unit 22 is written. This file is required for operation of the CHAINS code (see Section VIII).

2 IMTX

Transition matrix option. Generation of UNIT 24:

- Run for inventory calculation. No generation of UNIT 24

1 Run for pathway analysis. Generates unit 24 which contains the elements of the transition matrix. ACAB execution stops after unit 24 is written. This file is required for operation of the CHAINS code (see Section VIII).

2 Run for pathway analysis and inventory. Unit 24 is generated, but $\mathrm{ACAB}$ execution continues for a full inventory run.

3 IWDR Isotopic Waste Disposal Ratings:

$0 \quad$ No effect.

1 Generates total and isotope-dependent Waste 
4 IDOSE Dose rate requests:

0 No effect.

1 Dose rates estimates are requested - an additional input line must appear.

5 IPHCUT Photon energy cutoff options:

0 Only include photons with energies $>100 \mathrm{keV}$

1 Use full energy range for photons 


\section{Card \#2:}

Card \#2 only appears if IDOSE = 1 . Card \#2 is used to specify what type of dose rate estimates are desired. Three of the calculated dose rates are contact dose rates that would be experienced at the surface of a semi-infinite media that contained radionuclides in the calculated concentrations. The fourth dose rate is calculated for a very thin layer of material that contains radionuclides in the calculated concentrations.

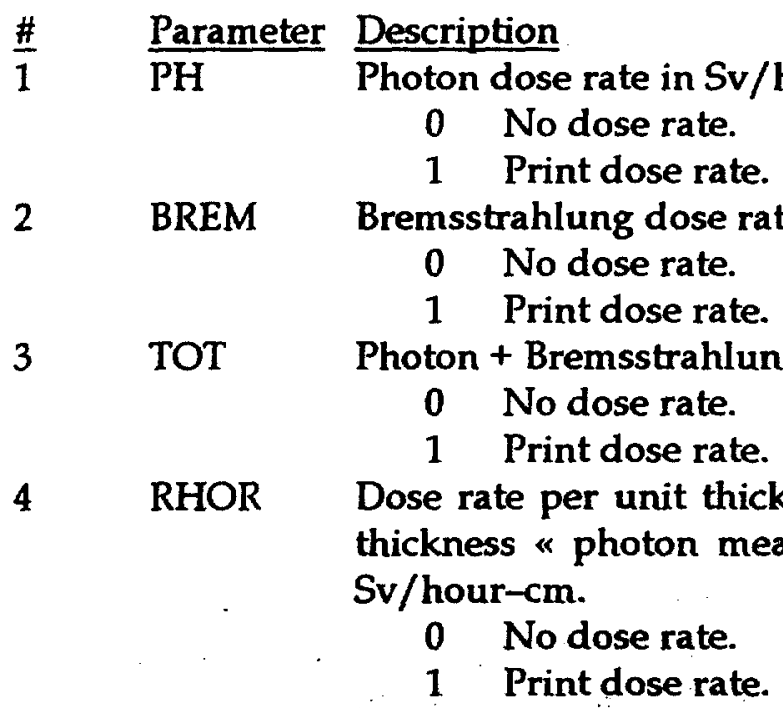

\section{Card \#3:}

When IDOSE $=0$, card \#2 will not appear, and thus, card \#3 will immediately follow card \#1. Complicated irradiation/cooling histories can often be simulated by defining a "unit" of sets that gets repeated a specified number of times. This unit can be followed by additional sets. Figure 3 demonstrates the concept of defining a unit. Card \#3 must be specified even when the unit will not be repeated.

\footnotetext{
\# Parameter Description

1 NOPUL Number of times to repeat the unit.

2 NTSEQ Number of sets within a unit.

3 NOTTS Total number of sets. \{ NOTTT $<150\}$

4 NVFL Flux scaling factors that allow the reference flux for each set to be scaled.

o Flux scaling factors not used.

1 Flux scaling factors are used and are given on the FVAR variable on card \#4.
} 


\section{Card \#4:}

When NVFL $=1$, the FVAR variable will be given to specify irradiation scaling factors for each irradiation period.

\begin{tabular}{|c|c|}
\hline Parameter & Description \\
\hline FVAR & $\begin{array}{l}\text { Flux scaling factor for each set in the unit and for additional } \\
\text { sets that follow the unit [NOTTS]. FVAR is only required } \\
\text { if the scaling factors are different from unity For } \\
\text { pure "cooling" sets FVAR may take any value. }\end{array}$ \\
\hline
\end{tabular}

Example \#1:

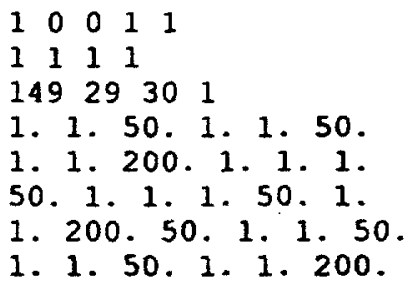

This example requests each of the four dose rates using the full range of photon energies. 29 sets are defined as a unit. The unit is repeated 149 times (149 repetitions + original loop $=150$ total times through the unit) and followed by a final set ( 30 total sets). The specified flux is to be multiplied by factors of 1,50 , and 200 for the various irradiation periods. The flux of the final set is to be multiplied by a factor of 200 ( 30 scaling factors are given as there are 30 sets). The listing of sets for this example appears in Section VI.

Example \#2:

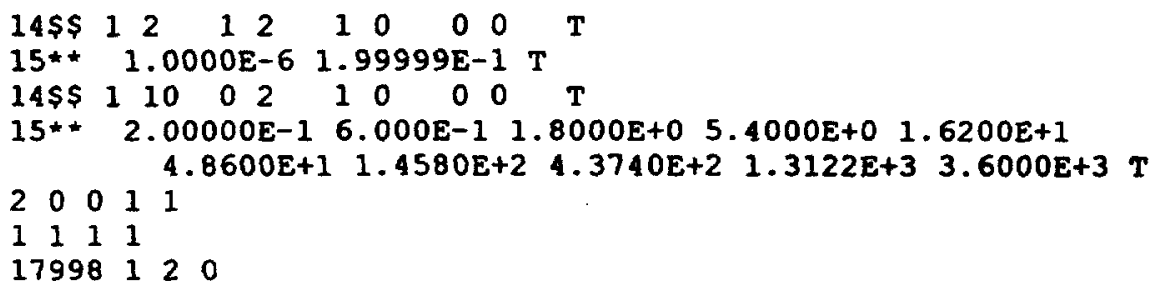

In this example, the sets have been shown to provide a full explanation. The first set is defined as a unit. In this case, irradiation takes place over $1 \mu s$, followed by nearly $200 \mathrm{~ms}$ of cooling. The unit gets repeated 17998 times for a total of 17999 irradiation/cooling cycles. A final set gives another $1 \mu$ s of irradiation and is followed by a series of cooling times. Since each of the irradiations is to use the same flux, NVFL = 0 and card \#4 is not required. 
Note that MSUB = 2 for the first set. This is necessary as each new irradiation will follow the cooling timestep in the previous loop. Also note that the irradiation time on the final set is given as $\mathbf{0 . 2}$ seconds. This is done, because the irradiation begins when the cooling ends at 0.199999 seconds in the previous set. The irradiation ending time of 0.2 seconds results in the final irradiation lasting for 1 $\mu s$.

Example \#2 simulates the operation of a Inertial Fusion Energy (IFE) power plant that is operating at $5 \mathrm{~Hz}$ for 1 hour. 
VI. Example problems.

Some examples of the exact text of the entire $A C A B$ input file are now given. Following the text, a description of the input is given for each example.

The first example demostrates how ACAB handle problems with different zones, and a pulsing irradiation scenario. The modelling of this irradiation schedule by using time sets grouped into a unit and flux scaling factors is shown.

Example \#1:

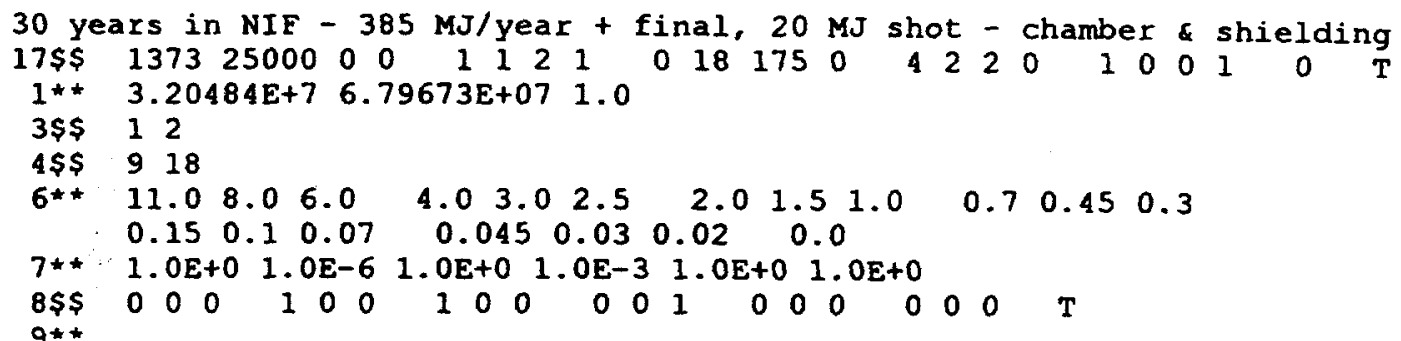
$9 *$

$.00000 \mathrm{E}+00$ $.00000 E+00$ $.00000 E+00$ $000 \mathrm{E}+00$ $.00000 E+00$ $.00000 \mathrm{E}+00 \quad .00000 \mathrm{E}+00$ $.00000 E+00$ $.00000 E+00 \quad .00000 E+00$ $.00000 E+00$ $.00000 \mathrm{E}+00$ $.00000 \mathrm{E}+00$ $.00000 E+00 \quad 3.75283 E+09 \quad 1.06790 E+09$ $.00000 \mathrm{E}+00$ $.00000 \mathrm{E}+00$ $.00000 E+00$ $2.41546 E+08 \quad 1.64104 E+08$ $\begin{array}{lllllll}3.84590 \mathrm{E}+08 & 1.64365 \mathrm{E}+08 & 3.92236 \mathrm{E}+08 & 1.74657 \mathrm{E}+08 & 2.94620 \mathrm{E}+08 & 1.35003 \mathrm{E}+08\end{array}$ $2.25813 E+08 \quad 1.00259 E+08 \quad 2.60161 E+08 \quad 1.14627 E+08 \quad 2.06422 E+08 \quad 8.98104 E+07$

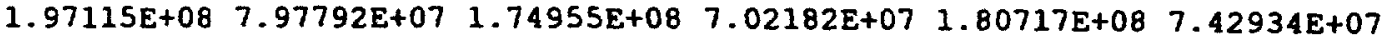
$\begin{array}{llllllll}1.56673 E+08 & 6.05528 E+07 & 1.85038 E+08 & 6.75537 E+07 & 1.65204 E+08 & 6.31651 E+07\end{array}$ $\begin{array}{llllll}1.38058 E+08 & 5.96646 \mathrm{E}+07 & 1.52241 \mathrm{E}+08 & 6.72402 \mathrm{E}+07 & 1.69858 \mathrm{E}+08 & 9.00193 \mathrm{E}+07\end{array}$ $\begin{array}{lllllll}1.62767 E+08 & 9.35198 E+07 & 1.60108 E+08 & 8.82952 E+07 & 2.08528 E+08 & 1.05223 E+08\end{array}$ $\begin{array}{llllll}1.92572 E+08 & 1.04753 E+08 & 2.63707 E+08 & 1.30249 E+08 \quad 2.42100 E+08 & 1.15985 E+08\end{array}$ $\begin{array}{llllll}2.84870 E+08 & 1.28315 E+08 & 3.34619 E+08 & 1.40907 E+08 & 3.03152 E+08 & 1.29047 E+08\end{array}$ $\begin{array}{llllll}3.66419 \mathrm{E}+08 & 1.39705 \mathrm{E}+08 & 4.11183 \mathrm{E}+08 & 1.56006 \mathrm{E}+08 & 4.53620 \mathrm{E}+08 & 2.06475 \mathrm{E}+08\end{array}$ $\begin{array}{llllll}5.78825 E+08 & 2.89493 E+08 & 5.55778 E+08 & 2.84791 E+08 & 7.95108 E+08 & 4.07725 E+08\end{array}$ $\begin{array}{llllll}7.68073 E+08 & 3.44926 E+08 & 8.37434 E+08 & 3.08563 E+08 & 1.01416 E+09 & 3.58510 E+08\end{array}$ $1.10435 E+09 \quad 3.91059 E+08 \quad 1.24540 E+09 \quad 4.57359 E+08 \quad 1.40274 E+09 \quad 4.45708 E+08$ $\begin{array}{llllll}1.52573 E+09 & 4.01926 \mathrm{E}+08 & 1.92129 \mathrm{E}+09 & 4.29407 \mathrm{E}+08 & 1.71520 \mathrm{E}+09 & 6.37398 \mathrm{E}+08\end{array}$ $2.55618 E+09 \quad 8.18168 E+08 \quad 2.94288 E+09 \quad 9.70203 E+08 \quad 2.34344 E+09 \quad 5.65298 E+08$ $1.70966 \mathrm{E}+09 \quad 3.15460 \mathrm{E}+08 \quad 1.67864 \mathrm{E}+09 \quad 4.00307 \mathrm{E}+08 \quad 1.45149 \mathrm{E}+09 \quad 4.54799 \mathrm{E}+08$ $9.49233 \mathrm{E}+08 \quad 2.87247 \mathrm{E}+08 \quad 1.93126 \mathrm{E}+09 \quad 4.23765 \mathrm{E}+08 \quad 1.52241 \mathrm{E}+09 \quad 4.96752 \mathrm{E}+08$ $\begin{array}{llllll}1.39942 E+09 & 4.01508 E+08 & 2.67141 E+09 & 1.11701 E+09 & 3.42597 E+09 & 9.25271 E+08\end{array}$ $\begin{array}{lllllll}5.52122 E+08 & 4.02344 E+08 & 1.50246 E+09 & 4.72824 E+08 & 2.73346 E+09 & 5.97168 E+08\end{array}$ $\begin{array}{lllllll}1.86478 E+09 & 5.59029 E+08 & 9.18873 E+08 & 4.33221 E+08 & 3.09689 E+08 & 3.77684 E+08\end{array}$ $\begin{array}{llllll}2.19940 E+09 & 5.64776 E+08 & 2.36228 E+09 & 6.40532 E+08 & 1.94345 E+09 & 7.87865 E+08\end{array}$ $\begin{array}{llllll}1.77836 E+09 & 8.76160 E+08 & 1.26092 E+09 & 6.68223 E+08 & 9.95437 E+08 & 5.65821 E+08\end{array}$ $\begin{array}{lllllll}1.20773 E+09 & 6.50459 E+08 & 4.24479 E+08 & 2.32284 E+08 & 4.38994 E+08 & 2.31605 E+08\end{array}$ $4.18052 E+08 \quad 1.95399 E+08 \quad 3.75394 E+08 \quad 1.88816 E+08 \quad 4.11737 E+08 \quad 3.43829 E+08$ $\begin{array}{lllllll}5.88021 E+08 & 3.72669 E+08 & 6.92728 E+08 & 3.85469 E+08 & 7.32506 E+08 & 4.08143 E+08\end{array}$ $\begin{array}{lllllll}7.39929 E+08 & 4.39491 E+08 & 5.01375 E+08 & 2.93046 E+08 & 3.44480 E+08 & 2.02034 E+08\end{array}$ $\begin{array}{lllllll}5.17884 E+08 & 3.06891 E+08 & 3.94119 E+08 & 2.36830 E+08 & 1.75620 E+08 & 1.06999 E+08\end{array}$ $2.14068 \mathrm{E}+08 \quad 1.31920 \mathrm{E}+08 \quad 4.01321 \mathrm{E}+08 \quad 2.51041 \mathrm{E}+08 \quad 1.91686 \mathrm{E}+08 \quad 1.17919 \mathrm{E}+08$ $\begin{array}{llllll}6.51621 E+08 & 4.19429 E+08 & 2.72460 E+08 & 2.99054 E+08 & 4.88633 E+08 & 3.42993 E+08\end{array}$ $9.10674 \mathrm{E}+08 \quad 5.40221 \mathrm{E}+08 \quad 1.69747 \mathrm{E}+08 \quad 1.00259 \mathrm{E}+08 \quad 1.67420 \mathrm{E}+08 \quad 1.03499 \mathrm{E}+08$ $\begin{array}{lllllll}1.69858 E+08 & 1.04753 E+08 & 1.73293 E+08 & 1.08149 E+08 & 1.76506 E+08 & 1.11963 E+08\end{array}$ $\begin{array}{lllll}1.78168 \mathrm{E}+08 & 1.14157 \mathrm{E}+08 \quad 2.22489 \mathrm{E}+08 \quad 1.41586 \mathrm{E}+08 \quad 1.48030 \mathrm{E}+08 \quad 9.76995 \mathrm{E}+07\end{array}$ 
$\begin{array}{lllll}1.90689 \mathrm{E}+08 & 1.24502 \mathrm{E}+08 \quad 1.98666 \mathrm{E}+08 \quad 1.27688 \mathrm{E}+08 & 2.01769 \mathrm{E}+08 \quad 1.33018 \mathrm{E}+08\end{array}$ $\begin{array}{lllll}2.08528 E+08 & 1.37249 E+08 & 1.29194 E+08 \quad 8.43768 E+07 & 4.13731 E+07 & 2.80873 E+07\end{array}$ $8.63251 \mathrm{E}+07 \quad 5.90376 \mathrm{E}+07 \quad 8.55163 \mathrm{E}+07 \quad 5.86719 \mathrm{E}+07 \quad 8.90176 \mathrm{E}+07 \quad 6.00303 \mathrm{E}+07$

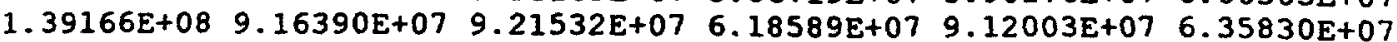
$\begin{array}{llllll}4.64256 \mathrm{E}+07 & 3.21572 \mathrm{E}+07 & 9.55770 \mathrm{E}+07 & 6.40532 \mathrm{E}+07 & 1.47809 \mathrm{E}+08 & 9.95803 \mathrm{E}+07\end{array}$ $\begin{array}{llllll}4.76999 \mathrm{E}+07 & 3.30506 \mathrm{E}+07 & 1.53570 \mathrm{E}+08 & 1.02558 \mathrm{E}+08 & 4.96610 \mathrm{E}+07 & 3.47382 \mathrm{E}+07\end{array}$ $\begin{array}{llllll}1.02912 \mathrm{E}+08 & 6.99047 \mathrm{E}+07 & 1.02546 \mathrm{E}+08 & 7.13676 \mathrm{E}+07 & 1.60329 \mathrm{E}+08 & 1.09611 \mathrm{E}+08\end{array}$ $5.31402 \mathrm{E}+07 \quad 3.71676 \mathrm{E}+07 \quad 1.62656 \mathrm{E}+08 \quad 1.13060 \mathrm{E}+08 \quad 1.10081 \mathrm{E}+08 \quad 7.75849 \mathrm{E}+07$ $\begin{array}{lllllll}1.14125 \mathrm{E}+08 \quad 7.92045 \mathrm{E}+07 \quad 1.18446 \mathrm{E}+08 & 8.07196 \mathrm{E}+07 \quad 6.01761 \mathrm{E}+07 \quad 4.07934 \mathrm{E}+07\end{array}$ $\begin{array}{llllll}1.81049 \mathrm{E}+08 \quad 1.25546 \mathrm{E}+08 \quad 6.15500 \mathrm{E}+07 & 4.27892 \mathrm{E}+07 \quad 1.25094 \mathrm{E}+08 \quad 8.69891 \mathrm{E}+07\end{array}$ $\begin{array}{lllll}1.26092 \mathrm{E}+08 & 8.88699 \mathrm{E}+07 \quad 1.92905 \mathrm{E}+08 \quad 1.35996 \mathrm{E}+08 \quad 2.04317 \mathrm{E}+08 \quad 1.41168 \mathrm{E}+08\end{array}$ $2.06755 \mathrm{E}+08 \quad 1.46967 \mathrm{E}+08 \quad 1.44263 \mathrm{E}+08 \quad 1.01513 \mathrm{E}+08 \quad 7.12562 \mathrm{E}+07 \quad 5.04328 \mathrm{E}+07$ $1.47144 \mathrm{E}+08 \quad 1.05641 \mathrm{E}+08 \quad 1.54567 \mathrm{E}+08 \quad 1.08514 \mathrm{E}+08 \quad 1.60662 \mathrm{E}+08 \quad 1.10343 \mathrm{E}+08$ $\begin{array}{llllll}1.60662 \mathrm{E}+08 \quad 1.13687 \mathrm{E}+08 \quad 2.50078 \mathrm{E}+08 & 1.77217 \mathrm{E}+08 \quad 2.64039 \mathrm{E}+08 \quad 1.85995 \mathrm{E}+08\end{array}$ $\begin{array}{llllll}1.78611 E+08 & 1.27897 E+08 & 2.81546 \mathrm{E}+08 & 2.02452 \mathrm{E}+08 & 1.90578 \mathrm{E}+08 & 1.40854 \mathrm{E}+08\end{array}$ $\begin{array}{llllll}3.05479 \mathrm{E}+08 & 2.19954 \mathrm{E}+08 \quad 4.41764 \mathrm{E}+08 & 3.23453 \mathrm{E}+08 & 3.41710 \mathrm{E}+08 & 2.52242 \mathrm{E}+08\end{array}$ $\begin{array}{llllll}3.64203 E+08 & 2.73715 E+08 & 5.28853 E+08 & 3.94142 E+08 & 4.34783 E+08 & 3.22617 \mathrm{E}+08\end{array}$ $\begin{array}{llllllll}4.47636 E+08 & 3.42157 E+08 & 6.86745 E+08 & 5.24024 E+08 & 5.92453 E+08 & 4.60703 E+08\end{array}$ $\begin{array}{lllllll}6.21372 E+08 & 4.84213 E+08 & 7.30511 E+08 & 5.77315 E+08 & 5.44144 E+08 & 4.39177 E+08\end{array}$ $9.35383 E+08 \quad 7.70102 E+08 \quad 7.73835 E+08 \quad 6.50459 E+08 \quad 3.65865 E+08 \quad 3.20736 E+08$ $4.38883 E+08 \quad 3.88133 E+08 \quad 4.83093 E+08 \quad 4.30714 E+08 \quad 5.25640 E+08 \quad 4.83795 E+08$ $\begin{array}{lllllll}5.70847 E+08 & 5.48057 E+08 & 6.32896 E+08 & 6.46279 E+08 & 6.90512 E+08 & 7.43456 E+08\end{array}$

$\begin{array}{llllll}3.68414 \mathrm{E}+08 & 4.27945 \mathrm{E}+08 & 9.56102 \mathrm{E}+09 & 1.69328 \mathrm{E}+10 & .00000 \mathrm{E}+00 \quad .00000 \mathrm{E}+00\end{array}$ T $.00000 \mathrm{E}+00 \quad .00000 \mathrm{E}+00$

0 IREST

$10 \$ \$ 120000130000140000220000240000$ 250000260000290000300000

11 * 2.944E-03 5.632E-02 2.316E-04 5.093E-05 4.691E-05 $2.072 E-04 \quad 1.165 E-042.559 E-05 \quad 6.218 E-05$ T

$10 \$ \$ 100005000060000 \quad 80000110000$ 120000130000140000190000200000 210000220000240000250000260000 280000290000300000

$11 * 1.304 E-02 \quad 8.070 E-04 \quad 1.094 E-04 \quad 4.345 E-02 \quad 9.146 E-04$ $2.337 E-04 \quad 4.059 E-03 \quad 1.578 E-02 \quad 4.369 E-04 \quad 1.443 E-03$ 2.923E-05 2.961E-05 2.001E-06 8.839E-06 3.344E-04 $2.239 E-05 \quad 1.092 E-06 \quad 2.653 E-05 T$

'Define unit as 29 shots

Unit time length is 72 days $=20 \times 1.25+7 \times 5.0+2 \times 6.0$

- Repeat unit 150 times to get 30 years

' shot \#1 - $100 \mathrm{~kJ}+1.25$ days cooling

$14 \$ \$ 241410000 \quad T$

$15 *$ 5.0000E-1 $1.0000 E+0 \quad 6.4800 E+41.0800 E+5 T$

' Shot \#2 - $100 \mathrm{~kJ}+1.25$ days cooling

$14 \$ \$ 2441410000$ T

$15 * * 10.80005 \mathrm{E}+410.80010 \mathrm{E}+46.4800 \mathrm{E}+41.0800 \mathrm{E}+5 \mathrm{~T}$

'Shot \#3 - $5 \mathrm{MJ}+5.0$ days cooling

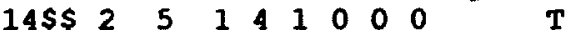

$15 * 10.80005 \mathrm{E}+4 \quad 10.80010 \mathrm{E}+4 \quad 8.6400 \mathrm{E}+4 \quad 2.5920 \mathrm{E}+5 \quad 4.3200 \mathrm{E}+5 \mathrm{~T}$

' Shot \#4 - $100 \mathrm{~kJ}+1.25$ days cooling

$14 \$ \$ 241510000 \quad T$

$15 *$ *3.20005E+4 43.20010E+4 6.4800E+4 1.0800E+5 T

' Shot $\# 5$ - $100 \mathrm{~kJ}+1.25$ days cooling

$14 \$ \$ 241410000$ T

$15 * \star 10.80005 \mathrm{E}+4 \quad 10.80010 \mathrm{E}+46.4800 \mathrm{E}+4 \quad 1.0800 \mathrm{E}+5$ T

'Shot \#6 - $5 \mathrm{MJ}+5.0$ days cooling

$14 \$ \$ 251410000 \quad T$

$15 * * 10.80005 E+4 \quad 10.80010 E+4$ 8.6400E+4 2.5920E+5 4.3200E+5 T

'Shot \#7 - $100 \mathrm{~kJ}+1.25$ days cooling 


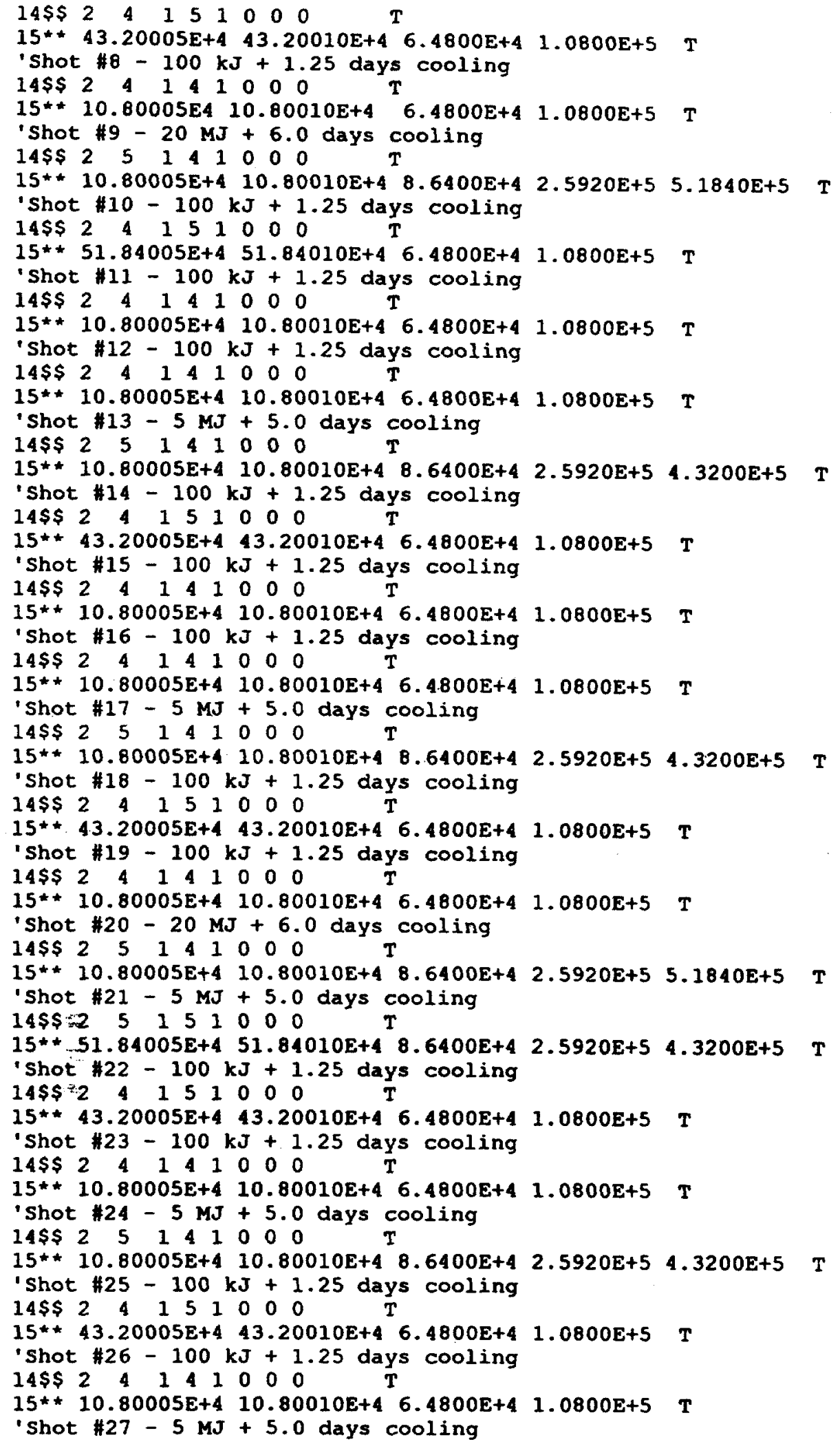




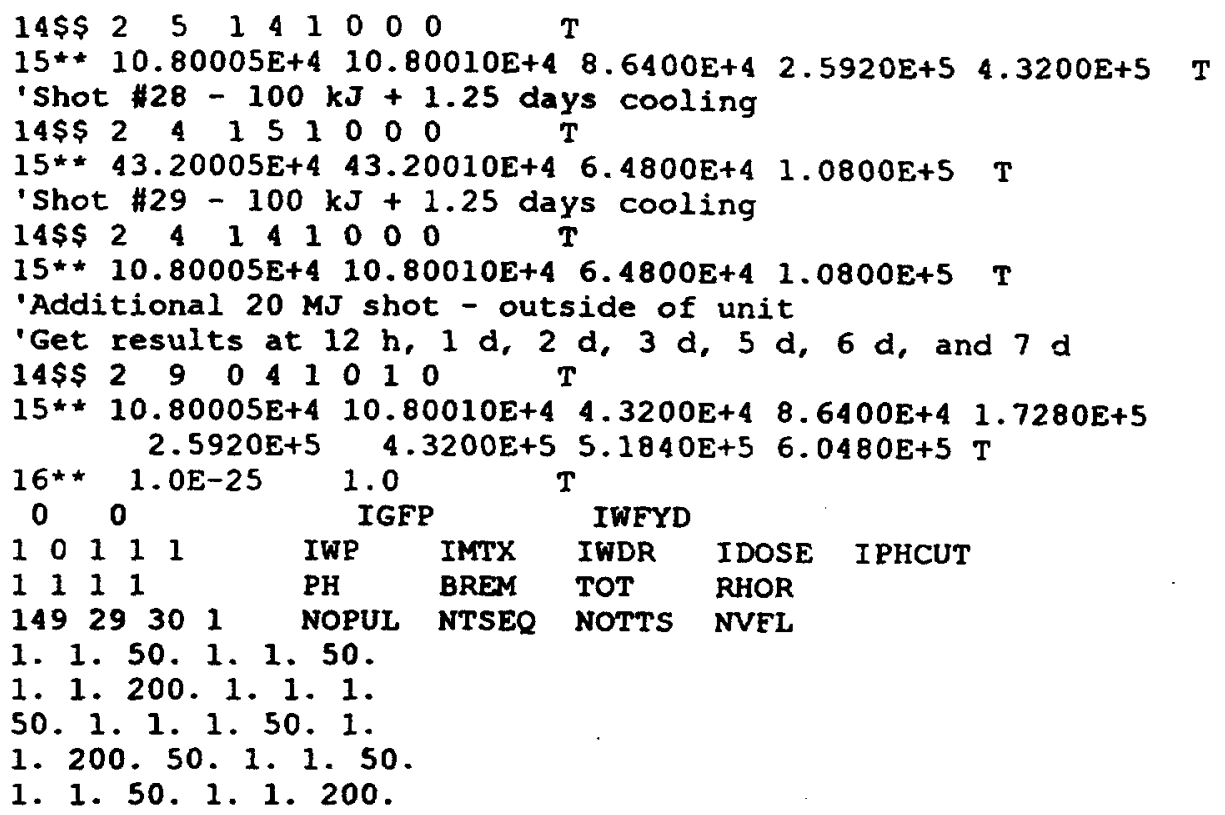

This example problem was used for a calculation of the neutron activation for the National Ignition Facility (NIF) Al-5083 target chamber and inner portion of the concrete (with Al-5083 rebar and boron) shield. The input simulates 30 years of operation of this facility.

The neutron activation is to be calculated for two zones. The zonal volumes are given on the $1^{* *}$ card since Monte Carlo was used for the neutron transport $(\mathrm{IGE}=4)$. The $3 \$ \$$ card specifies that the first zone contains material \#1 and the second contains material \#2. Material \#1 consists of 9 elements, and material \#2 is composed of 18 elements. The $8 \$ \$$ card is used to request the various output tables: grams for all isotopes, activity for all isotopes, and afterheat for the most important isotopes. The $7^{\star \star}$ gives cutoff limits for each of the types of output tables. This card specifies that isotopes will only be included in mass tables if they are present in more than $1 \mu \mathrm{g}$, in activity tables if they have an activity of more than $1 \mathrm{~Bq}$, and in afterheat tables if their decay heat is greater than $1 \mathrm{~mW}$. Dummy values of $\mathbf{1 . 0}$ are specified for the remaining tables (that are not requested as output). The second timestep is used to impose the cutoffs.

The 175-group neutron fluxes are specified using the $9^{\star \star}$ card in descending energy order alternating between the first and second zone (highest energy for zone \#1, highest energy for zone \#2,..., lowest energy for zone \#1, and lowest energy for zone \#2).

A non-restart case is addressed (IREST $=0$ ), then initial composition is read from BLOCK \#5 (cards $10 \$ \$$ and $11^{* *}$ ). The first occurrence of the $10 \$ \$$ and $11^{* *}$ cards gives the composition for Al-5083. The second gives the composition for concrete with Al-5083 rebar and boron. 
Comments are given throughout the input file by placing a single quote (') in the first column of an input line.

A total of 30 sets are given with the first 29 sets being defined as a unit which gets repeated a total of $\mathbf{1 5 0}$ times. Flux scaling factors are used to change to total flux level for each irradiation within the unit and for the final irradiation. The use of the flux scaling factors makes it possible to model $100 \mathrm{~kJ}, 5 \mathrm{MJ}$, and $20 \mathrm{MJ}$ fusion yields on the NIF.

The generation of fission products is not addressed in calculation. (IGFP=0).

$\mathrm{ACAB}$ writes the complete output for one zone before starting another zone. Output tables appear in the order given in Table 15. Tables 16 through 21 are excerpts of the ACAB output for the above example problem. Each output table appears with the isotopes in rows and the various cooling times in columns. If more than 10 cooling times were requested, the first ten would have been given in one table and the remaining times would follow in additional table(s). 
Table16. Example ACAB output. Isotopic masses are given for the NIF Al-5083 target chamber as a function of cooling time after 30 years of operation at $385 \mathrm{MJ}$ /year plus a final, $20 \mathrm{MJ}$ experiment. Isotopes with masses $<1 \mu \mathrm{g}$ at shut-down were omitted from the output.

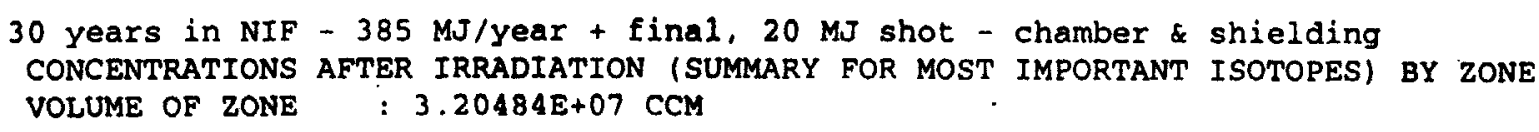


Table17. Example ACAB output. Radionuclide activities are given in disintegrations/second $(\mathrm{Bq})$ for the NIF Al-5083 target chamber as a function of cooling time after 30 years of operation at $385 \mathrm{MJ} /$ year plus a final, 20 $\mathrm{MJ}$ experiment. Isotopes with activities $<1 \mathrm{~Bq}$ at shutdown were omitted from the output.

30 years in NIF - $385 \mathrm{MJ} /$ year + final, $20 \mathrm{MJ}$ shot - chamber \& shielding

CONCENTRATIONS AFTER IRRADIATION (SUMMARY FOR MOST IMPORTANT ISOTOPES) BY ZONE VOLUME OF ZONE $: 3.20484 \mathrm{E}+07 \mathrm{CCM}$

NUCLIDE RADIOACTIVITY, DISINTEGRATIONS/SEC

$$
\text { ZONE } \quad 1
$$

SHUTDOWN 4.320E+04S $\quad 8.640 E+04 S \quad 1.728 E+05 S \quad 2.592 \mathrm{E}+05 \mathrm{~S} \quad 4.320 \mathrm{E}+05 \mathrm{~S} \quad 5.184 \mathrm{E}+05 \mathrm{~S} \quad 6.048 \mathrm{E}+05 \mathrm{~S}$

H $37.84424 E+08 \quad 7.84363 E+08 \quad 7.84303 E+08 \quad 7.84182 E+08 \quad 7.84061 E+08 \quad 7.83820 E+08 \quad 7.83699 E+08 \quad 7.83579 E+08$

$\begin{array}{lllllllllll}0 & 19 & 3.99504 \mathrm{E}+02 & .00000 \mathrm{E}+00 & .00000 \mathrm{E}+00 & .00000 \mathrm{E}+00 & .00000 \mathrm{E}+00 & .00000 \mathrm{E}+00 \quad .00000 \mathrm{E}+00 \quad .00000 \mathrm{E}+00\end{array}$

$\begin{array}{lllllllllll}F & 20 & 2.81782 \mathrm{E}+05 & .00000 \mathrm{E}+00 & .00000 \mathrm{E}+00 & .00000 \mathrm{E}+00 & .00000 \mathrm{E}+00 & .00000 \mathrm{E}+00 & .00000 \mathrm{E}+00 & .00000 \mathrm{E}+00\end{array}$

\begin{tabular}{lllllllllll}
\hline & 21 & $8.59677 \mathrm{E}+04$ & $.00000 \mathrm{E}+00$ & $.00000 \mathrm{E}+00$ & $.00000 \mathrm{E}+00$ & $.00000 \mathrm{E}+00$ & $.00000 \mathrm{E}+00$ & $.00000 \mathrm{E}+00$ & $.00000 \mathrm{E}+00$
\end{tabular}

$\begin{array}{llllllllll}F & 22 & 1.69027 \mathrm{E}+03 & .00000 \mathrm{E}+00 & .00000 \mathrm{E}+00 & .00000 \mathrm{E}+00 & .00000 \mathrm{E}+00 & .00000 \mathrm{E}+00 & .00000 \mathrm{E}+000 & .00000 \mathrm{E}+000\end{array}$

NE $23 \quad 1.90906 \mathrm{E}+13 \quad .00000 \mathrm{E}+00 \quad .00000 \mathrm{E}+00 \quad .00000 \mathrm{E}+00 \quad .00000 \mathrm{E}+00 \quad .00000 \mathrm{E}+00 \quad .00000 \mathrm{E}+000.00000 \mathrm{E}+000$

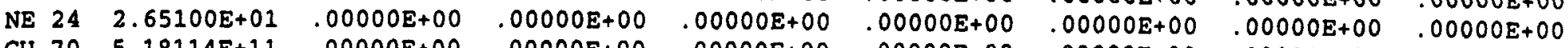

$\begin{array}{lllllllll}\text { CU } 70 & 5.18114 \mathrm{E}+11 & .00000 \mathrm{E}+00 & .00000 \mathrm{E}+00 & .00000 \mathrm{E}+00 & .00000 \mathrm{E}+00 & .00000 \mathrm{E}+00 & .00000 \mathrm{E}+00 & .00000 \mathrm{E}+00\end{array}$

CU 70M 6.21478E+09 $.00000 \mathrm{E}+00 \quad .00000 \mathrm{E}+00 \quad .00000 \mathrm{E}+00 \quad .00000 \mathrm{E}+00 \quad .00000 \mathrm{E}+00 \quad .00000 \mathrm{E}+00 \quad .00000 \mathrm{E}+00$

ZN $63 \quad 1.30176 \mathrm{E}+09 \quad 2.66549 \mathrm{E}+03 \quad 5.45787 \mathrm{E}-03 \quad 2.28831 \mathrm{E}-14 \quad 9.59414 \mathrm{E}-26 \quad .00000 \mathrm{E}+00 \quad .00000 \mathrm{E}+00 \quad .00000 \mathrm{E}+00$

ZN $65 \quad 3.46975 \mathrm{E}+07 \quad 3.46483 \mathrm{E}+07 \quad 3.45992 \mathrm{E}+07 \quad 3.45011 \mathrm{E}+07 \quad 3.44034 \mathrm{E}+07 \quad 3.42088 \mathrm{E}+07 \quad 3.41118 \mathrm{E}+07 \quad 3.40152 \mathrm{E}+07$

ZN $692.51962 E+07 \quad 1.99129 E+04 \quad 8.04600 E+03 \quad 2.40105 E+03 \quad 7.16789 E+02 \quad 6.38810 E+01 \quad 1.90705 E+01 \quad 5.69314 E+00$

ZN 69M 2.50891E+04 $1.37082 E+04 \quad 7.48987 E+03 \quad 2.23596 E+03 \quad 6.67506 E+02 \quad 5.94888 E+01 \quad 1.77593 E+01 \quad 5.30171 E+00$

TOTAL $1.01241 \mathrm{E}+17 \quad 2.44152 \mathrm{E}+12 \quad 1.38891 \mathrm{E}+12 \quad 4.84202 \mathrm{E}+11 \quad 1.78897 \mathrm{E}+11 \quad 3.38985 \mathrm{E}+10 \quad 1.84634 \mathrm{E}+10 \quad 1.15581 \mathrm{E}+10$ 
Table 18. Example ACAB output. Decay heat is given in Watts $(W)$ for the inner portion of the NIF concrete shielding as a function of cooling time after 30 years of operation at $385 \mathrm{MJ} /$ year plus a final, $20 \mathrm{MJ}$ experiment. Isotopes with a decay heat of $<10^{-3} \mathrm{~W}$ at shutdown were omitted from the output.

30 years in NIF - $385 \mathrm{MJ} /$ year + final, $20 \mathrm{MJ}$ shot - chamber shielding CONCENTRATIONS AFTER IRRADIATION (SUMMARY FOR MOST IMPORTANT ISOTOPES) BY ZONE VOLUME OF ZONE : $6.79673 \mathrm{E}+07 \mathrm{CCM}$

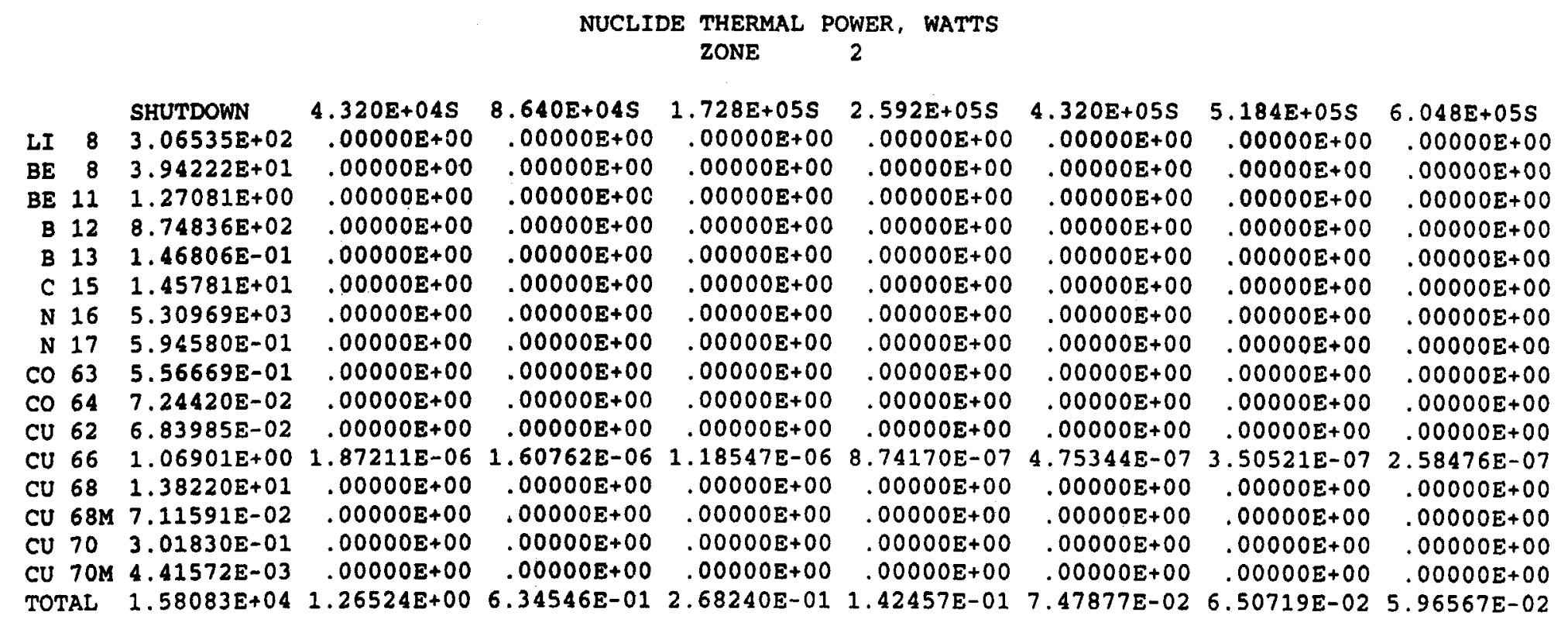


Table 19. Example $A C A B$ output. Contact $\gamma$-ray dose rate from a semi-infinite medium that contains the calculated concentra-tions of each radionuclide is given in Sv/hour for the NIF Al-5083 target chamber as a function of cooling time after 30 years of operation at $385 \mathrm{MJ} /$ year plus a final, $20 \mathrm{MJ}$ experiment. Isotopes that contribute less than $1 \mu \mathrm{Sv} /$ hour at shutdown were omitted from the output.

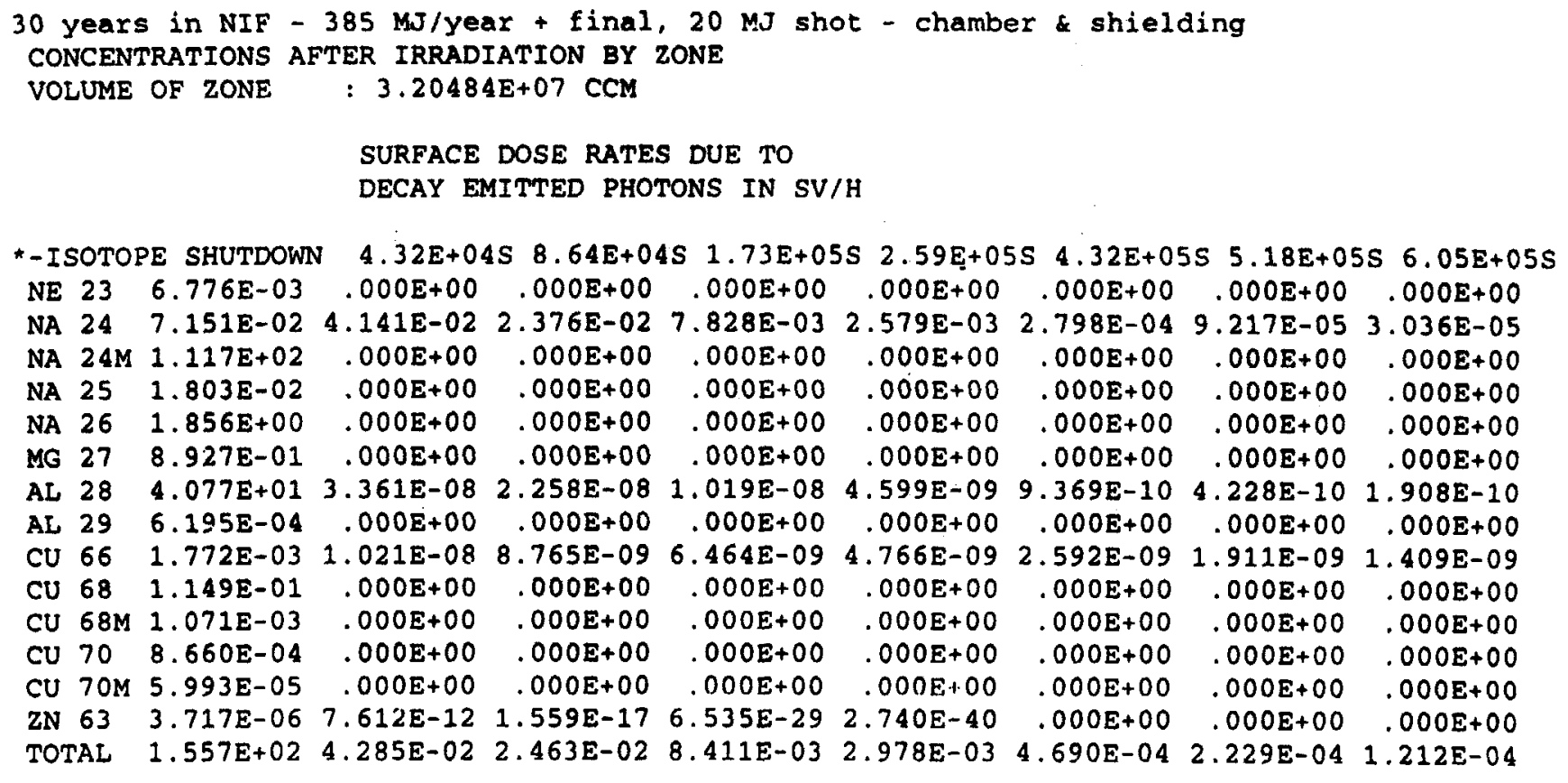


Table 20. Example ACAB output. Contact Bremsstrahlung dose rate from a semi-infinite medium that contains the calculated concentrations of each radionuclide is given in Sv/hour for the inner portion of the NIF concrete shielding as a function of cooling time after 30 years of operation at $385 \mathrm{MJ} / \mathrm{year}$ plus a final, 20 $\mathrm{MJ}$ experiment. Isotopes that contribute less than $1 \mu \mathrm{Sv} /$ hour at shutdown were omitted from the output.

30 years in NIF - $385 \mathrm{MJ} /$ year + final, $20 \mathrm{MJ}$ shot - chamber \& shielding CONCENTRATIONS AFTER IRRADIATION BY ZONE

VOLUME OF ZONE : $6.79673 \mathrm{E}+07 \mathrm{CCM}$

BREMSSTRAHLUNG CONTACT DOSE RATE IN SV/H

\begin{tabular}{|c|c|c|c|c|c|c|c|c|c|}
\hline \multicolumn{2}{|c|}{ ISOTOPE } & SHUTDOWN & $4.32 \mathrm{E}+04 \mathrm{~S}$ & & & & $4.32 E+05 S$ & $5.18 E+05 S$ & $6.05 E+05 S$ \\
\hline LI & 8 & $2.937 \mathrm{E}-01$ & $.000 E+00$ & $.000 E+00$ & $.000 E+00$ & $.000 E+00$ & $.000 \mathrm{E}+00$ & $.000 \mathrm{E}+00$ & $.000 \mathrm{E}+00$ \\
\hline $\mathrm{BE}$ & 11 & $6.144 E-04$ & $.000 \mathrm{E}+00$ & $.000 E+00$ & $.000 \mathrm{E}+00$ & $.000 \mathrm{E}+00$ & $.000 E+00$ & $.000 E+00$ & $.000 \mathrm{E}+00$ \\
\hline B & 12 & $8.167 E-01$ & $.000 \mathrm{E}+00$ & $.000 \mathrm{E}+00$ & $.000 \mathrm{E}+00$ & $.000 \mathrm{E}+00$ & $.000 \mathrm{E}+00$ & $.000 E+00$ & $.000 \mathrm{E}+\mathrm{C}$ \\
\hline B & 13 & $1.366 \mathrm{E}-04$ & $.000 \mathrm{E}+00$ & $.000 \mathrm{E}+00$ & $.000 \mathrm{E}+00$ & $.000 \mathrm{E}+00$ & $.000 \mathrm{E}+00$ & $.000 \mathrm{E}+00$ & \\
\hline C & 15 & $2.183 \mathrm{E}-03$ & $.000 \mathrm{E}+00$ & $.000 E+00$ & $.000 \mathrm{E}+00$ & $.000 \mathrm{E}+00$ & $.000 \mathrm{E}+00$ & $.000 E+00$ & $.000 \mathrm{E}+0$ \\
\hline $\mathrm{N}$ & 16 & $5.995 \mathrm{E}-01$ & $.000 E+00$ & $.000 E+00$ & $.000 \mathrm{E}+00$ & $.000 \mathrm{E}+00$ & $.000 E+00$ & $.000 \mathrm{E}+00$ & $.000 E+00$ \\
\hline $\mathrm{N}$ & 17 & $9.708 \mathrm{E}-05$ & $.000 \mathrm{E}+00$ & $.000 \mathrm{E}+00$ & $.000 \mathrm{E}+00$ & $.000 \mathrm{E}+00$ & $.000 \mathrm{E}+00$ & $.000 \mathrm{E}+00$ & $.000 E+00$ \\
\hline N & 18 & $6.117 \mathrm{E}-05$ & $.000 E+00$ & $.000 \mathrm{E}+00$ & $.000 \mathrm{E}+00$ & $.000 \mathrm{E}+00$ & $.000 \mathrm{E}+00$ & $.000 \mathrm{E}+00$ & $.000 \mathrm{E}+\mathrm{C}$ \\
\hline 0 & 19 & $4.079 E-05$ & $.000 E+00$ & $.000 \mathrm{E}+00$ & $.000 \mathrm{E}+00$ & $.000 E+00$ & $.000 \mathrm{E}+00$ & $.000 E+00$ & $.000 E+0$ \\
\hline $\mathrm{MN}$ & 58 & $1.291 \mathrm{E}-04$ & $.000 E+00$ & $.000 E+00$ & $.000 E+00$ & $.000 \mathrm{E}+00$ & $.000 \mathrm{E}+00$ & $.000 \mathrm{E}+00$ & $.000 \mathrm{E}+00$ \\
\hline MN & $58 M$ & $5.288 E-06$ & $.000 \mathrm{E}+00$ & $.000 E+00$ & $.000 E+00$ & $.000 E+00$ & $.000 E+00$ & $.000 \mathrm{E}+00$ & $D E+00$ \\
\hline $\mathrm{CO}$ & $62 M$ & $3.186 \mathrm{E}-05$ & $8.347 E-21$ & $2.187 E-36$ & $.000 \mathrm{E}+00$ & $E+00$ & $.000 E+00$ & $.000 \mathrm{E}+00$ & $.000 E+00$ \\
\hline CO & 63 & $7.755 \mathrm{E}-05$ & $.000 \mathrm{E}+00$ & $.000 \mathrm{E}+00$ & +00 & $E+00$ & $.000 \mathrm{E}+00$ & $.000 \mathrm{E}+00$ & $.000 E+00$ \\
\hline $\mathrm{CO}$ & 64 & $2.854 \mathrm{E}-05$ & $.000 E+00$ & $.000 E+00$ & $.000 \mathrm{E}+00$ & $.000 \mathrm{E}+00$ & $.000 E+00$ & $.000 \mathrm{E}+00$ & $.000 \mathrm{E}+00$ \\
\hline $\mathrm{CU}$ & 62 & $4.242 E-06$ & $.000 \mathrm{E}+00$ & $.000 \mathrm{E}+00$ & $.000 E+00$ & $.000 E+00$ & $.000 \mathrm{E}+00$ & $.000 \mathrm{E}+00$ & $.000 \mathrm{E}+00$ \\
\hline $\mathrm{CU}$ & 66 & $8.330 E-05$ & $1.459 \mathrm{E}-10$ & $1.253 \mathrm{E}-10$ & $9.238 \mathrm{E}-11$ & $6.812 E-11$ & $3.704 \mathrm{E}-11$ & $2.731 \mathrm{E}-11$ & $2.014 \mathrm{E}-1$ \\
\hline $\mathrm{CU}$ & 68 & $1.273 \mathrm{E}-03$ & $.000 E+00$ & $.000 \mathrm{E}+00$ & $.000 E+00$ & $.000 E+00$ & $.000 E+00$ & $.000 E+00$ & $.000 E+00$ \\
\hline $\mathrm{CU}$ & 70 & $8.416 \mathrm{E}-05$ & $.000 \mathrm{E}+00$ & $.000 \mathrm{E}+00$ & $.000 \mathrm{E}+00$ & $.000 \mathrm{E}+00$ & $.000 \mathrm{E}+00$ & $.000 E+00$ & $.000 \mathrm{E}+00$ \\
\hline TOT & & $1.805 \mathrm{E}+00$ & $1.141 E-05$ & $3.705 E-06$ & $1.082 \mathrm{E}-06$ & $3.483 E-07$ & $4.643 E-08$ & $2.080 \mathrm{E}-08$ & $1.094 \mathrm{E}-0$ \\
\hline
\end{tabular}


Table 21. Example ACAB output. Calculated $\gamma$-ray spectrum is given in photons $/ \mathrm{cm}^{3} / \mathrm{second}$ in each of the 18 groups specified on the $6^{* *}$ card. The spectrum was calculated for the NIF Al-5083 target chamber as a function of cooling time after 30 years of operation at $385 \mathrm{MJ} /$ year plus a final, $20 \mathrm{MJ}$ experiment. The spectrum can be used for subsequent photon transport to obtain a more accurate estimate of the target chamber dose rate.

30 years in NIF - $385 \mathrm{MJ} /$ year + final, $20 \mathrm{MJ}$ shot - chamber \& shielding ACTIVATION GAMMA RAY SPECTRUM AS A FUNCTION OF TIME BY ZONE

VOLUME OF ZONE $3.20484 E+07 \mathrm{CCM}$

GROUP PHOTON RELEASE RATES, PHOTONS/CCM/SEC

ZONE 1

\begin{tabular}{lcccccccc} 
EMEAN & \multicolumn{7}{c}{ TIME AFTER SHUTDOWN } \\
(MEV) & SHUTDOWN & $4.32 E+04 S$ & $8.64 E+04 S$ & $1.73 E+05 S$ & $2.59 E+05 S$ & $4.32 E+05 S$ & $5.18 E+05 S$ & $6.05 E+05 S$ \\
$9.50 E+00$ & $7.25 E-17$ & $.00 E+00$ & $.00 E+00$ & $.00 E+00$ & $.00 E+00$ & $.00 E+00$ & $.00 E+00$ & $.00 E+00$ \\
$7.00 E+00$ & $9.10 E-10$ & $.00 E+00$ & $.00 E+00$ & $.00 E+00$ & $.00 E+00$ & $.00 E+00$ & $.00 E+00$ & $.00 E+00$ \\
$5.00 E+00$ & $3.29 E+04$ & $4.53 E-01$ & $2.60 E-01$ & $8.56 E-02$ & $2.82 E-02$ & $3.06 E-03$ & $1.01 E-03$ & $3.32 E-04$ \\
$3.50 E+00$ & $6.97 E+04$ & $4.42 E+01$ & $2.36 E+01$ & $7.74 E+00$ & $2.55 E+00$ & $2.77 E-01$ & $9.11 E-02$ & $3.00 E-02$ \\
$2.75 E+00$ & $4.68 E+05$ & $7.13 E+04$ & $4.09 E+04$ & $1.35 E+04$ & $4.44 E+03$ & $4.82 E+02$ & $1.59 E+02$ & $5.23 E+01$ \\
$2.25 E+00$ & $2.38 E+05$ & $2.76 E+02$ & $1.09 E+01$ & $2.68 E-02$ & $9.20 E-03$ & $8.39 E-03$ & $8.03 E-03$ & $7.68 E-03$ \\
$1.75 E+00$ & $1.82 E+08$ & $5.76 E+02$ & $2.30 E+01$ & $9.47 E-02$ & $3.32 E-02$ & $1.58 E-02$ & $1.32 E-02$ & $1.18 E-02$ \\
$1.25 E+00$ & $5.06 E+06$ & $8.31 E+04$ & $4.90 E+04$ & $1.76 E+04$ & $6.83 E+03$ & $1.45 E+03$ & $8.11 E+02$ & $4.95 E+02$ \\
$8.50 E-01$ & $7.09 E+06$ & $5.19 E+03$ & $2.71 E+03$ & $1.81 E+03$ & $1.25 E+03$ & $6.04 E+02$ & $4.25 E+02$ & $3.02 E+02$ \\
$5.75 E-01$ & $2.40 E+09$ & $3.98 E+00$ & $3.56 E+00$ & $3.15 E+00$ & $2.81 E+00$ & $2.23 E+00$ & $2.00 E+00$ & $1.78 E+00$ \\
$3.75 E-01$ & $2.94 E+05$ & $1.37 E-01$ & $1.12 E-01$ & $8.25 E-02$ & $6.55 E-02$ & $4.68 E-02$ & $4.08 E-02$ & $3.59 E-02$ \\
$2.25 E-01$ & $1.05 E+05$ & $1.85 E+02$ & $1.55 E+02$ & $1.09 E+02$ & $7.68 E+01$ & $3.90 E+01$ & $2.81 E+01$ & $2.04 E+01$ \\
$1.25 E-01$ & $5.05 E+04$ & $1.97 E-11$ & $1.96 E-11$ & $1.93 E-11$ & $1.90 E-11$ & $1.84 E-11$ & $1.81 E-11$ & $1.79 E-11$ \\
$8.50 E-02$ & $8.81 E+03$ & $9.76 E-02$ & $8.54 E-02$ & $6.52 E-02$ & $4.99 E-02$ & $2.91 E-02$ & $2.22 E-02$ & $1.70 E-02$ \\
$5.75 E-02$ & $8.30 E+02$ & $5.37 E+00$ & $3.47 E-02$ & $1.45 E-06$ & $6.15 E-11$ & $7.67 E-13$ & $7.67 E-13$ & $7.67 E-13$ \\
$3.75 E-02$ & $1.14 E-01$ & $7.64 E-02$ & $5.13 E-02$ & $2.32 E-02$ & $1.05 E-02$ & $2.19 E-03$ & $1.01 E-03$ & $4.81 E-04$ \\
$2.50 E-02$ & $1.04 E+02$ & $8.37 E-13$ & $3.37 E-13$ & $5.47 E-14$ & $8.89 E-15$ & $2.34 E-16$ & $3.80 E-17$ & $6.17 E-18$ \\
$1.00 E-02$ & $1.80 E+04$ & $2.20 E-05$ & $1.54 E-06$ & $7.39 E-08$ & $6.70 E-08$ & $6.64 E-08$ & $6.61 E-08$ & $6.58 E-08$ \\
TOTAL & $2.60 E+09$ & $1.61 E+05$ & $9.28 E+04$ & $3.30 E+04$ & $1.26 E+04$ & $2.58 E+03$ & $1.42 E+03$ & $8.72 E+02$ \\
$M E V / S E C$ & $1.71 E+09$ & $3.06 E+05$ & $1.76 E+05$ & $6.07 E+04$ & $2.18 E+04$ & $3.67 E+03$ & $1.82 E+03$ & $1.03 E+03$
\end{tabular}


The second example shows an input file dealing with calculation of fission products.

Example \#2:

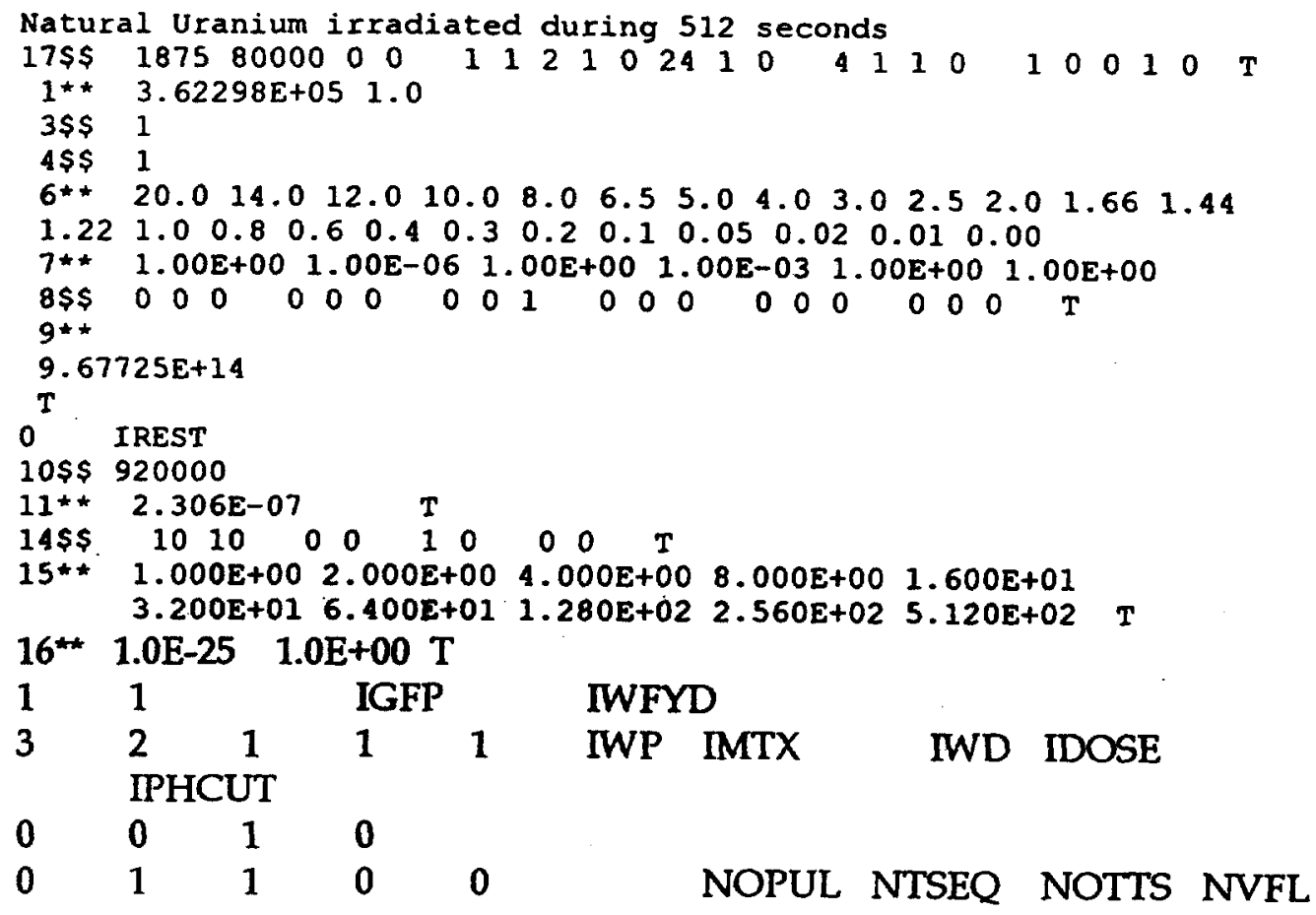

This input is used for a calculation of the inventory coming from irradiation of natural Uranium during $\mathbf{5 1 2}$ seconds.

Initial composition is read from Cards $10 \$$ and $11^{\star *}$ ( non-restart case, IREST $=0$ ). Fission products are included in the inventory calculation $(\mathrm{IGFP}=1)$, and the fission yields cross sections from all the fissionable nuclides included in the activation library are considered (IWFYD=1).

In example \#3 we simulate the same situation that the one simulated using inputs examples \#4 and \#5 succesively. With these three examples we illustrate the use of the restart option ( parameter IREST) as well as the new capabilities for simulating a pulsed irradiation/cooling history.

Example \#3:

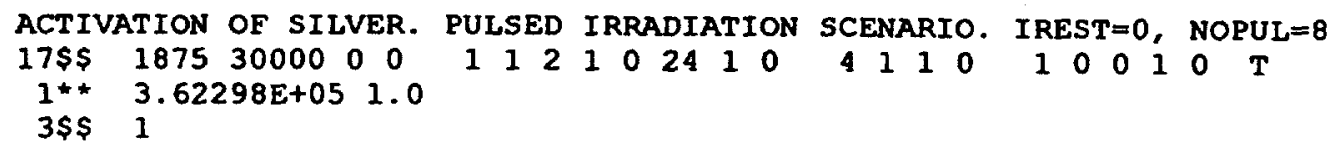




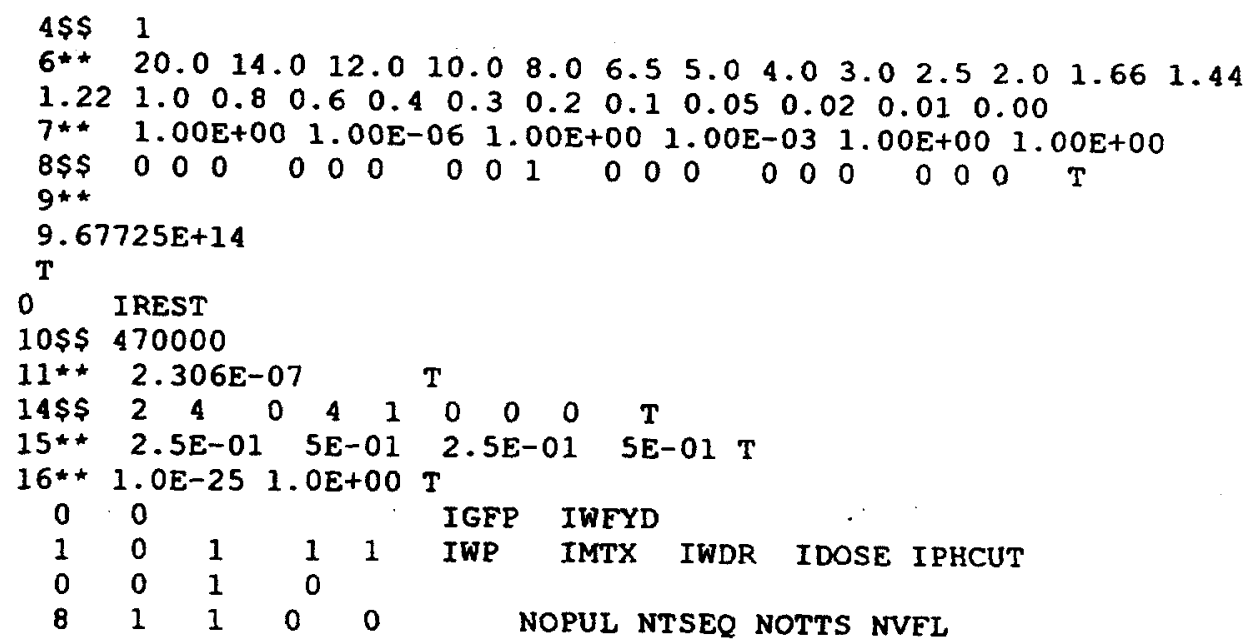

This input is used for a calculation of the neutron activation for Ag under a pulsed irradiation scenario. The only set of the input is defined as an unit. In this case, irradiation takes places over 0.5 seconds, followed by 0.5 seconds of cooling. The unit gets repeated 8 times for a total of 9 irradiation/cooling cycles. It is seen that no additional sets to those the unit must be given to end up the simulation of a pulsed irradiation scenario, as it was needed in the former ACAB version.

The initial material composition is read in cards $10 \$ \$$ and $11^{\star \star}$ (IREST $=0$ ). \#3.

In the examples \#4 and \#5, we simulate the same scenario than in example

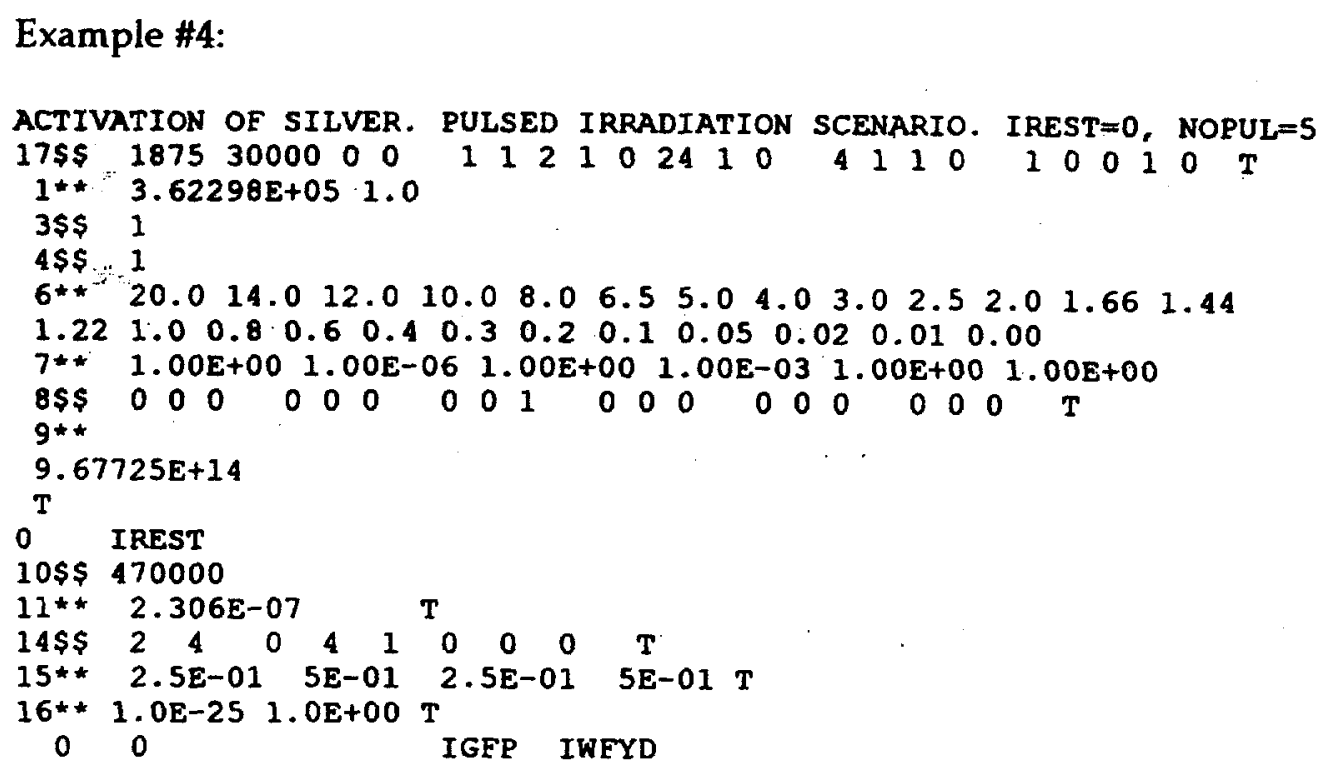


$\begin{array}{cccccccc}1 & 0 & 1 & 1 & 1 & \text { IWP } & \text { IMTX IWDR } & \text { IDOSE IPHCUT } \\ 0 & 0 & 1 & 0 & & & \\ 5 & 1 & 1 & 0 & 0 & & \text { NOPUL NTSEQ NOTTS NVFL }\end{array}$

The only difference between input \#3 and \#4 is the value assigned to the parameter NOPUL.

In this case the unit gets repeated $5($ NOPUL $=5)$ times for a total of 6 irradiation/cooling cycles.

Example \#5:

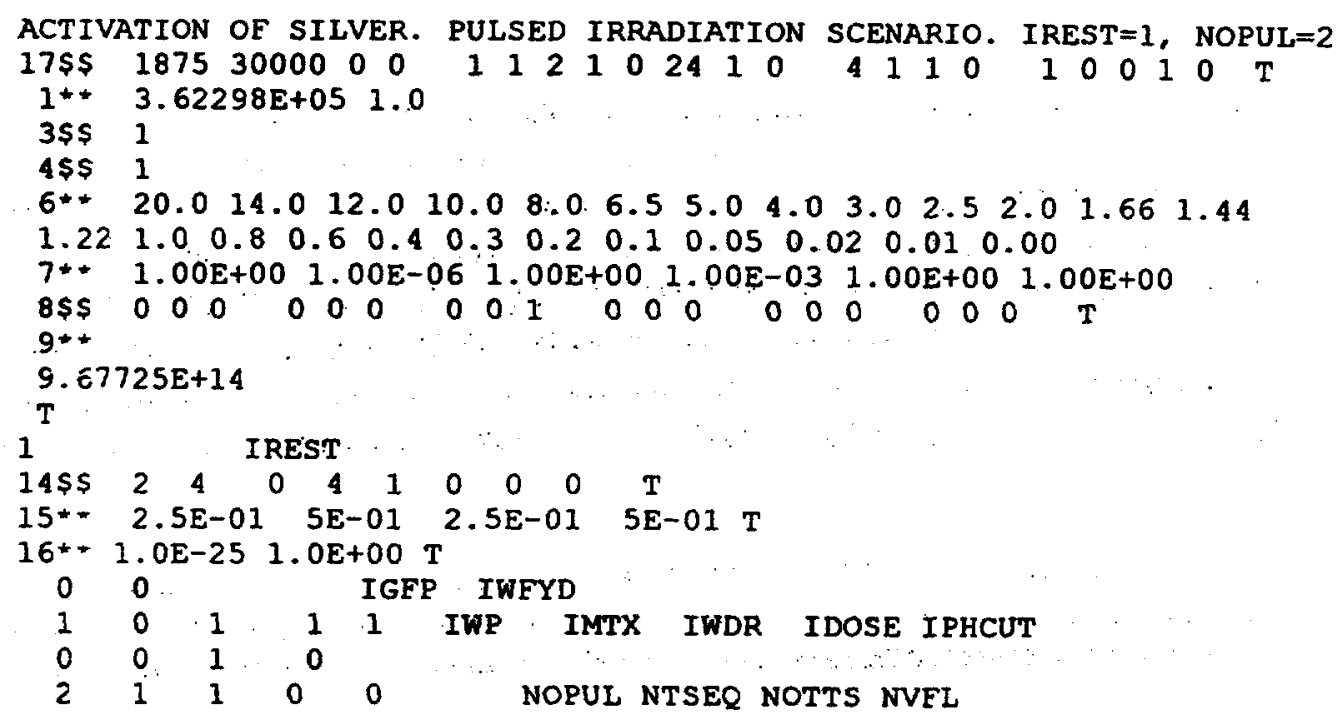

This input is used for a restart problem. The parameter IREST $=1$ tells ACAB to read initial material compositions from UNIT 37. Cards $10 \$ \$$ and $11^{\text {** }}$, corresponding to a non-restart problem, are not given.

The unit ( defined the same than in examples \#3 and \#4) gets repeated 2 times for a total of three irradiation/cooling cycles.

This input \#5 together with the UNIT 37 written by a run using file \#4 make $A C A B$ output the same results than those computed with input \#3.

Inputs \#4 and \#5 tell $A C A B$ to calculate for 9 cycles $(6+3)$. This number of cycles is the same when runnig with input \#3. 


\section{Pathways analysis. Chains Code}

\section{CHAINS Description}

The purpose of the CHAINS code is to generate and output the possible pathways for the formation of a particular nuclide. All possible pathways that require up to a specified number of steps are ranked according to their estimated importance to the total production of the nuclide. The user gives an importance cutoff that is used to truncate the list of possible pathways.

CHAINS has been modified to include in the pathway analysis all the nuclear processes implemented in the present version of $A C A B$.

CHAINS can be executed in three different modes. In the first mode (IFLAG $=0$ ), the code calculates all transmutation sequences that results in the formation of a particular radionuclide (variable IFINAL) with a maximum number of steps (variable NMAX) in the chain. No initial nuclide is specified when operating in this mode. In addition to giving the actual chains, the code outputs the coefficients (transmutation rates or probability per nucleus per unit time) of neutron reaction or radioactive decay corresponding to each step of the chain. The CHAINS output is given in order of increasing number of steps of each chain. That is, all two-step chains are given before three-step chains are listed.

In the second mode of operation, CHAINS calculates all pathways starting from a specified parent nuclide (INITIAL) that result in a specified daughter nuclide (IFINAL) and take no more than NMAX steps: CHAINS also estimates the relative importance of each pathway. This is accomplished through the use of a "pseudo probability" for each pathway. The pseudo probabilities are summed over all pathways that are possible in NMAX or less steps. This sum is the total pseudo probability. Each pseudo probability may be divided by the total pseudo probability to get an estimate of the relative importance of each pathway.

The relative importances may not be an actual ranking of the relative contributions from each pathway, but they are useful for distinguishing those pathways that may be important from those that may be negligible.

As output for the second mode of operation, CHAINS writes the pathways in order of decreasing relative importance. The user specifies a cutoff value with the PCNT variable. Pathways that contribute less than PCNT percent to the total pseudo probability are omitted. The coefficients associated with each step in a pathway are also given.

The following example illustrates the concept of pseudo probability rankings described above. Assuming that there are two possible pathways for the production of nuclide $F$ from nuclide I, the pathways might be written as: 
(2)

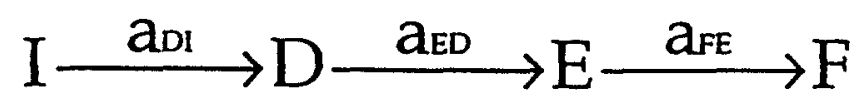

where:

$$
a_{i}=\lambda_{i}+\sum_{j} \sigma_{i} \rightarrow j
$$

and:

$a_{i}$ are the coefficients of the transition matrix that give the reaction $(\sigma \phi)$ or decay $(\lambda)$ probability per nucleus per unit time, $\sigma$ is the energy-averaged reaction cross section, $\phi$ is the energy-averaged neutron flux, $\lambda$ is the radioactive decay constant, and

The pseudo probabilities can be written as:

$$
\begin{aligned}
& P_{1}=\frac{a_{A I}}{a_{1}} \times \frac{a_{B A}}{a_{A}} \times \frac{a_{C B}}{a_{B}} \times \frac{a_{F C}}{a_{C}} \\
& P_{2}=\frac{a_{D I}}{a_{I}} \times \frac{a_{E D}}{a_{D}} \times \frac{a_{F E}}{a_{E}}
\end{aligned}
$$

The total and relative pseudo probabilities can be written as:

$$
\begin{aligned}
& P_{\text {tot }}=P_{1}+P_{2} \\
& P_{R_{1}}=P / P_{\text {tot }} \\
& P_{R_{2}}=P 2 / P_{\text {tot }}
\end{aligned}
$$

The relative importances would be written into the CHAINS output file in order of decreasing importance. If either of the relative importances is less than the value of PCNT, it would be omitted from the output.

In the third mode of operation, CHAINS searches for all cyclic pathways or "loops" that include a user-specified final nuclide IFINAL. All pathways are included that are possible within NMAX steps. As in the first mode of operation, the pathways are listed in order of increasing number of steps and the transmutation rates are given for each step within a pathway. 


\section{CHAINS Support Files}

In addition to a standard input file, CHAINS requires two ACABproduced files for its operation. Unit 22 is a binary file that contains the identifiers of the nuclides found in the decay library and the elements of the transition matrix. Each element of the transition matrix contains the identifier corresponding to the neutron reaction or decay process occurring within that element. Unit 22 is generated by running $A C A B$ with IWP $=1$.

Unit 24 is a binary file that contains the transition matrix transformation rates. It also contains the diagonal elements which give the total depletion rates. Unit 24 is generated by running $A C A B$ with IMTX $=1$ or 2 .

Unit 23 is a temporary binary file that is created during a CHAINS run. This file contains all possible pathways which are later ordering according to their relative pseudo probabilities. This file may become quite large but may be deleted after CHAINS execution.

\section{CHAINS Input/Output}

A CHAINS input file consists of five cards. Some card may be omitted for certain types of operation. The structure of the CHAINS input file is now described.

\section{Card Variable Format \\ 1 \\ IFLAG \\ I3}

2 INITIAL I6

3 IFINAL I6

4 NMAX I3

5 $\quad$ PCNT $\quad$ F6.2

\section{Description}

Indicates mode CHAINS operation mode:

1 Pathways to produce nuclide IFINAL.

2 Pathways to produce nuclide IFINAL from nuclide INITIAL.

3 Cyclic pathways to produce nuclide IFINAL.

Identifier for the first initial nuclide. The nuclide identifier is defined in the same manner as NUCLID in ACAB $(10000 \times Z+10 \times A+$ IS). INITIAL is omitted if IFLAG $\neq 2$.

Identifier for the final nuclide. The identifier $s$ defined in the same manner as INITIAL.

Maximum number of steps considered for possible pathways. (NMAX $\leq 10$ ). Output option: only pathways with relative pseudo probabilities greater than or equal to PCNT will be printed .PCNT is omitted if IFLAG $\neq 2$. $|0 \leq P C N T \leq 100|$. 
Some example input and output are now given. First, a sample input file for the first mode of operation.

Example \#1:

$\begin{array}{ll}1 & \text { IFLAG } \\ 110240 & \text { IFINAL Na-24 } \\ 2 & \text { NMAX }\end{array}$

In this example, all pathways that result in the production of ${ }^{24} \mathrm{Na}$ that require two or less steps will be given. An portion of the output from this problem is given below:

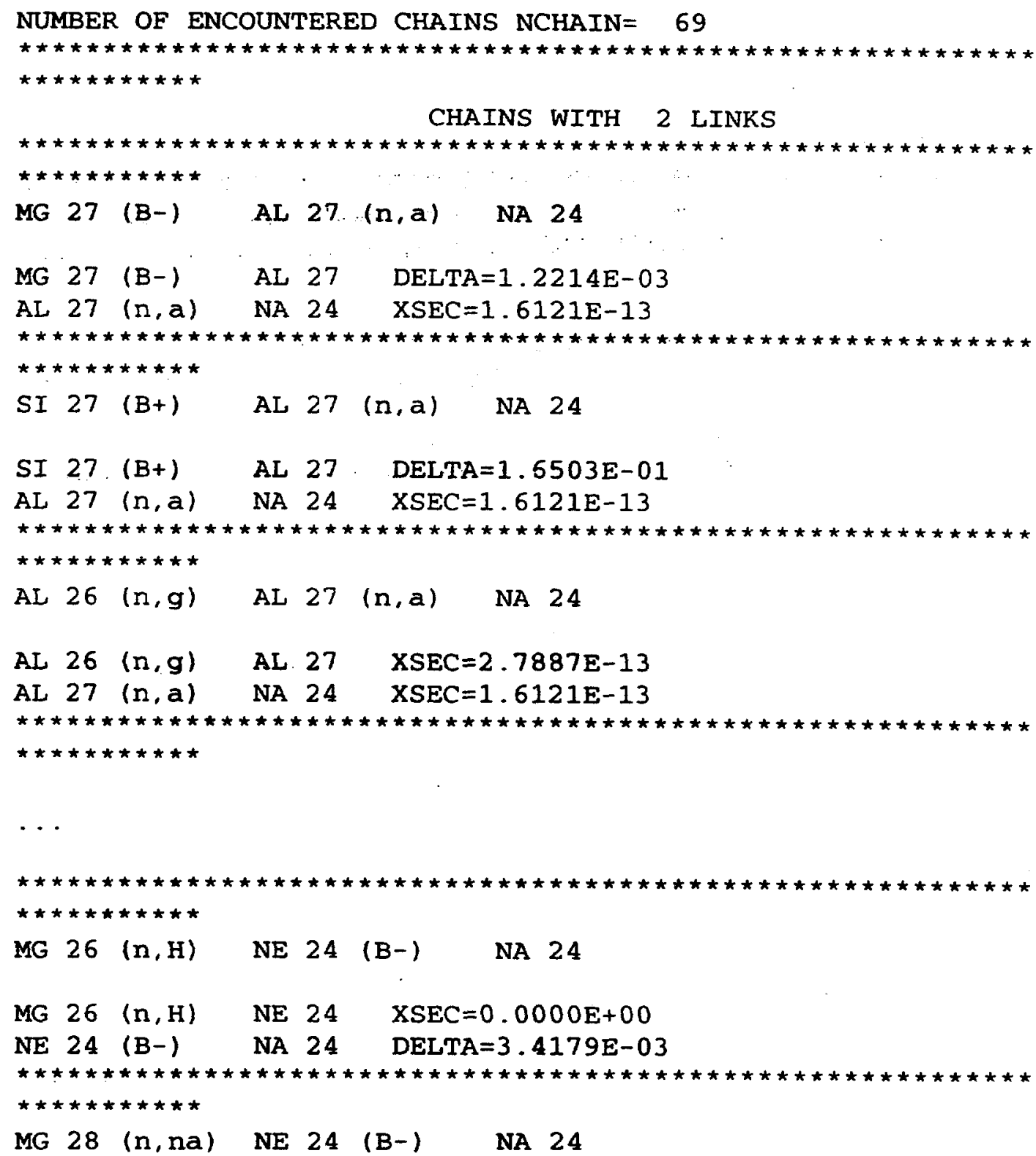


$\begin{array}{lllll}\text { MG } 28 & (\mathrm{n}, \mathrm{na}) & \mathrm{NE} & 24 & \mathrm{XSEC}=5.0353 E-16 \\ \text { NE } 24 & (\mathrm{~B}-) & \text { NA } 24 & \text { DELTA }=3.4179 E-03\end{array}$

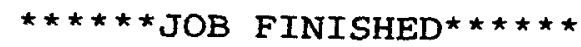

Each pathway is listed along with the reaction $(\sigma \phi)$ or decay $(\lambda)$ probabilities per nucleus per unit time.

The second example demonstrates the operation of CHAINS in mode \#2.

Example \#2:

$\begin{array}{lll}2 & \text { IFLAG } & \\ 130270 & \text { INITIAL } & \text { AI-27 } \\ 110240 & \text { IFINAL } & \text { Na-24 } \\ 4 & \text { NMAX } & \\ 0.1 & \text { PCNT } & \end{array}$

This input file will cause CHAINS to output all possible pathways for the production ${ }^{24} \mathrm{Na}$ from ${ }^{27} \mathrm{Al}$ that require up to 4 steps and contribute at least $0.1 \%$ to the total pseudo probability. An excerpt of the output from this problem is given below:

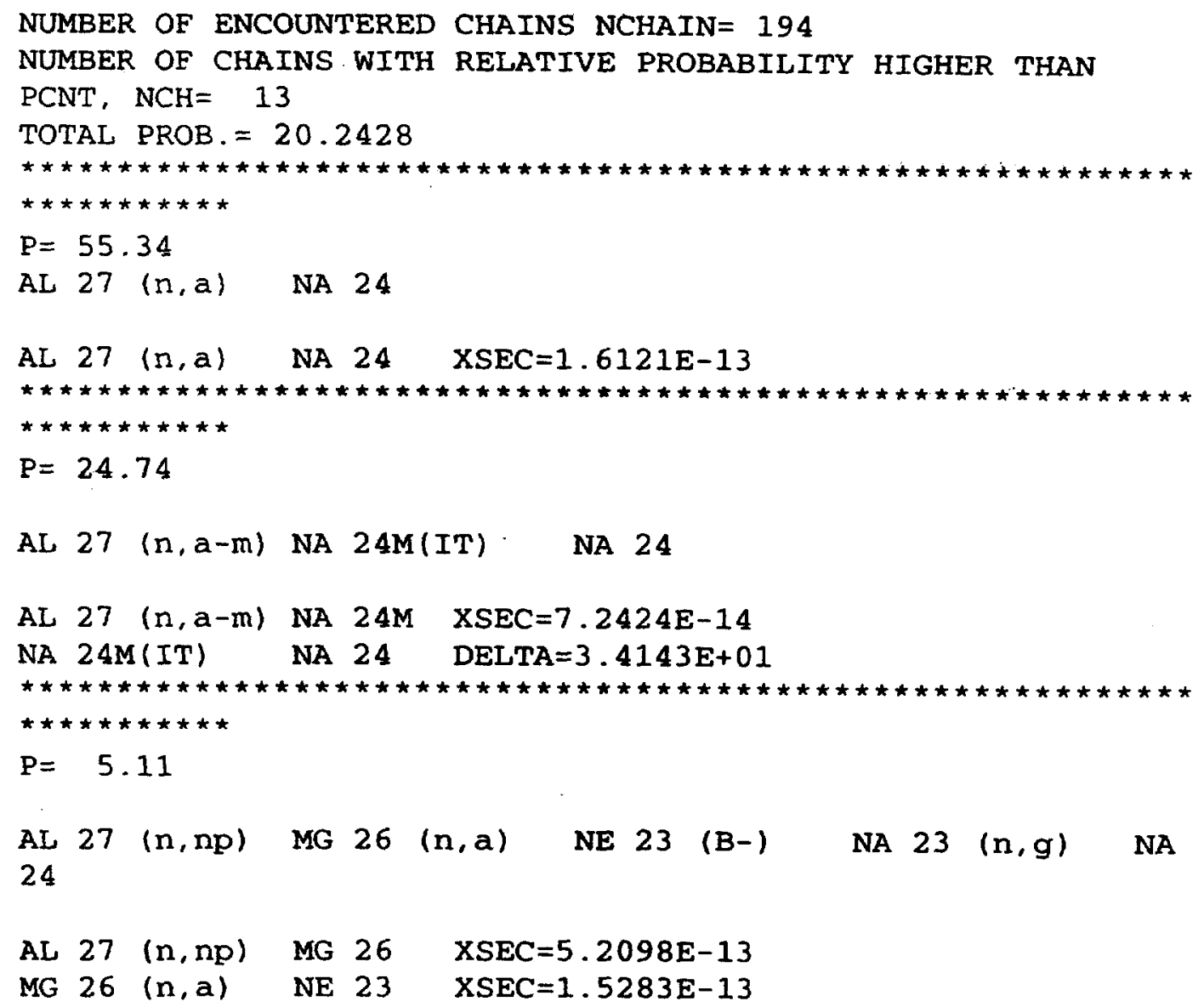




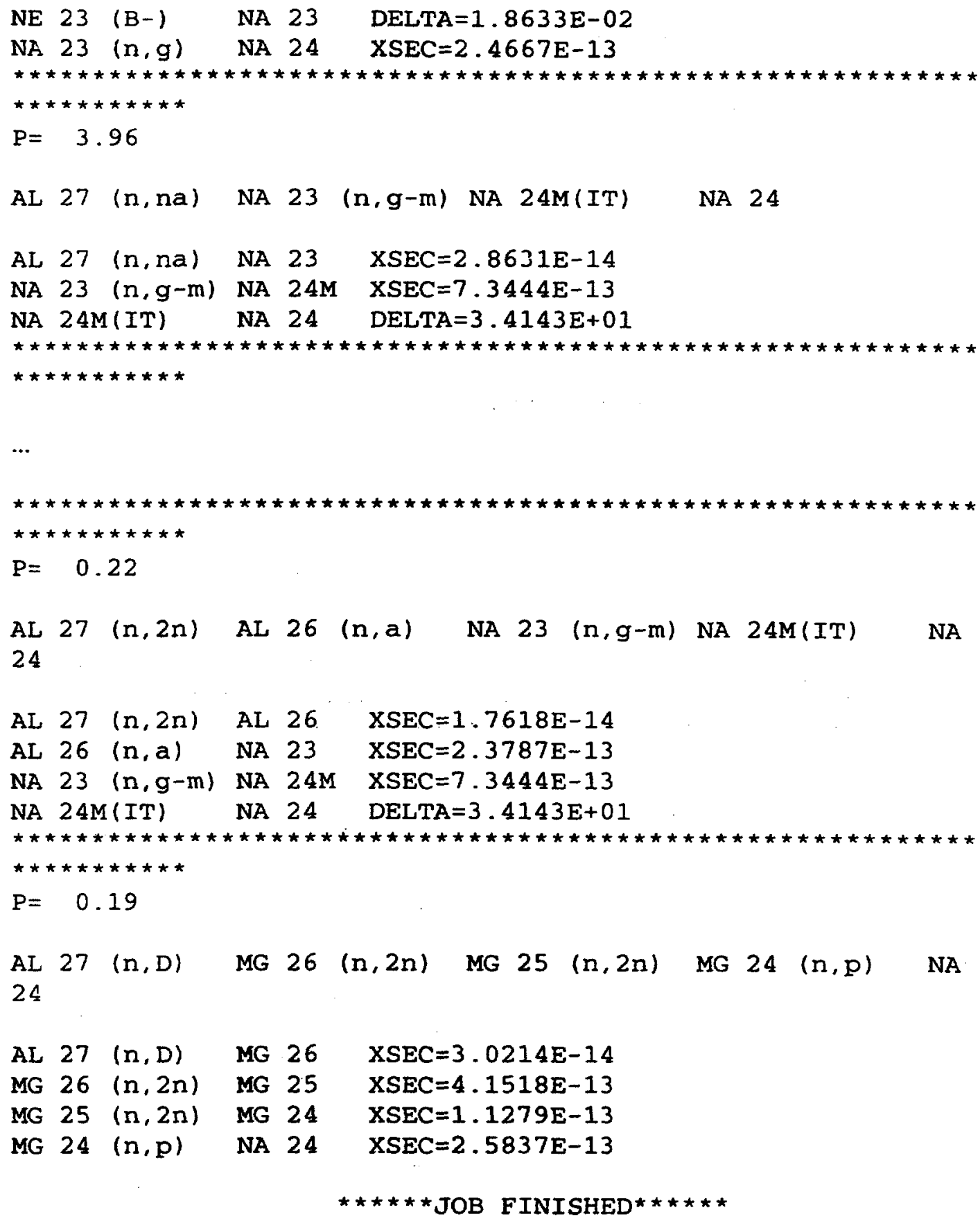

Note that the first line of output indicates that a total of 194 pathways that result in the production of ${ }^{24} \mathrm{Na}$ from ${ }^{27} \mathrm{Al}$ within 4 steps were identified. The second line of output indicates, however, that only 13 of these possible pathways make a contribution of at least $0.1 \%$ to the total pseudo probability. Several of these pathways are listed in the output above. For each pathway, the total percentage contribution to the total pseudo probability is given. This is followed by a listing of the pathway and the reaction or decay probabilities per nucleus per unit time for each step in the pathway. 
The next example, that also addresses the operation of CHAINS in mode number \#2, is intended to show how the present version of CHAINS includes the fission channel in the pathway analysis.

Example \#3:

$\begin{array}{lll}1 & \text { IFLAG } & \\ 922380 & \text { INITIAL } & U-238 \\ 551370 & \text { IFINAL } & \text { CS }-137 \\ 4 & \text { NMAX } & \\ 0.1 & \text { PCNT } & \end{array}$

This input file will cause CHAINS to output all possible pathways for the production Cs-137 from U-238 that require up to 4 steps and contribute at least $0.1 \%$ to the total pseudo probability.

The complete output from this problem is given below:

NUMBER OF ENCOUNTERED CHAINS NCHAIN $=2327$

NUMBER OF CHAINS WITH RELATIVE PROBABILITY HIGHER THAN , $\mathrm{XCH}=4$

PTOT $=2.0273$

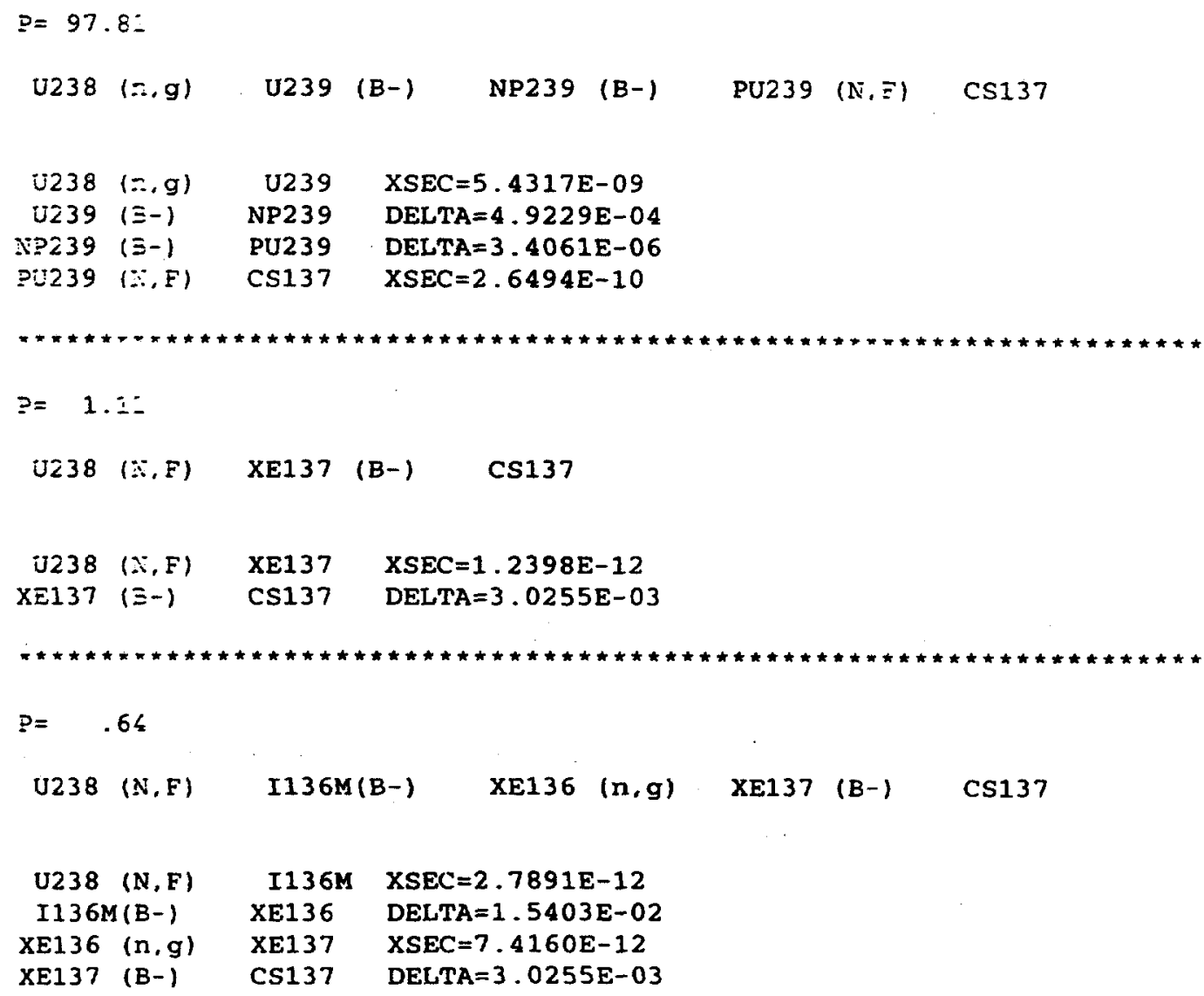




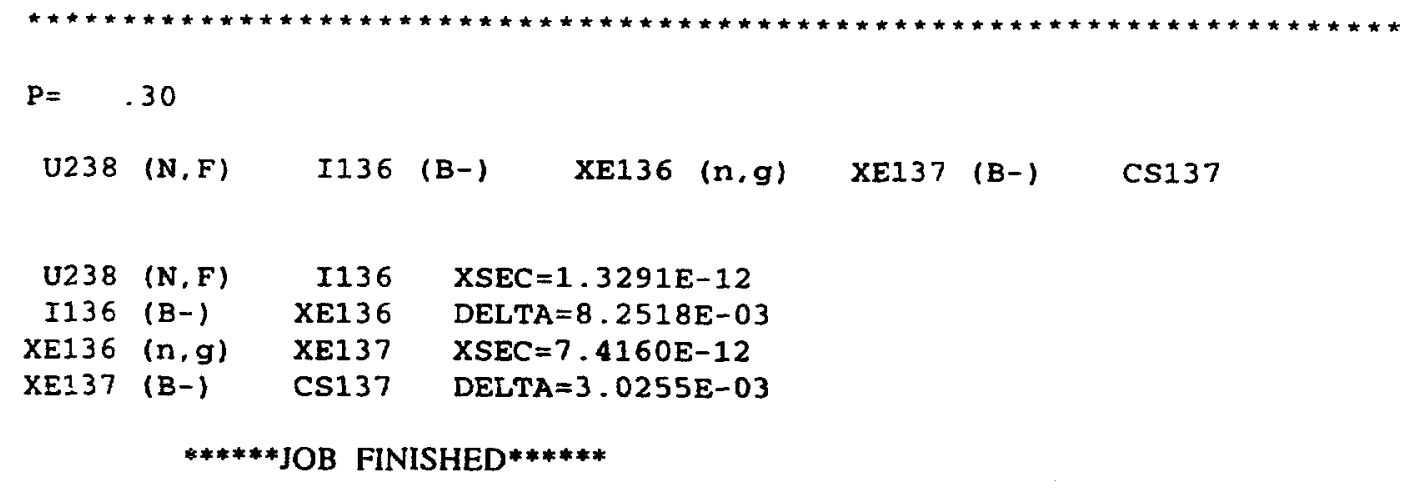

The final example demonstrates the operation of CHAINS in mode \#3.

Example \#4:

$\begin{array}{lll}3 & \text { IFLAG } & \\ 110240 & \text { INITIAL } & \mathrm{Na}-24 \\ 4 & \text { NMAX } & \end{array}$

This example causes CHAINS to output all possible pathways for the production of ${ }^{24} \mathrm{Na}$ from an original ${ }^{2-} \mathrm{Na}$ atom. All pathways that require up to 4 steps are given. These are called cyclical pathways. An excerpt of the output is given below:

NUMBER OF ENCOUNTERED CHAINS NCHAIN= 42

CHAINS WITH 2 LINKS

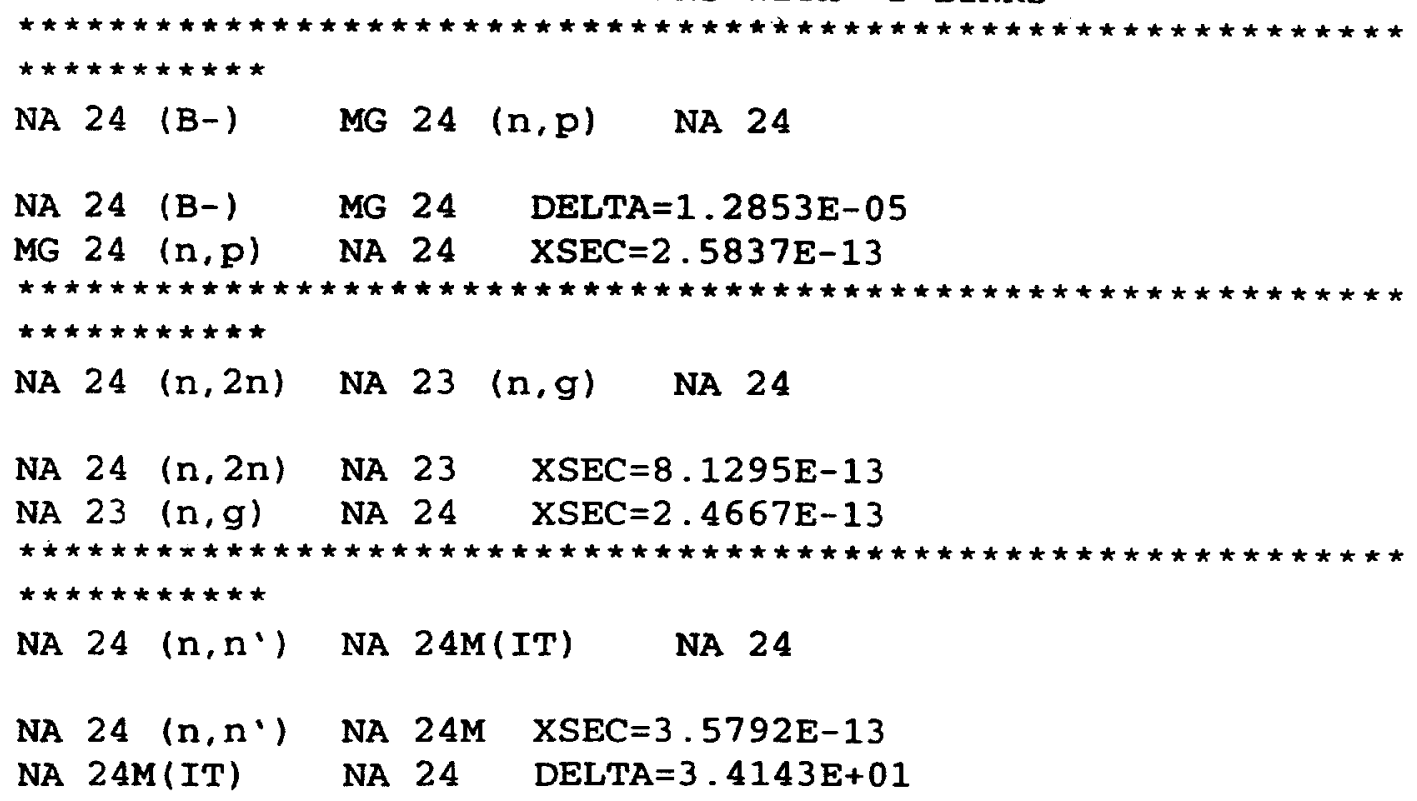




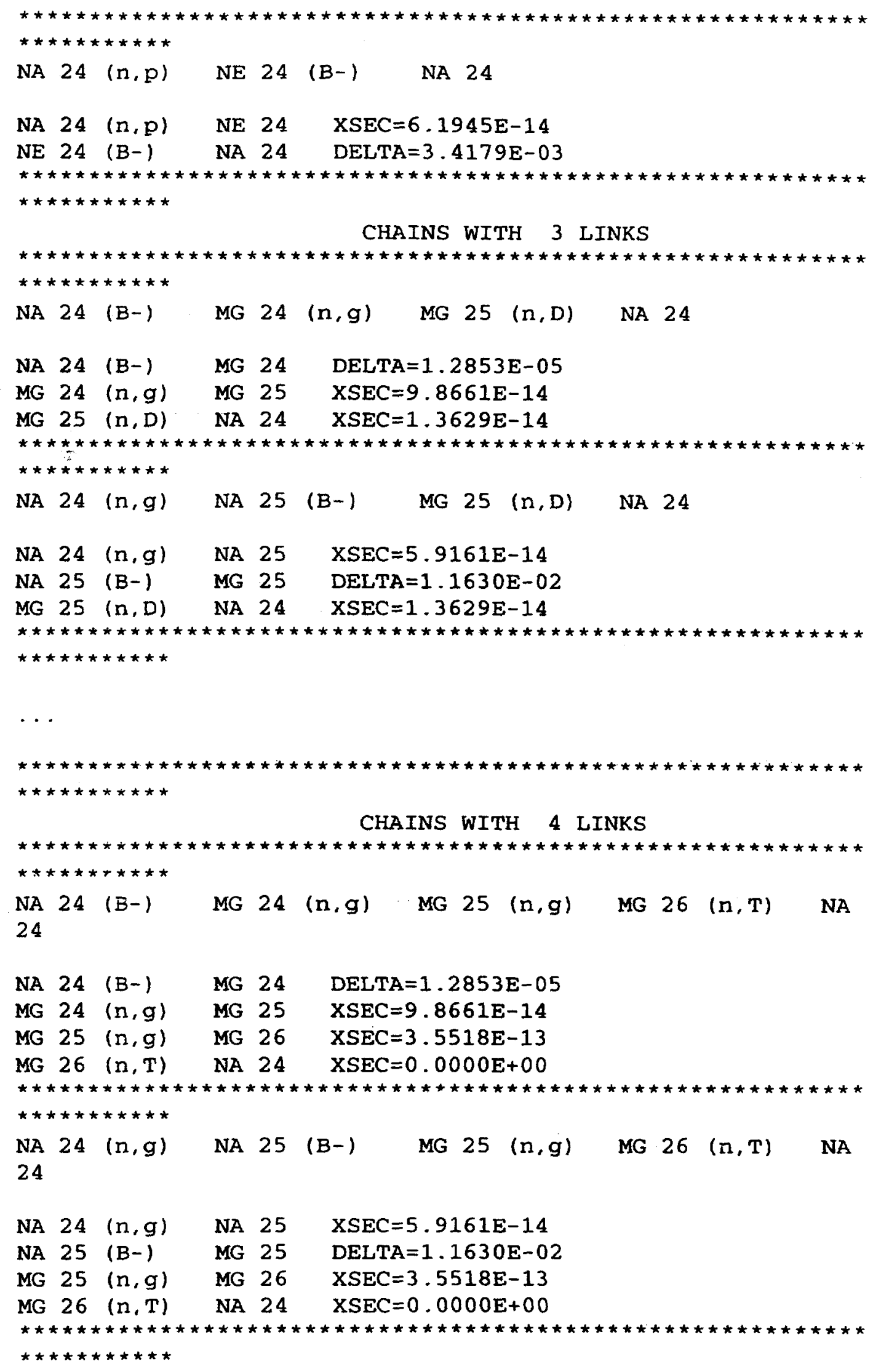




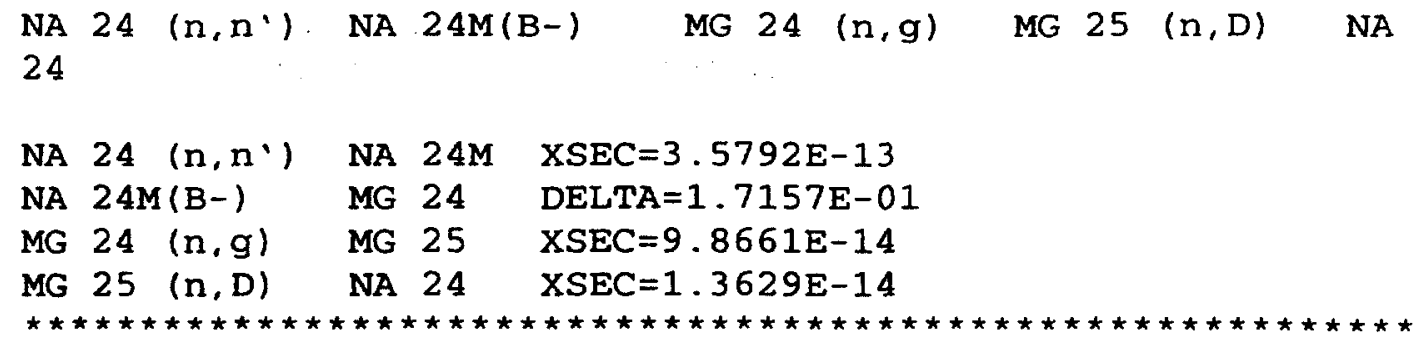

The first line of output indicates that a total of 42 pathways were identified. Note, however, that the first two pathways with 4 steps both end with the " $\mathrm{Mg}$ $(n, t){ }^{24} \mathrm{Na}$ reaction. This reaction has an energy-averaged cross section of 0 barns (the threshold is $14.7 \mathrm{MeV}$ but the flux is 0 above $14.1 \mathrm{MeV}$ ). When operated in mode \#3, CHAINS makes no attempt to extract possible pathways that will not contribute to the overall production.

\section{CHAINS Availability}

The CHAINS utility currently operates on Crays and an HP/735 workstations. As is ACAB, CHAINS is written in standard FORTRAN 77. Thus, porting of CHAINS onto other machines should not be difficult. 
IX.- References.

1.- A.G. Croff, A User's Manual for the ORIGEN2 computer code. ORNL/TM7175,1980 .

2.- H. Brockmann and U. Ohling, ACFA: A General Purpose Activation Code, Jülich 1866, 1983.

3.- E.T. Cheng, R.A. Forrest and A. Paschenko, Report on the Second International Activation Calculation Benchmark Comparison Study, TSI Research Report TSIR-21 FINAL Draft, 1993.

4.- J. Sanz, J.M. Perlado, D. Guerra, S. Pérez, J. Latkowski, M. Tobin, $A C A B$, Activation Code for Fusion Applications User's Manual V2.0, Lawrence Livermore National Laboratory, UCRL-MA-122002, August 1995.

5.- A.B. Pashchenko, H. Wienkle, J. Kopecky, J. Chu. Sublet, R.A. Forrrest, FENDL/A-2.0, Neutron activation cross section data library for fusion applications. Version 1 of March 1996. International Atomic Energy Agency IAEA-NDS-173, Presented at the IAEA Advisory Group Meeting, FENDL-2, Vienna, March 1997.

6.- R.A. Forrest, FENDL/D-2.0 and testing of FENDL/A-2.0. Presented at the IAEA Advisory Group Meeting, FENDL-2 Vienna, March 1997.

7.- Summary Report of the IEF Working Group on Benchmark Testing, Data Processing and Evaluation, NEA Paris, 12th-13th June 1995, Report JEF/DOC-538, Ph. Finck (Chairman, CEN Cadarache), M. Konieczny (Secretary, NEA Data Bank),

8.- J. Kopecky and D. Nierop, The European Activation File EAF-4. Summary documentation. ECN-C-95-072. December 1995.

9.- Summary report of the IAEA Specialists' Meeting on Extension and Improvement of the FENDL Library for Fusion Applications (FENDL-2). Vienna, 3-7 March 1997, Report INDC (NDS)-373, July 1997, prepared by M. Herman and A.B. Pashchenko.

10.- Proc. 3rd RCM on Activation cross sections for the geration of long-lived radionuclites of importance in fusion reactor technology, St. Petersburg, Russia, June 19-23, 1995, IAEA Report INDC (NDS)-342, Feb. 1996. A.B. Pashchenko, Ed.

11.- J. Kopecky et al., The European File EAF-3 with Neutron Activation and Trasmutation Cross-Sections, Netherlands Energy Researach Foundation. Report ECN-C-92-058, 1992. 
12.- J.F. Latkowsky, Inertial Fusion Energy: A Clearer view of the safety and envirommental perspectives. PhD dissertation, University of California at Berkeley, May 1996. UCRL-LR-125741, November 1996.

13.- R.W. Moir et al., HYLIFE-II: A molten-salt inertial fusion energy power plant design-Final Report. Fusion Technology, 25, 5-25, 1994.

14.- S. Fetter, E.T. Cheng and F.M. Mann, Long-term radioactive waste from fusion reactors: Part II, Fusion Eng. Des., 13, 239, 1990.

15.- J. Sanz, C. González, J. Juan, Long-lived activity of elements: effect of new activation cross sections and their uncertainties on the selection of materials for IFE renctors, to be presented on the 8th International Conference on Fusion Reactor Materials, ICFRM-8, Sendai, Japan, October 1997.

16.- J.K. Tuli, Nuclear Wallet Cards (Fifth edition), National Nuclear Data Center, Brookhaven National Laboratory, July 1995.

17.- J.H. Hubbell, Photon Mass Attenuatuion and Energy-Absorption Coefficients from $1 \mathrm{keV}$ to $20 \mathrm{MeV}$, Int. J. Appli. Radiat. Isot., 33, 1982. 


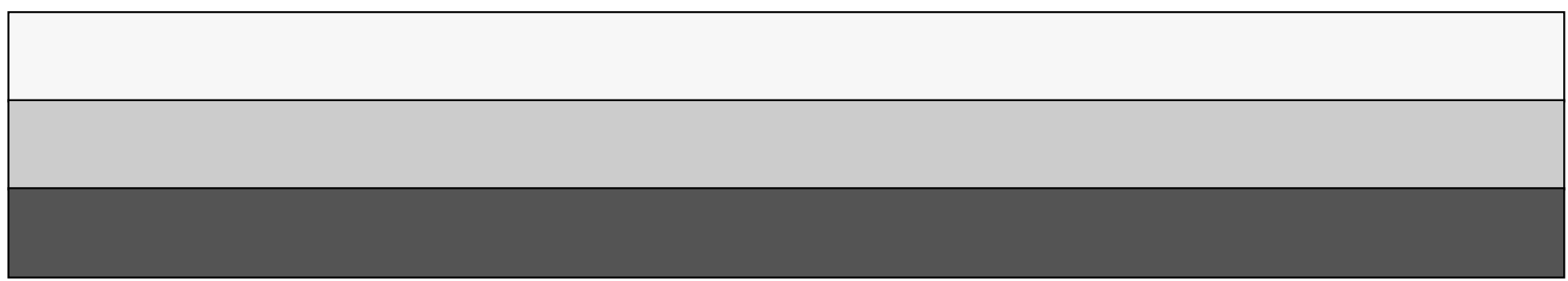

